UNIVERSIDADE DE SÃO PAULO

FACULDADE DE ECONOMIA, ADMINISTRAÇÃO E CONTABILIDADE DEPARTAMENTO DE ADMINISTRAÇÃO PROGRAMA DE PÓS-GRADUAÇÃO EM ADMINISTRAÇÃO

MANUFATURA AVANÇADA: A INFLUÊNCIA DA ESTRATÉGIA DA MANUFATURA E DA PERCEPÇÃO DE AFFORDANCES

Ricardo Caruso Vieira

Orientadora: Profa. Dra. Adriana Marotti de Mello 
Prof. Dr. Marcos Antonio Zago

Reitor da Universidade de São Paulo

Prof. Dr. Adalberto Américo Fischmann

Diretor da Faculdade de Economia, Administração e Contabilidade

Prof. Dr. Roberto Sbragia

Chefe do Departamento de Administração

Prof. Dr. Moacir de Miranda Oliveira Júnior

Coordenador de Programa de Pós-Graduação em Administração 
RICARDO CARUSO VIEIRA

\section{Manufatura Avançada: A influência da estratégia da manufatura e da percepção de affordances}

Dissertação apresentada ao Programa de PósGradução em Administração do Departamento de Administração da Universidade de São Paulo, como requisito parcial para obtenção do título de Mestre em Ciências

Orientadora: Profa. Dra. Adriana Marotti de Mello

\section{Versão Corrigida}

(versão original disponível na Biblioteca da Faculdade de Economia, Administração e Contabilidade)

São Paulo

2017 


\section{FICHA CATALOGRÁFICA}

Elaborada pela Seção de Processamento Técnico do SBD/FEA/USP

\section{Vieira, Ricardo Caruso}

Manufatura avançada: a influência da estratégia da manufatura e da percepção de affordances / Ricardo Caruso Vieira. - São Paulo, 2017.

$107 \mathrm{p}$.

Dissertação (Mestrado) - Universidade de São Paulo, 2017.

Orientador: Adriana Marotti de Mello.

1. Tecnologia da informação 2. Manufatura 3. Estratégia organizacional I. Universidade de São Paulo. Faculdade de Economia, Administração e Contabilidade. II. Título. 


\section{Prefácio}

A pesquisa científica exige do pesquisador o equilíbrio entre duas forças, de naturezas opostas. A primeira, o grande envolvimento necessário com o objeto investigado de modo a manter vivo o entusiasmo e interesse pela busca dos objetivos, mesmo com as diversas dificuldades inerentes ao processo. A outra é a isenção, que assegura o distanciamento, essencial para que os resultados sejam derivados puramente da análise de dados empíricos e da literatura pertinente, sem contaminação por opiniões pessoais.

Manter o entusiasmo e envolvimento não exigiu esforços exagerados, uma vez que o autor atua profissionalmente na área da pesquisa e, com prazer, mergulhou na busca dos correspondentes conhecimentos acadêmicos. Seu contato profissional com projetos de implantação de tecnologias da informação e comunicação (TIC) para a área industrial remonta ao ano de 2005, logo em seguida à colação de grau em engenharia elétrica e ganhou maior força nos últimos anos, com o acompanhamento de discussões sobre Manufatura Avançada, em diferentes eventos da área industrial. Em muitos desses eventos, fornecedores e consumidores de tecnologia recebem informações, ora distorcidas por interesses comerciais, ora imprecisas ou com grande complexidade técnica, levando a um clima de incerteza e desconfiança sobre o tema.

Mas se, por um lado, o envolvimento profissional pavimenta o caminho, por outro impõe maior disciplina quanto à isenção exigida do pesquisador. Assim, o autor despendeu constantes esforços para que percepções pessoais e crenças do meio profissional não influenciassem a condução e as conclusões do trabalho. Entres esses esforços foram empreendidas várias discussões, com professores e colegas, sobre resultados preliminares e sua congruência com a literatura científica da área de administração.

Esta dissertação procura ser uma pequena contribuição para a compreensão desse assunto. $\mathrm{O}$ autor espera, com ela, incentivar novas pesquisas sobre Manufatura Avançada que consigam, em conjunto, trazer maior segurança aos gestores e incentivar a adoção de iniciativas tecnológicas bem-sucedidas para o parque industrial nacional. 



\section{Agradecimentos}

Embora resulte de um projeto de pesquisa individual, esta dissertação não seria viável sem a colaboração de uma série de pessoas, algumas das quais aqui mencionadas pelas instituições que representam.

Agradeço a Profa. Dra. Adriana Marotti pela orientação competente, dedicada e paciente e por conduzir meus primeiros passos na área da Administração, sempre alertando para o necessário rigor na pesquisa e escrita científicas.

A meu pai, Celso, pelo grande incentivo desde o ingresso no curso de mestrado e grande dedicação à revisão dos textos da dissertação; a minha mãe, Meck, pelo apoio durante todo o processo e a meu irmão, Renato, pelo exemplo de dedicação à pesquisa acadêmica.

A Michele, minha noiva que, mesmo nos momentos de minha ausência, manteve a compreensão e o apoio, presentes, também, quando se fez necessário estender o prazo de dedicação a este trabalho.

À Aquarius Software, empresa onde trabalho que, durante o desenvolvimento das pesquisas, solicitou acesso a seus clientes e fornecedores de onde foram colhidos importantes subsídios para os estudos empíricos desta dissertação. Agradeço, em especial, a Márcia Campos, por permitir dedicar-me à pesquisa por todo o tempo necessário, nos últimos anos, a Carlos Paiola, pelas valiosas discussões sobre o novo cenário tecnológico da indústria e Rafael Matsubara por me apresentar ao programa da FEA e me mostrar a relevância desse tema à área da administração.

Aos gestores das indústrias estudadas, que forneceram informações para os casos de pesquisa, abrindo, gentilmente, suas portas e oferecendo rico material, essencial para a conclusão deste texto.

À Faculdade de Economia, Administração e Contabilidade da USP, a seus professores e funcionários, por toda experiência de aprendizado e pelo entusiasmo científico proporcionados em todas as fases do curso de mestrado. 



\section{Resumo}

O termo Indústria 4.0 tornou-se, nos últimos anos, frequente nas discussões relativas à indústria. Sua origem é o programa alemão Industrie 4.0, que buscou fortalecer a competitividade do parque industrial do país aplicando novas tecnologias da informação e comunicação, à manufatura. Iniciativas semelhantes também foram criadas em outros países, como a americana Industrial Internet of Things. No Brasil, o Banco Nacional de Desenvolvimento Econômico e Social (BNDES) e a Empresa Brasileira de Pesquisa e Inovação Industrial (EMBRAPII) conduzem programas de incentivo à pesquisa, sob o nome de Manufatura Avançada.

Conceitos como cadeias de suprimentos integradas e Cyber-Physical Production Systems (CPPS), aliados a aplicações de tecnologias como Internet of Things e inteligência artificial, são comuns a todas essas iniciativas, com expectativas de grandes ganhos em flexibilidade da produção, em qualidade e em eficiência.

A relação entre adoção tecnológica e impactos em negócio, porém, é apontada como indireta e complexa, pelos pesquisadores de gestão de sistemas de informação e gestão de operações.

A literatura da gestão de operações aponta que, para o esperado impacto em desempenho, as tecnologias adotadas devem estar alinhadas com as prioridades competitivas e com o modelo de produção da companhia. Dessa forma, não são viáveis recomendações genéricas de adoção de sistemas que não levem em conta o segmento de atuação e o mercado atendido pela empresa. Outro fator importante é a aplicação de tecnologias que tenham surgido fora do ambiente industrial e não sejam familiares às equipes de tecnologia desse ambiente. Artefatos tecnológicos, quanto utilizados em diferentes contextos, apresentam capacidades diferentes.

Da sociologia da tecnologia, o termo affordance determina a possibilidade de ação de um agente quando em contato com um determinado objeto. Uma ferramenta tecnológica pode permitir a seu usuário uma gama de diferentes ações, dependentes de seus objetivos e conhecimentos. Uma régua de cálculo, por exemplo, permite a realização de uma série de operações matemáticas a um utilizador que conheça seus mecanismos, mas tem pouca utilidade a usuários sem conhecimentos prévios sobre seu funcionamento. No contexto da manufatura avançada, a percepção dos affordances das novas tecnologias, para modelar suas aplicações, exigirá novos conhecimentos, hoje detidos por diferentes equipes da companhia. 
Com base nas teorias de affordances e de estratégia de operações este trabalho utilizou um framework como ponto inicial para a realização de estudos de caso, em cinco projetos, em três empresas brasileiras de grande porte. Para que o impacto de diferentes estratégias de manufatura nas tecnologias adotadas pudesse ser estudado, foram selecionadas empresas de segmentos distintos, representativos do parque brasileiro: açúcar e álcool, montagem de eletrônicos e bebidas.

A disponibilidade de amplo conhecimento tecnológico se mostrou uma preocupação central dos gestores que buscam a implantação de projetos de Manufatura Avançada; sua ausência é muitas vezes vista como uma barreira para a adoção de recursos como sistemas com inteligência artificial. Nos casos estudados, alguns dos projetos só foram viabilizados com a formação de equipes muldisciplinares, capazes de lidar com combinações inovadoras de tecnologias de sistemas de informação e automação industrial ou agrícola. Esse resultado é condizente com a teoria de affordances que posiciona o conhecimento do usuário como central para a percepção das oportunidades de adoção de novas tecnologias. de affordances. Empresas com diferentes prioridades estratégicas decidiram pela adoção de sistemas com diferentes características, demostrando que a Manufatura Avançada não pode ser vista como um conjunto único e rígido de abordagens. Projetos em atividades com maior pressão por redução de custos apresentaram grande ênfase na integração vertical, ao passo que a procura por maior flexibilidade leva à busca de recursos para integração horizontal.

Novas tecnologias se mostraram capazes, ou demonstraram possuir affordances, não só para habilitar novas funcionalidades, mas para proporcionar recursos a custos expressivamente menores que suas predecessoras. Foram observados exemplos onde tecnologias de menor custo permitiram a expansão de projetos implantados parcialmente no passado ou, ainda, a implantação de projetos em áreas com características que os tornavam anteriormente financeiramente inviáveis.

Em razão desses resultados, o framework proposto sofreu revisão passando a incluir a adoção de novas tecnologias por questões relacionadas a custo e à formação de equipes muldisciplinares. Esse novo framework é apresentado como a contribuição final deste trabalho, que se espera possa servir der base para futuras investigações sobre o tema.

Palavras-chave: Indústria 4.0, Industrial Internet of Things, Affordances, Estratégia de Manufatura. 


\begin{abstract}
Industry 4.0 has become a very common term in recent discussions about the industry. It was originated in the Industrie 4.0 German program, which aims to strengthen their national industrial park competitiveness using new information and communication technologies to the manufacturing. Similar initiatives were created in different countries, such as the American Industrial Internet of Things. The Banco Nacional de Desenvolvimento Econômico e Social (BNDES) and the Empresa Brasileira de Pesquisa e Inovação Industrial (EMBRAPII) are conducting in Brazil technology research incentive program, with the name Manufatura Avançada (Smart Manufacturing).

In all these initiatives, concepts like integrated supply chains and Cyber-Physical Production Systems (CPPS), can be found with the same expectations of great improvements in productions flexibility, quality, and efficiency.

The information systems management and operations management researchers say that the relationship between technology adoption and business impacts indirect and complex.

The operations management literature shows that the adopted technologies have to be aligned with the competitive priorities and the company production model to generate the expected impact. Thereby generic system adoption recommendations are not possible, only taking account the company segment and its attended market. The application of technologies that have emerged outside the industrial environment and are not familiar with the technology teams of that environment is another important factor. If the utilization context of the technological artifact changes, their capabilities became different.

The term affordance, in the technology sociology, is an agent action possibility when in when in contact with a given object. A technological tool can allow its users a range of different actions, depending on their goals and knowledge. A slide rule, for example, allows a series of mathematical operations to be performed by a user who knows their mechanisms, but has little use for users without prior knowledge of their operation. In the Manufatura Avançada context, the technologies affordance perception, that shapes their applications, will require new knowledge, present in different departments today.

Based on the affordance and operations strategy theories, this work applies a framework as a starting point for case studies conduction in five projects in three large Brazilian companies. In order to study the impact of different manufacturing strategies on technology adoption, were selected companies from different market segments that represent well the Brazilian industry: sugar and ethanol, electronics assembly, and beverages.
\end{abstract}


The availability of extensive technological knowledge has been proven to be a central concern of managers seeking the implementation of Advanced Manufacturing projects. Its absence is often seen as a barrier to the adoption of features such as artificial intelligence systems. In the studied cases, some of the projects were only made possible by the formation of multidisciplinary teams capable of dealing with innovative combinations of information systems technologies and industrial or agricultural automation. This result is consistent with the theory of affordances where the user knowledge is central to the perception of the opportunities of adoption of new technologies. Companies with different strategic priorities decided to adopt systems with different characteristics, demonstrating that Manufatura Avançada can not be seen as a single and rigid set of approaches. Projects, in high pressure for cost reduction activities, have a great emphasis on vertical integration, while searching for greater flexibility leads to horizontal integration.

New technologies have proved capable, or demonstrated to have affordances, not only to enable new features, but to provide features at significantly lower costs than their predecessors. Examples were observed where lower cost technologies allowed the expansion of partially implemented projects or the implementation of projects in areas with characteristics that made them previously financially infeasible

Due to these results, the proposed framework underwent revision, including the adoption of new technologies due to costs and the formation of multidisciplinary teams. This new framework is presented as the final contribution of this work, which is expected to serve as the basis for future research on the subject

Keywords: Industry 4.0, Industrial Internet, Affordances, Manufacturing Strategy 


\section{Lista de figuras}

Figura 1 - S95 enterprise-control model (ANSI/ISA-95.00.03-2013, 2005) …...................... 27

Figura 2 - Modelo C-MES versão 2.1 (“MESA Model,” 2011) ............................................ 29

Figura 3 - Os quatro estágios da Revolução Industrial (Henning et al., 2013) ........................ 31

Figura 4 - Publicações sobre Manufatura Avançada............................................................... 40

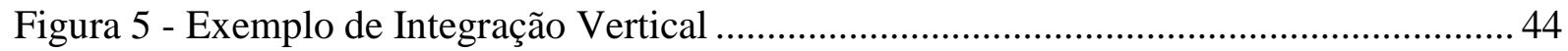

Figura 6 - Exemplo de Integração Horizontal ...................................................................... 44

Figura 7 - Exemplo de Integração no Ciclo de Vida do Produto ............................................. 45

Figura 8 - Modelo de Estratégia de Manufatura (Leong et al., 1990) .................................... 49

Figura 9 - Tipologia de sistemas de produção (Kim \& Lee, 1993) ........................................ 51

Figura 10 - Framework relacionando prioridades competitivas, estrutura de processo e aplicação de TIC em empresas de manufatura (Kathuria \& Igbaria, 1997)........... 53

Figura 11- Estrutura dos Tipos de Affordance (Pozzi et al., 2014) ...................................... 57

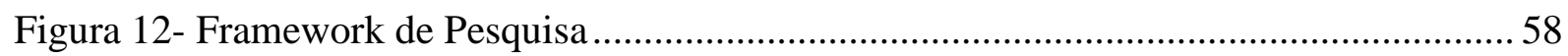

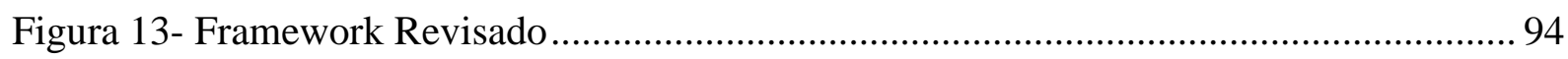

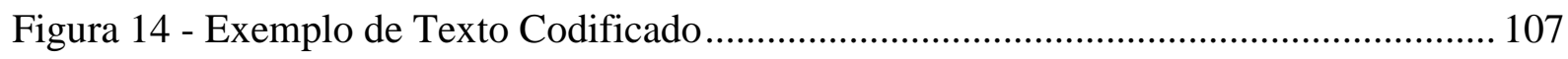




\section{Lista de tabelas}

Tabela 1 - Uso e importância para a manufatura, das tecnologias digitais (SONDAGEMIndústria 4.0: novo desafio para a indústria brasileira, 2016) ............................... 36

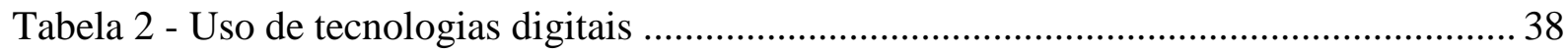

Tabela 3 - Iniciativas regionais de Manufatura Avançada ...................................................... 39

Tabela 4 - Journals com maior número de publicações sobre Manufatura Avançada ............. 41

Tabela 5 - Países com maiores quantidades de publicações sobre Manufatura Avançada ...... 41

Tabela 6 - Áreas de interesse dos journals com artigos sobre Manufatura Avançada ............. 42

Tabela 7 - Categorias operacionais das oportunidades da Manufatura Avançada (Davis et al.,

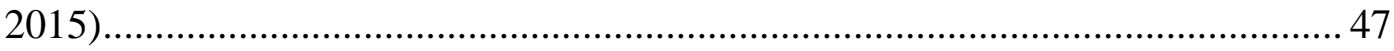

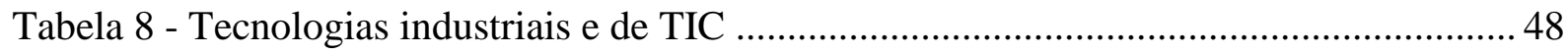

Tabela 9- Interação entre consenso estratégico e alinhamento estratégico (Walter et al., 2013)

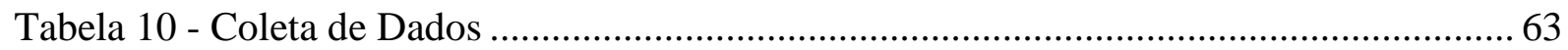

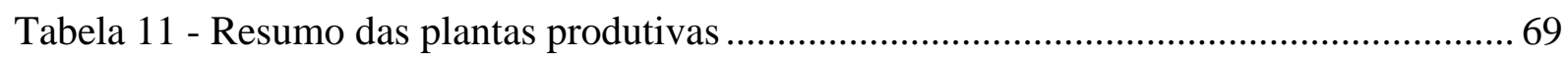

Tabela 12 - Modelos de produção e tecnologias adotadas nos casos estudados ...................... 83

Tabela 13 - Diferenças entre TI e TO (Qian \& Hou, 2015) .................................................. 87 


\section{Lista de Siglas}

AMT

AS/RS

AVT

BNDES

BOM

CAD

CAM

CAPP

CIM

C-MES

$\mathrm{CNC}$

CPS

CPPS

DCS

EDI

EDM

EMBRAPII

ERP

FMS

HPPC

ICT

IEEE

IFAC

IoT

IIoT

ISA

MES

MESA

MRP

MTO

OEE

PERA
Advanced Manufacturing Technology

Automated Storage and Retrieval System

Autonomous Vehicle Technology

Banco Nacional do Desenvolvimento

Bill of Materials

Computer-Aided Design

Computer-Aided Manufacturing

Computer-Aided Process Planning

Computer-Integrated Manufacturing

Collaborative Manufacturing Execution System

Computer Numeric Control

Cyber-Physical System

Cyber-Physical Production System

Distributed Control System

Electronic Data Interchange

Engineering Data Management

Empresa Brasileira de Pesquisa e Inovação Industrial

Enterprise Resource Planning

Flexible Manufacturing System

Higiene Pessoal Perfumaria e Cosméticos

Information and Communication Technology

Institute of Electric and Electronic Engineers

International Federation of Automation Control

Internet of Things

Industrial Internet of Things

International Society of Automation

Manufacturing Execution System

Manufacturing Enterprise Solutions Association

Material Resource Planning

Make to Order

Overall Equipment Effectiveness

Purdue Enterprise Reference Architecture 
PDM

PLC

PLM

RFID

RBOM

SaaS

SCADA

SJR

SOA

TA

TI

TIC
Product Data Management

Programmable Logic Controller

Product Lifecycle Management

Radio-Frequency IDentification

Reverse Bill of Materials

Software as a Service

Supervisory Control and Data Acquisition

Scientific Journal Ranking

Service Oriented Architecture

Tecnologia da Automação

Tecnologia da Informação

Tecnologia da Informação e Comunicação 


\section{Sumário}

FICHA CATALOGRÁFICA ................................................................iv

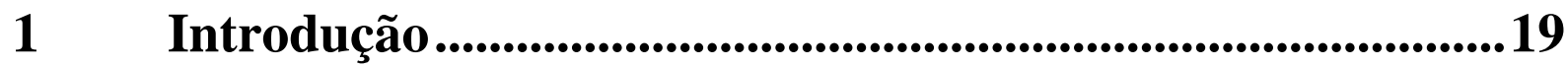

2 Levantamento Bibliográfico................................................25

2.1 Manufatura Avançada ............................................................................ 25

2.1.1 Antecedentes ...................................................................................................... 25

2.1.2 Programas Regionais ..................................................................... 29

2.1.3 Discussão sobre Manufatura Avançada na literatura científica referente a gestão e tecnologia ..............................................................39

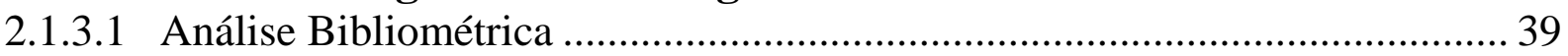

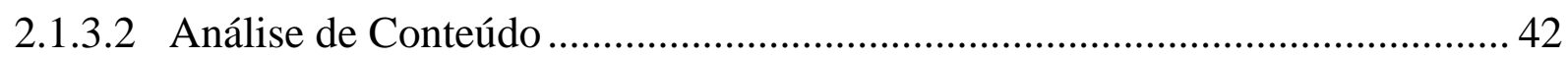

2.2 Estratégia de Manufatura ...................................................... 49

2.3 TIC e Estratégia de Manufatura ............................................5 52

2.4 Affordances ............................................................................................. 54

2.5 Framework de Pesquisa Proposto ................................................ 57

3 Metodologia....................................................................61

$4 \quad$ Estudos de Caso ................................................................665

4.1 Grupo de Açúcar e Álcool .................................................................. 65

4.1.1 Projeto de Sistema Integrado para Usinas ............................................66

4.1.2 Projeto de Sistema Integrado para Área Agrícola............................. 69

4.2 Indústria de Bebidas ............................................................................... 71

4.2.1 Projeto Coleta de Dados ................................................................73

4.3 Indústria de Montagem de Eletrônicos ........................................... 74

4.3.1 Projeto de Reciclagem....................................................................................... 75

4.3.2 Projeto Aplicativos ............................................................................. 77

5 Discussão dos Casos Analisados ............................................79

5.1 Grupo de Açúcar e Álcool ........................................................... 79

5.2 Indústria de Bebidas ............................................................... 81

5.3 Indústria de Montagem de Eletrônicos ......................................8 81

5.4 O impacto da estratégia ............................................................ 82

5.5 Tecnologias com affordances de novas funcionalidades ou por novos padrões de custo............................................................... 84

5.6 O papel das áreas de gestão de tecnologia e das equipes multidisciplinares, na percepção e realização de affordances.. 86

5.7 O ERP como principal sistema corporativo .................................. 88 
5.8 As barreiras para a adoção de sistemas de integração.............. 88

5.9 O impacto da mudança de perfil do consumidor ........................ 89

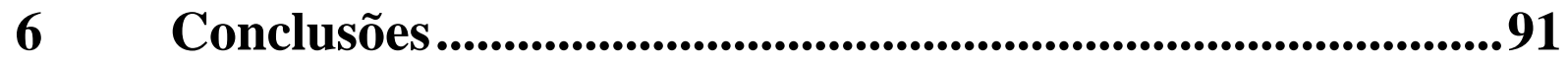

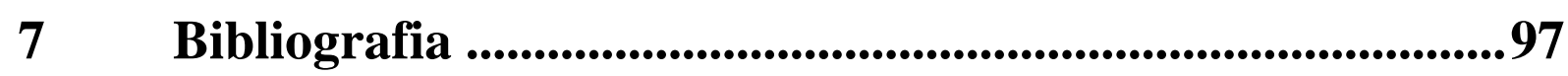

Anexo A - Questionário utilizado para as estrevistas ...............105

Anexo B - ATLAS.ti ......................................................................107 


\section{Introdução}

Nos últimos três anos o termo Indústria 4.0 prevaleceu, no Brasil, como assunto mais discutido em revistas, feiras e conferências relativas à indústria. Com repercussão semelhante ao redor do mundo, foi tema de discussão no Fórum Econômico Mundial de Davos de 2016, em artigos na imprensa internacional, em relatórios de grandes empresas de consultoria, como a PricewatershouseCoppers e a McKinsey \& Company e de grandes fornecedores mundiais de tecnologia, como General Electric (GE), SAP e Siemens.

O título Industrie 4.0 foi cunhado na Alemanha, em 2011, nominando seu programa de fortalecimento do parque industrial nacional, o Industrie 4.0 Platform, concebido para fazer frente a crescentes ameaças competitivas estrangeiras provenientes, principalmente, de países orientais (Vogel-Heuser \& Hess, 2016). O programa logrou carrear grandes investimentos para aplicação em novas tecnologias da informação e comunicação (TIC) aplicadas à manufatura, buscando impactos em produtividade, qualidade, flexibilidade e sustentabilidade das cadeias de suprimentos (Kang et al., 2016).

Marcado por tecnologias como inteligência artificial e grande interconectividade, viabilizadas pelas TIC, o programa alemão aponta, ainda na escolha de seu nome original, para uma nova revolução industrial. A quarta revolução industrial, representada pelo conceito de Indústria 4.0, viria a suceder a primeira revolução, promovida pela máquina a vapor, a segunda, com as máquinas elétricas e, a terceira, com a informática e automação industrial (Sergi, 2015).

Em paralelo com citados estudos, outras regiões do mundo empreenderam iniciativas semelhantes. De bastante impacto mundial, foram duas as iniciativas dos Estados Unidos: o Industrial Internet Consortium, promotor do termo Industrial Internet of Things (IIoT), e o Smart Manufacturing Leadership Coalition, com o termo Smart Manufacturing. Outros movimentos regionais importantes são o Nouvelle France Industrielle, da França, European Factory of the Future Research Association, da União Europeia e Smart Industry, da Holanda (Toro, Barandiaran, \& Posada, 2015). Como resposta, países orientais com importantes economias industriais também apresentaram programas como o Made in China 2015, da China, e Manufacturing Innovation 3.0, da Coreia do Sul.

Embora o Brasil não tenha uma organização especialmente criada para o desenvolvimento desses programas, o poder público disponibiliza recursos para investimentos, além de criar grupos de pesquisas, pelo Banco Nacional do Desenvolvimento Econômico e Social (BNDES) e pela Empresa Brasileira de Pesquisa e Inovação Industrial (EMBRAPII). 
Ambos se referem a Manufatura Avançada ${ }^{1}$ para identificar suas iniciativas e este será o termo utilizado neste trabalho como sinônimo de Industrie 4.0, Industrial Internet of Things e Smart Manufacturing, assim como das denominações equivalentes utilizadas em outros países.

Dois conceitos centrais da Manufatura Avançada são o Cyber-Physical System (CPS) e a integração de sistemas de manufatura em três eixos.

CPS são sistemas formados por equipamentos físicos e aplicativos virtuais e que se aproveitam de tecnologias de sensores, de aquisição de dados e de redes computacionais (J. Lee, Bagheri, \& Kao, 2014). Diretamente relacionados a inovações de TIC como Cloud Computing e Internet of Things, os sistemas CPS são vistos como a solução para a produção e para logísticas colaborativas (Kang et al., 2016). Muitas vezes o termo Cyber-Physical Production System (CPPS) é empregado para especificar sua aplicação industrial.

A integração nos três eixos da manufatura, que pode ser vista como uma descrição funcional do CPPS, propõe sistemas que sejam capazes de transitar informações, tanto verticalmente entre equipamentos de produção e sistemas corporativos, como horizontalmente entre empresas de uma mesma cadeia de valor, transitando, ainda, no decorrer do ciclo de vida do produto, desde o desenvolvimento até o descarte ou reciclagem (Schmidt, Lüder, Rosendahl, Foehr, \& Vollmar, 2015). Essa proposta de integração é muito semelhante ao modelo Computer-Integrated Manufacturing (CIM), da década de 1980, que não conseguiu trazer os impactos em desempenho, esperados nas implantações práticas (Cagliano \& Spina, 2000).

Alguns autores, porém, consideram essas ideias muito ambiciosas e distorcidas por esforços excessivos de marketing (Drath R. \& Horch A., 2014; Toro et al., 2015). O impacto da adoção da tecnologia no negócio é amplamente estudado pela literatura científica, mas, uma possível relação direta com melhorias do desempenho não é reportada pelos pesquisadores de gestão de sistemas de informação ou gestão de operações.

Trabalhos empíricos, que investigaram o assunto, encontraram uma série de elementos indiretamente relacionados a artefatos tecnológicos, como mediadores do desempenho. Podem ser citados os resultados de dois estudos que investigaram a implantação de sistemas de gestão de cadeias de suprimentos, a volatilidade da demanda, em Saldanha, Melville, Ramirez, \& Richardson (2013) e a agilidade na cadeia de suprimentos, em Liu, Ke, Wei, \& Hua (2013), ambos tratando de implantações em sistemas industriais.

\footnotetext{
${ }^{1} \mathrm{O}$ termo Manufatura Avançada, nesse caso, é a tradução de Smart Manufacturing. Alguns autores o utilizam como tradução de Advanced Manufacturing, como em Sprakel \& Severiano Filho (1999), se referindo ao conjunto de tecnologias de manufatura disponíveis na década de 80 , entre elas o CAD / CAM.
} 
Kathuria \& Igbaria ( 1997) propõem que o impacto em performance da manufatura só ocorre quando as aplicações de TIC estão alinhadas com as tarefas de gestão-chave, para o atendimento das prioridades competitivas e da estrutura de processo industrial delas decorrentes. Prioridades competitivas, em estratégia de operações, são objetivos a serem buscados pela manufatura e são dependentes das características da empresa e do mercado em que está inserida (Leong, Snyder, \& Ward, 1990). Objetivos como custo, qualidade, velocidade de entrega e flexibilidade, impactados por sistemas de TIC, não têm os mesmo grau de importância em diferentes mercados e companhias (Choudhari, Adil, \& Ananthakumar, 2010; Miltenburg, 2005).

Como as tecnologias a serem adotadas, assim como seu modelo de aplicação, são dependentes do segmento industrial e das características da própria indústria, a propositura de recomendações genéricas de aplicação de tecnologias é inadequada e, a simples adoção de modelos vindos do exterior, possivelmente insuficientes para o impacto da competitividade no Brasil. O país tem entre seus principais produtos de exportação commodities agrícolas e minerais, ao contrário da Alemanha e Estados Unidos, cuja pauta sobressaem produtos industrializados e de alta tecnologia, conforme a base de dados BACI (Simoes Gaspar, 2012). Aqui é importante ressaltar que, não obstante a menor presença na exportação, os produtos da indústria de transformação nacional têm grande importância econômica para o mercado interno e para geração de empregos.

Além da adequação à estratégia, existe outra complexidade na adoção da Manufatura Avançada: o conhecimento de novas tecnologias de TIC. O entendimento desses novos recursos, que na maioria dos casos têm origem fora do ambiente industrial, é requisito para que sejam aplicados de forma adequada no contexto industrial. Recursos humanos capazes de lidar com esse novo cenário e com todas suas fases de implantação são escassos, não só no Brasil, mas nas indústrias de outras partes do mundo (Sommer, 2015).

Artefatos tecnológicos, quando utilizados em diversos contextos ou por usuários distintos, podem apresentar diferentes capacidades. O conceito de affordance, oriundo da sociologia da tecnologia (Hutchby, 2001), determina a possibilidade de ação de um agente em contato com um determinado objeto. É na percepção dos affordances de determinadas tecnologias, alinhadas com seus objetivos, que é exigido maior conhecimento de quem atue na implementação da Manufatura Avançada (Pozzi, Pigni, \& Vitari, 2014).

O objetivo deste trabalho é investigar como diferentes estratégias de manufatura e percepções sobre as capacidades tecnológicas (affordances) influenciam na adoção de tecnologias de Manufatura Avançada. Essa exploração será realizada através da proposição de 
um framework integrando as literaturas de affordances e estratégias de manufatura, além de um estudo múltiplo de casos de cinco projetos, implantados ou em andamento em três empresas brasileiras de grande porte, de diferentes segmentos.

A pesquisa realizada buscou contribuir, mediante a apresentação de um trabalho empírico sobre Manufatura Avançada, assunto ainda pouco explorado na literatura de gestão de operações, com uma proposta de integração entre as teorias de Affordances e Estratégia de Operações e, ainda, com uma visão da Manufatura Avançada dentro do contexto dos modelos de sistemas de integração que a antecederam.

A relevância acadêmica desse tema se verifica pela contextualização da produção científica atual sobre Manufatura Avançada, predominantemente do domínio da engenharia, à literatura de administração encontrando suas relações com o negócio. Isto pode apresentar uma contribuição prática a gestores que avaliem a adoção dessas tecnologias ou sejam responsáveis por políticas públicas de incentivo ao desenvolvimento e adoção das mencionadas tecnologias na indústria.

A questão de pesquisa principal dessa investigação é:

Como as prioridades estratégicas influenciam a decisão de adotar sistemas de Manufatura Avançada?

E como questões secundárias:

Como tecnologias habilitadoras viabilizaram projetos de manufatura avançada?

Como novas tecnologias de TIC para aplicações industriais são identificadas, implantadas e gerenciadas?

Este documento terá seus próximos capítulos estruturados da seguinte forma:

- Levantamento Bibliográfico: pesquisa na literatura acadêmica e gerencial que trate dos assuntos manufatura avançada, estratégia de manufatura e affordances;

- Metodologia: critérios utilizados na pesquisa empírica, explanação do modelo de pesquisa adotado e apresentação dos casos selecionados;

- Estudos de Caso: descrição dos casos em que se baseiam os resultados obtidos empiricamente e apresentados neste trabalho; 
- Discussão: análise de cada caso e entre os casos, à luz da literatura científica;

- Conclusões: considerações finais e análise das proposições;

- Bibliografia: referências apresentadas nos demais capítulos. 


\section{Levantamento Bibliográfico}

Como base conceitual deste trabalho foi utilizada literatura sobre Manufatura Avançada e sistemas de gestão de manufatura, estratégia de manufatura e affordances. Os resultados desse levantamento bibliográfico são apresentados neste capítulo.

\subsection{Manufatura Avançada}

Os movimentos de Manufatura Avançada resultam de interesses econômicos de diversas regiões, lideradas pelos Estados Unidos e Alemanha, da disponibilidade de novas tecnologias, com o potencial de viabilizar o fortalecimento de objetivos industriais que tradicionalmente impactam a competitividade e, também, de objetivos emergentes, como sustentabilidade.

Conforme afirma Bartodziej (2017), a ideia de uma manufatura integrada por sistemas TIC se originou no CIM, da década de 80. Apesar de a literatura apontar o CIM como proposta que não apresentou sucesso em aplicações práticas (Cagliano \& Spina, 2000; Deuel, 1994), algumas de suas funções deram origem a novos sistemas, como o Manufacturing Execution System (MES) e o Product Lifecycle Management (PLM), com inúmeras implantações.

Neste capítulo são explorados esses antecedentes históricos, assim como os movimentos registrados de Manufatura Avançada.

\subsubsection{Antecedentes}

A década de 1980 foi marcada pelo desenvolvimento e popularização, na computação, de novas tecnologias de software e hardware, assim como pelo aumento das pressões competitivas do mercado industrial. Assim, iniciou-se a busca por um sistema único que pudesse integrar o desenvolvimento de produtos com a execução e coordenação da produção. Dessa forma, o CIM foi considerado a peça central da operação da "fábrica do futuro" (Rosenthal, 1984).

As tecnologias agrupadas como Advanced Manufacturing Technolgy (AMT) receberam bastante interesse devido ao potencial de trazer vantagem em custos. Esta vantagem é verificada no comando numérico computadorizado (CNC), nos sistemas flexíveis de manufatura (FMS), no desenho assistido por computador (CAD), no planejamento de processo assistido por 
computador (CAPP), nos sistemas automatizados de armazenagem e recuperação (AS / RS) e no planejamento de materiais (MRP) (Cagliano \& Spina, 2000). O CIM é o sistema responsável por integrar todos esses sistemas trazendo, não só eficiência, mas flexibilidade, melhorias de qualidade, reduções no tempo de lançamento de produtos e respostas mais rápidas a mudanças para atendimento a necessidades dos consumidores (Cagliano \& Spina, 2000; Dhinesh Kumar, Karunamoorthy, Roth, \& Mirnalinee, 2005; Swink \& Nair, 2007).

No início da década de 1990 muitas implantações de CIM não haviam, ainda, trazido o retorno esperado. Algumas, devido a projetos falhos, além de pouco entendimento de sua aplicação estratégica por parte dos gestores (Cagliano \& Spina, 2000) mas, muitas, por causa dos altos custos de desenvolvimento e manutenção de interfaces complexas, com muitos sistemas e fornecedores (Deuel, 1994).

Como uma nova proposta de sistema integrado para manufatura, o Manufacturing Execution System (MES) foi desenvolvido com uma arquitetura modular, permitindo implantação parcial, que supre a lacuna existente entre os sistemas Enterprise Resource Planning (ERP) e os de automação de chão de fábrica, já largamente adotados nesta época (Deuel, 1994; S. M. Lee, Hong, Katerattanakul, \& Kim, 2012). As primeiras definições sobre a composição do sistema foram criadas pela Manufacturing Execution System Association (MESA - posteriormente renomeada para Manufacturing Enterprise Solutions Association), com a seleção de onze funcionalidades (MESA, 1997): plano detalhado de produção, alocação de recursos, envio de ordens para unidades produtivas, controle de documentação, rastreabilidade e genealogia de produtos, análise de desempenho, gestão de mão de obra, gestão da manutenção, gestão de processos, gestão de qualidade e coleta de dados.

Os objetivos de negócio do MES, de acordo com a literatura, são bastante parecidos com os propostos pelo CIM, mas, o MES cobre apenas as funções de execução da produção e integração com equipamentos de chão de fábrica, enquanto o CIM apresenta maior amplitude. Alguns destes objetivos de negócios são redução do tempo de lançamento de produtos, redução do custo de produção, maior poder de decisão dos operadores (Deuel, 1994) e conversão precisa do plano de produção em produto final (S. M. Lee et al., 2012). Devido ao interesse das companhias nesse modelo, organizações profissionais realizaram fóruns de discussão e de criação de normas para esses sistemas. A International Society of Automation (ISA) publicou em 2000 a primeira parte da norma S95, que passou a ser largamente adotada por desenvolvedores de softwares e integradores de sistemas (ou ANSI/ISA 95) (Saenz de Ugarte, Artiba, \& Pellerin, 2009; Scholten, 2007). Uma de suas maiores contribuições foi o mapeamento das interações entre as diversas funções do MES e sistemas corporativos, 
adaptando a Purdue Enterprise Reference Architecture (PERA) (Williams, 1994) ao seu contexto (Saenz de Ugarte et al., 2009), esquematizado na Figura 1.

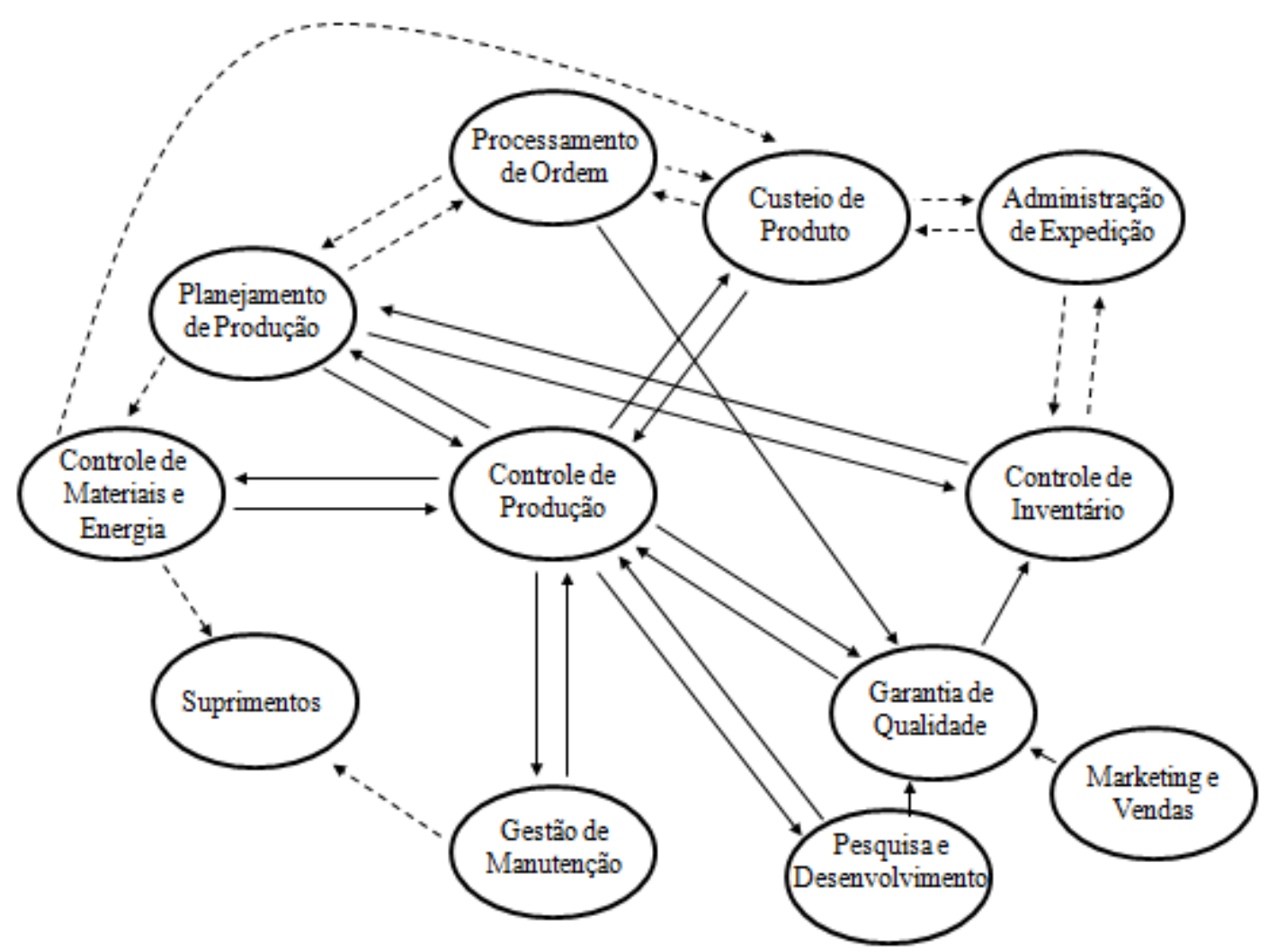

Figura 1 - S95 enterprise-control model (ANSI/ISA-95.00.03-2013, 2005)

O modelo PERA foi proposto por Williams (1994), como um mapeamento completo das funções de uma empresa industrial, com o objetivo de servir como arquitetura básica para sistemas CIM, mapeando os fluxos de informações entre sistemas, controles e pessoas. A S95 tem sido apontada como uma possível referência para a arquitetura dos novos sistemas de Manufatura Avançada (Morgan \& O’Donnell, 2015). A norma, porém, utiliza, ao invés de MES, a nomenclatura Manufacturing Operations Management (MOM), que foi adotada posteriormente em muitos textos da MESA.

Embora o MES seja visto muitas vezes como o sucessor do CIM, ele não abrange um conjunto importante das funcionalidades deste último, que correspondem à engenharia de produto. Com a larga adoção de sistemas CAD, usados como base para CAM e configuração de CNC, a gestão dos arquivos de projetos começou a aumentar de complexidade. Já no final década da década de 1980, surgiram novos sistemas que se propunham a organizar esses desenhos. Inicialmente chamados de Engineering Data Management (EDM), com funções de agrupamento e gestão de versões de projetos, logo evoluíram para Product Data Management 
(PDM), gerenciando toda a lista de materiais e relacionando o projeto do produto ao de seus componentes (Saaksvuori \& Immonen, 2002).

Na década de 1990, o PDM foi novamente expandido, dando origem ao Product Lifecycle Management (PLM). O PLM é um sistema colaborativo que gerencia, não só os dados do produto, mas também os de manufatura e serviços pós-produção (Gunendran \& Young, 2010; Saaksvuori \& Immonen, 2002). Seu objetivo é manter disponíveis informações relacionadas a todas as fases do ciclo de vida do produto, para todos os envolvidos, com funcionalidades adequadas para cada um dos diferentes contextos (Guerra-Zubiaga, Donato, Ramirez, \& Contero, 2006). Os principais recursos de um sistema PLM, de acordo com Saaksvuori \& Immonen (2002), são gestão de itens (desenhos CAD, por exemplo), gestão de estrutura de produto, gestão de documentos, gestão de mudanças, consulta a informações, gestão de workflow e distribuição. Segundo o autor, os usuários típicos do sistema são as áreas de desenvolvimento de produtos, compras e suprimentos, vendas e marketing, parceiros e subcontratados, pós-vendas e produção.

Os impactos em processos de negócio da implantação de um sistema PLM, apontados pela literatura, são vários. Alguns, diretamente ligados à gestão da inovação, como maior controle da fase de desenvolvimento de produtos (David \& Rowe, 2016), redução do tempo de disponibilização para o mercado (time-to-market) (Gunendran \& Young, 2010) e redução do tempo para atingir o volume de produção projetado (time-to-volume) (Saaksvuori \& Immonen, 2002). Outros impactos, para a fase de serviços ao cliente, como o tempo de resposta a solicitações de serviço (time-to-service) ou qualidade do serviço (Gunendran \& Young, 2010). Por fim, alguns impactos mais gerais e coincidentes com os esperados para o MES, como flexibilidade, correspondente à reação rápida a necessidades de alterações em produtos (Saaksvuori \& Immonen, 2002) ou, ainda, a relação entre custo, qualidade e tempo, fatores estes decorrentes das melhorias no processo de desenvolvimento (Guerra-Zubiaga et al., 2006).

Saaksvuori \& Immonen (2002) justificam os grandes impactos, para o negócio, decorrentes da implantação do PLM, afirmando que $80 \%$ do custo do produto são determinados na fase de projeto, sendo que muitos dos problemas de qualidade são provocados pela falta de informações sobre alterações em produtos, pela complexidade de produtos e processos e, também, pela falta de rastreabilidade de componentes usados na montagem final.

Considerando implantações práticas e pacotes de software comerciais, muitas vezes os limites entre os sistemas não são bem definidos. Em uma pesquisa de 2008 conduzida pelo Aberdeen Group (Brown \& Houlihan, 2008) envolvendo 260 empresas de manufatura, os dados 
de processos de manufatura são armazenados, em 17\% dos casos, no PLM, em 50\%, no ERP, em 17\%, no MES e em 16\%, em outros sistemas ou não estão em qualquer sistema.

Modelos para que o ERP, MES e PLM atuem de forma integrada, ainda são investigados pela literatura científica. Hatakeyama \& Machado (2016) apresentam uma proposta para as responsabilidades de cada sistema, em um cenário integrado para a indústria automobilística. Moones et al. (2015) propõem uma modelagem de dados baseada na norma S95, incluindo dados do PLM. Ben Khedher, Henry, \& Bouras (2011) também usam a S95 para mapear os fluxos de dados entre eles.

A MESA, em sua conferência anual de 2004, criou o termo Collaborative MES (CMES) para descrever o sistema atuando nesse ambiente integrado (Ferrazzi, 2013). O modelo proposto para o C-MES, depois da mais recente revisão, em 2008, pode ser visto na Figura 2 (“MESA Model," 2011).

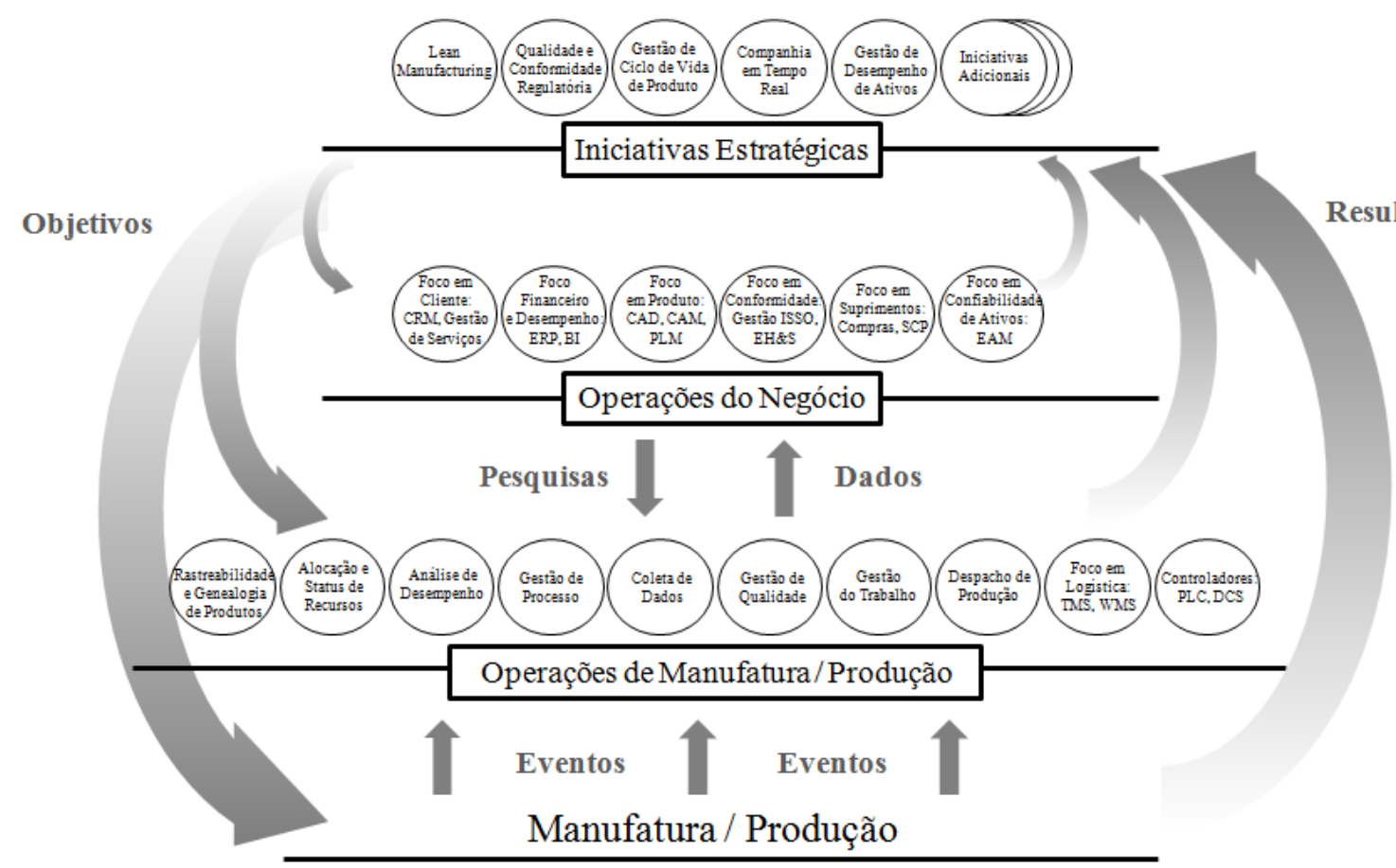

Figura 2 - Modelo C-MES versão 2.1 ("MESA Model,” 2011)

\subsubsection{Programas Regionais}

A intensa terceirização da produção das indústrias ocidentais para países do oriente, na década de 1990, resultou em vinte anos de declínio da manufatura na Europa e nos Estados Unidos (Prause, 2015). Devido à importância dos parques industriais para a geração de empregos, impulso à inovação e competitividade econômica, foram empreendidas diversas iniciativas públicas e privadas para a recuperação da competitividade dos parques industriais 
ocidentais (Buchholz, 2011). Esses programas têm em comum o incentivo do uso da TIC atual, para a criação de cadeias de suprimentos mais conectadas e sustentáveis (Gorbach, Polsonetti, \& Chatha, 2014; Henning, Wolfgang, \& Johannes, 2013). Os programas mais divulgados são o Industrie 4.0, da Alemanha, e o Smart Manufacturing, dos Estados Unidos.

O termo Industrie 4.0 foi usado pela primeira vez durante a Hannover Messe de $2011 \mathrm{e}$ tem se tornado cada vez mais popular, não só na Alemanha, como ao redor do mundo (VogelHeuser \& Hess, 2016). Deu origem a um grupo de trabalho formado por organizações públicas e empresas particulares e, apoiado pelos ministérios germânicos da educação e pesquisa e pelo de assuntos econômicos e da energia. Em seu primeiro relatório, de abril de 2013, o grupo de trabalho descreve sua visão como (Henning et al., 2013):

Germany has one of the most competitive manufacturing industries in the world and is a global leader in the manufacturing equipment sector. This is in no small measure due to Germany's specialization in research, development and production of innovative manufacturing technologies and the management of complex industrial processes. Germany's strong machinery and plant manufacturing industry, its globally significant level of IT competences and its know-how in embedded systems and automation engineering mean that it is extremely well placed to develop its position as a leader in the manufacturing engineering industry. Germany is thus uniquely positioned to tap into the potential of a new type of industrialization: Industrie 4.0. (p. 5)

O nome se refere à chamada quarta revolução industrial. A primeira, do final do século dezoito, aconteceu com a introdução da máquina a vapor, mecanizando a manufatura. A segunda, no início do século 20 , com a eletricidade viabilizando a produção em massa. A terceira, no início da década de 1970, com a automação, fruto da eletrônica digital. A quarta revolução industrial, acontecendo nos dias de hoje e ora aqui enfocada, seria baseada em recursos antes indisponíveis, que possibilitam a criação da internet das coisas e serviços, integrando recursos, informações, objetos e pessoas (Henning et al., 2013). 


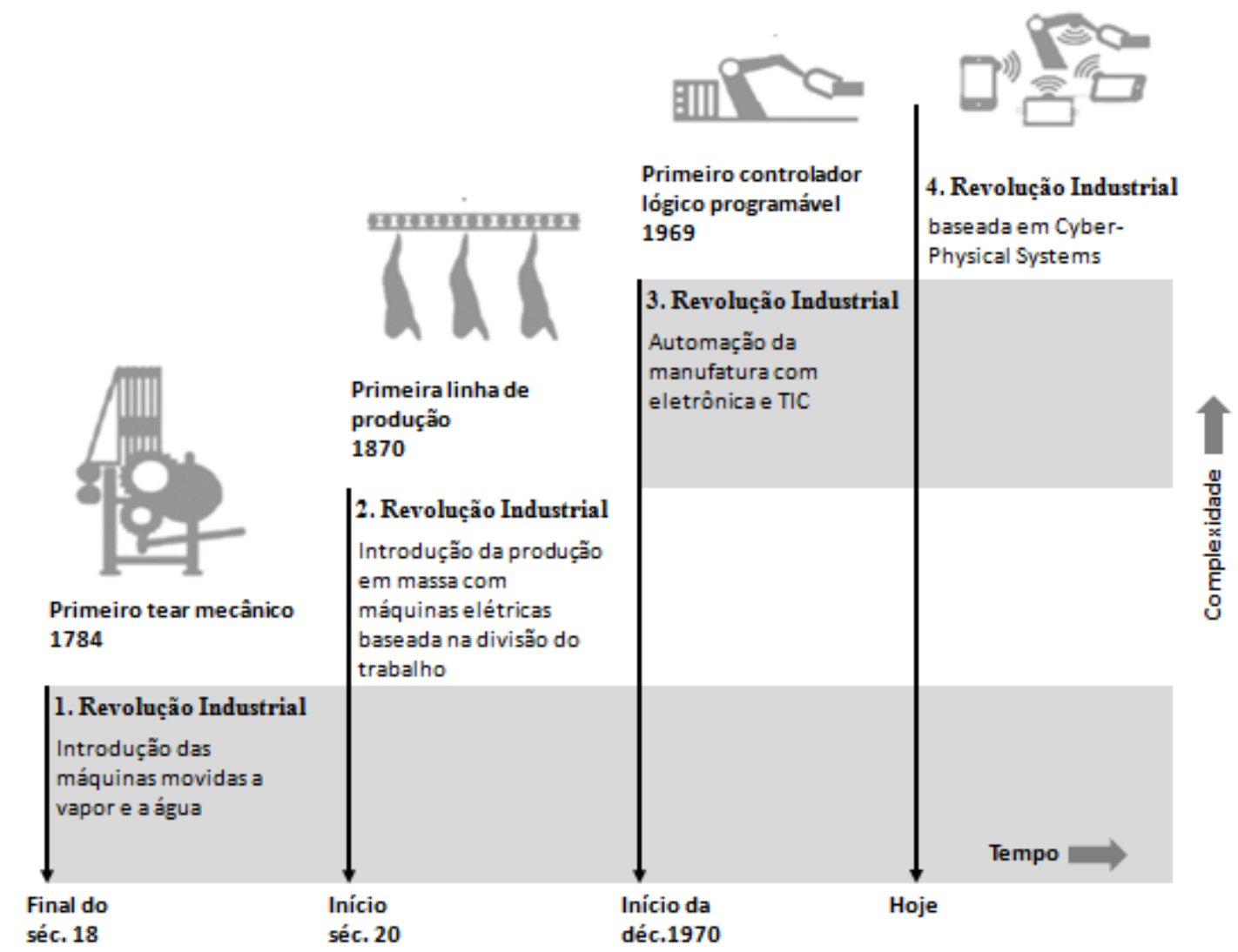

Figura 3 - Os quatro estágios da Revolução Industrial (Henning et al., 2013)

Os potenciais impactos da quarta revolução, de acordo com o relatório do grupo de trabalho alemão, acima mencionado, são (Henning et al., 2013):

- Atender a requisitos individuais de consumidores: Permite que tais requisitos sejam atendidos, influenciando o projeto, configuração, planejamento, manufatura e fases da produção. Dessa forma, produções de lotes com volumes muito baixos poderiam se manter lucrativas.

- Flexibilidade: Um sistema baseado em CPS pode se reconfigurar dinamicamente em variadas dimensões, como qualidade, tempo, risco, robustez, preço e adequação a parâmetros do meio ambiente. Com isso, é possível reagir rapidamente a falhas e o processo de engenharia pode ser mais ágil.

- Processo de decisão otimizado: Permite uma visão global dos processos em tempo real, com rápida verificação dos impactos sobre decisões de projeto e correspondentes respostas a falhas.

- Produtividade e eficiência de recursos: Ainda se aplicam os objetivos estratégicos da manufatura, de produzir o máximo possível com os recursos disponíveis, utilizando o 
mínimo de recursos, para um determinado nível de produção. Dessa forma, impactos correspondentes a consumo de energia e emissão de poluentes, podem ser reduzidos.

- Criação de novas oportunidades de valor, por meio de novos serviços: Criação de novos empregos e serviços baseados no grande volume de dados gerados pelos equipamentos inteligentes e por sensores. Essas oportunidades são acessíveis, também, a startups e pequenas empresas.

- Resposta à mudança de perfil do trabalhador: Em conjunto com iniciativas de organização do trabalho e desenvolvimento de competências, as interações entre tecnologia e trabalhadores abrirão oportunidades para o aproveitamento das mudanças de perfil destes, decorrentes de fatores como diversidade do ambiente de trabalho e redução da disponibilidade de especialistas.

- Equilíbrio entre trabalho e vida pessoal: Empresas que usam o CPS poderão atender às necessidades dos empregados, de equilíbrio entre trabalho e vida pessoal, assim como desenvolvimento pessoal e profissional. Sistemas inteligentes podem auxiliar em uma organização do trabalho mais flexível, atendendo a requisitos dos empregados e das empresas.

- Uma economia de altos salários, mas ainda competitiva: $\mathrm{Na}$ Alemanha, onde o trabalhador é bem remunerado, a Industrie 4.0 tem uma estratégia dupla, permitindo que o país mantenha a liderança como fornecedor e passe a liderar o mercado de soluções para esta tecnologia.

Nos Estados Unidos, o movimento é liderado por dois grupos. O Smart Manufacturing Leadership Coalition, criado em 2010 para reduzir os riscos do desenvolvimento de tecnologias de manufatura avançada, mediante a criação de padrões e plataformas de teste, e o Industrial Internet Consortium, formado em 2014 em colaboração entre indústria, governo e área acadêmica, para o desenvolvimento do Industrial Internet of Things.

O Smart Manufacturing Leadership Coalition, em seu folder de divulgação, descreve o desafio da Manufatura Avançada da seguinte forma (Smart Manufacturing Leadership Coalition, 2012):

Smart Manufacturing (SM) is integrating network- based data and information that comprises the real-time understanding, reasoning, planning and management of all aspects of a manufacturing and supply chain enterprise. SM is facilitated through use of advanced sensor-based data analytics, modeling and simulation in real-time. SM is 
manufacturing in which all information is available when it is needed, where it is needed and in the form it is most useful-infusing manufacturing intelligence throughout the lifecycle of design, engineering, planning and production.

Unfortunately, a cost effective infrastructure to integrate real-time manufacturing intelligence and active management across the control systems of an entire production operation does not exist today. (para. 1)

O Industrial Internet Consortium, na primeira edição de seu periódico Journal of Innovation, aponta como seus principais temas de interesse (Lin, 2015):

- Manutenção e operações inteligentes: Este primeiro passo objetiva garantir a comunicação de todos os ativos que operam em ilhas isoladas, permitindo o monitoramento remoto e a análise de sua saúde e operação. Dessa forma, as primeiras ações de aumento da eficiência e melhoria de processos vão garantir os primeiros retornos dessa tecnologia.

- Otimização global: Com os dispositivos conectados, o próximo passo é garantir a operação otimizada do parque de ativos. Por meio de uma inteligência centralizada, são enviados planos para executar as melhores operações, considerando disponibilidade, custos e demanda.

- Autonomia local: Embora manter uma inteligência centralizada seja a solução mais simples para a coordenação, em alguns casos pode não ser viável. Sistemas que exigem decisões rápidas, ou com redes de comunicação lentas, devem ter inteligência local que leve em conta seus dados e os dos dispositivos mais próximos. Sistemas como esse, com capacidade de aprendizado e adaptação, podem trabalhar de forma eficiente e robusta com pouca ou nenhuma comunicação com um sistema central.

Esta última iniciativa, tratando de forma mais geral dispositivos inteligentes, busca atuar em um contexto mais amplo, englobando não só a manufatura mas, também, áreas como energia, saúde e transportes, assim como cidades inteligentes. Em 2016 o Industrial Internet Consortium firmou uma parceria com a Industrie 4.0 Platform, da Alemanha, buscando a convergência entre as arquiteturas propostas e, ainda, "reduzir a confusão do mercado" (“Collaboration for Interoperability," 2016).

Drath e Horch, em seu reverenciado artigo Industrie 4.0: Hit or Hype? (Drath R. \& Horch A., 2014), com 70 citações na base Scopus, atribuem a mencionada confusão do mercado 
à diversidade de definições provenientes das diferentes iniciativas e ao marketing excessivamente ambicioso, presentes em "quase todas as feiras, conferências ou chamadas de financiamentos públicos relacionados à indústria" (Drath R. \& Horch A., 2014, p.1).

Essa divulgação e a abertura de linhas de financiamentos despertaram, nas indústrias, a grande interesse no assunto e, consequentemente, o desenvolvimentos de produtos e serviços de empresas de consultoria e fornecedores de tecnologia. Muitas dessas empresas apresentaram sua visão em artigos e relatórios públicos, como a Accenture (Alter, Banerjee, E.Daugherty, \& Negm, 2014), a McKinsey \& Company (Wee, Kelly, Cattel, \& Breunig, 2015), a General Electric (Evans \& Annunziata, 2012) e a Schneider Electric (Schneider Electric, 2015). Todos esses textos trouxeram grandes expectativas de ganhos com a adoção da Manufatura Avançada.

A PricewaterhouseCoopers, em 2016, divulgou seu relatório "Indústria 4.0: Digitização como vantagem competitiva para o Brasil" (Reinhard Geissbauer, Vedso, \& Schrauf, 2016). Nele, é apresentado o resultado de pesquisa realizada com gestores de 32 indústrias brasileiras e de outros 25 países sobre o estado atual e planos futuros do que chama de digitização. O termo digitização é definido como "utilizado pela $\mathrm{PwC}$ para representar a transformação das empresas por meio das ferramentas digitais." (Reinhard Geissbauer et al., 2016, p.1). No trabalho são apontadas possibilidades de utilização de tecnologias digitais nas integrações horizontais e verticais e para o próprio produto, com oportunidades de aplicação em novos modelos de serviços. São, também, apresentados dados mostrando que, embora as expectativas de adoção, pelos empresários brasileiros, sejam parecidas com as mundiais, o estágio atual e os investimentos nacionais referentes à Manufatura Avançada, são bastante piores. Na conclusão do relatório é proposto modelo com fases e áreas da digitização.

As políticas dos Estados Unidos e Alemanha são referências para as políticas brasileiras, como mostra artigo de Daudt \& Willcox (2016), publicado pelo Banco Nacional do Desenvolvimento (BNDES), com o título "Reflexões críticas a partir das experiências dos Estados Unidos e da Alemanha em manufatura avançada". Nele são estudados os acertos e erros verificados ao longo de mais de cinco anos, sendo defendido que a incorporação da tecnologia pelas indústrias não acontece de forma espontânea, mas, estimulada por políticas públicas que levem em conta demandas efetivas para apoiar o desenvolvimento tecnológico.

Uma das iniciativas importantes na área, do governo federal do Brasil, foi a criação da Empresa Brasileira de Pesquisa e Inovação Industrial (EMBRAPII), em 2013. Gerida pelo Ministério da Ciência, Tecnologia, Inovações e Comunicações, em conjunto com o Ministério da Educação, foi inspirada na sociedade Fraunhofer, da Alemanha, e coordena instituições de pesquisas públicas e privadas, visando apoiar a inovação em empresas industriais, reduzindo os 
riscos inerentes, por meio de financiamentos (“EMBRAPII - Quem Somos,” n.d.). Dentro das competências tecnológicas, o grupo Produtos Conectados apresenta as linhas de atuação Industry 4.0 e Industrial Internet of Things, com definições compatíveis com as dos programas da Alemanha (restrito à área industrial) e Estados Unidos (inclui transportes, cuidados médicos e energia).

Em abril de 2016, a Confederação Nacional da Indústria publicou o relatório "Indústria 4.0: novo desafio para a indústria brasileira". Nele é apresentado o resultado de uma pesquisa com 2.225 indústrias brasileiras sobre adoção de tecnologias digitais para manufatura (SONDAGEM-Indústria 4.0: novo desafio para a indústria brasileira, 2016). A Tabela 1 mostra o resultado do uso e a importância para a competitividade, conforme considerada pelos respondentes, das tecnologias apresentadas. 
Tabela 1 - Uso e importância para a manufatura, das tecnologias digitais (SONDAGEM-Indústria 4.0: novo desafio para a indústria brasileira, 2016)

$\begin{array}{lll}\text { Estágio / Foco Tecnologia } & \text { Uso (\%) } & \begin{array}{l}\text { Importância para } \\ \text { Competitividade }\end{array} \\ (\%)\end{array}$

Automação digital com sensores para controle de processo

Processo Monitoramento e controle remoto da produção com sistemas do tipo MES e SCADA

Automação digital com sensores com identificação de produtos e condições operacionais, linhas flexíveis

Sistemas integrados de engenharia para desenvolvimento de produtos e manufatura de produtos

Desenvolvimento / redução time to market

Manufatura aditiva, prototipagem rápida ou impressão 3D

Simulações/análise de modelos virtuais para projeto e comissionamento

Coleta, processamento e análise de grandes quantidades de dados (big data)

Utilização de serviços em nuvem associados ao produto

Produto / novos modelos de negócio

Incorporação de serviços digitais nos produtos (Internet das Coisas ou Product Service Systems)

Projetos de manufatura por computador $\mathrm{CAD} / \mathrm{CAM}$ 
Entre as tecnologias estão algumas já disponíveis há várias décadas, como automação digital e SCADA (Supervisory Control and Data Acquisition), e outras mais recentes e normalmente relacionadas à Manufatura Avançada, como análise de Big Data. Com base na matriz de adoção tecnológica, foi proposto um ranking entre os segmentos industriais para cada aplicação da tecnologia, conforme Tabela 2. 
Tabela 2 - Uso de tecnologias digitais

Foco em Processo

\begin{tabular}{ll} 
Setor & $\%$ \\
\hline Equipamentos de informática, eletrônicos e ópticos & 43 \\
Coque, derivados do petróleo e biocombustíveis & 43 \\
Metalurgia & 42 \\
Máquinas, aparelhos e materiais elétricos & 36 \\
Produtos de material plástico & 36 \\
Produtos têxteis & 35 \\
Químicos (exceto HPPC) & 35 \\
Veículos automotores & 35 \\
Celulose e papel & 34 \\
Alimentos & 32 \\
\hline
\end{tabular}

Foco em Desenvolvimento

\begin{tabular}{ll} 
Setor & $\%$ \\
\hline Equipamentos de informática, eletrônicos e ópticos & 41 \\
Máquinas, aparelhos e materiais elétricos & 40 \\
Veículos automotores & 36 \\
Máquinas e equipamentos & 35 \\
Produtos diversos & 28 \\
Calçados e suas partes & 24 \\
Produtos de metal & 22 \\
Metalurgia & 22 \\
Móveis & 22 \\
Produtos de material plástico & 21 \\
Celulose e papel & 21 \\
\hline
\end{tabular}

Foco em Produto

\begin{tabular}{ll} 
Setor & $\%$ \\
\hline Equipamentos de informática, eletrônicos e ópticos & 22 \\
Máquinas, aparelhos e materiais elétricos & 22 \\
Produtos de material plástico & 19 \\
Produtos têxteis & 17 \\
Químicos (Exceto HPPC) & 17 \\
Outros equipamentos de transporte & 17 \\
Higiene pessoal, perfume e cosméticos & 16 \\
Calçados e suas partes & 15 \\
Impressão e reprodução & 14 \\
Couros e artefatos de couro & 14 \\
\hline
\end{tabular}


Como em muitas publicações, esse relatório trata as tecnologias de forma genérica, sem considerar a adequação para cada um dos setores e as prioridades competitivas de cada empresa. São apontadas como barreiras para a adoção de tecnologias digitais, o baixo conhecimento dos gestores e o alto custo de implantação (SONDAGEM-Indústria 4.0: novo desafio para a indústria brasileira, 2016).

Na Tabela 3 são apresentadas algumas das iniciativas de Manufatura Avançada com destaque das regiões correspondentes aos países (ou instituição) que as lideram.

Tabela 3 - Iniciativas regionais de Manufatura Avançada

Iniciativa

Região

\begin{tabular}{ll}
\hline Industrial Internet Consortium & Estados Unidos \\
\hline Smart Manufacturing Leadership Coalition & Estados Unidos \\
\hline Industrie 4.0 (High Tech Strategy 2020) & Alemanha \\
\hline European Factories of the Future Research Association & União Europeira \\
\hline Nouvelle France Industrielle & França \\
\hline Smart Industry & Holanda \\
\hline Made in China 2025 & China \\
\hline Manufacturing Innovation 3.0 & Coreia do Sul \\
\hline Connected Smart Factory & Coreia do Sul \\
\hline
\end{tabular}

\subsubsection{Discussão sobre Manufatura Avançada na literatura científica referente a gestão e tecnologia}

Assim como as publicações técnicas e gerenciais, a academia tem mostrado bastante interesse na Manufatura Avançada, nos últimos anos. Além do conteúdo da literatura científica, este tópico do trabalho explora alguns dados bibliométricos, que dão uma visão quantitativa e da evolução desse campo de estudo na administração.

\subsubsection{Análise Bibliométrica}

Os repositórios de publicações científicas Web of Science, da Thompson Reuters, e Scopus, da Reed Elsevier, são considerados os mais abrangentes da atualidade e, portanto, os mais adequados para análises bibliométricas e comparações da produção acadêmica entre países e instituições (Archambault, Campbell, Gingras, \& Larivière, 2009). Conforme Archambault et 
al. (2009), as duas bases de publicações apresentam alta correlação para estudos de quantidades de artigos e correspondentes fatores de impactos. Dessa forma, foi selecionada a base Scopus para a amostragem de artigos deste estudo. Foram considerados, ainda, apenas artigos de publicações com revisão por pares, desconsiderando os apresentados em conferências, livros e capítulos de livros. Somente publicações em inglês foram utilizadas.

As palavras-chave foram pesquisadas nos campos título, palavras-chave e resumo. Para a seleção de artigos sobre Manufatura Avançada foram escolhidas as principais iniciativas "Industry 4.0" e "Industrial Internet" (J. Lee et al., 2014; Toro et al., 2015). O termo Nouvelle France Industrielle foi testado e não retornou nenhuma publicação. O termo Smart Manufacturing não foi utilizado por ser usado frequentemente em outros contextos. Houve o retorno de 300 artigos, havendo sido utilizada a seguinte pesquisa, no dia primeiro de julho de 2017:

\begin{tabular}{|c|c|c|c|c|}
\hline TITLE-ABS-KEY ( "Industry & $4.0^{\prime \prime}$ & "Industrial & Internet" ) & AND \\
\hline TO ( DOCTYPE, & AND & ( LIMIT-TO ( SRCTYPE & "j" ) ) & AND \\
\hline
\end{tabular}

A quantidade de artigos por ano pode ser vista na Figura 4. Ela demonstra que se trata de uma literatura bastante recente, de interesse ainda crescente, pois $75 \%$ dos artigos foram publicados entre o ano de 2016 e junho de 2017. A primeira metade do ano de 2017 já é responsável por um terço do total produzido até o ano anterior.

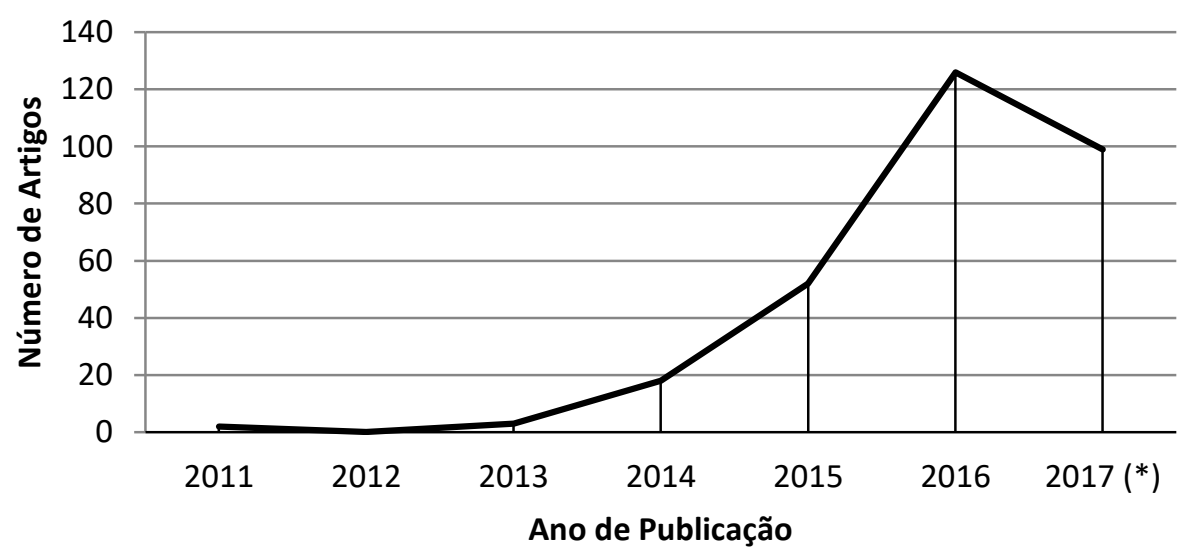

(*) Dados coletados até jun/2017

Figura 4 - Publicações sobre Manufatura Avançada

Na Tabela 4 se vê um grupo de journals, com maior número de artigos publicados sobre o tema, e seus fatores de impacto, representados pelo Scientific Journal Ranking (SJR). Os dois 
com maior número de documentos, Procedia Manufacturing e IFAC Papersonline, dedicam-se à publicação rápida de trabalhos de eventos e congressos; o primeiro dedicado à área de manufatura e, o segundo, aos eventos da International Federation of Automation Control (IFAC). Esse grupo de journals apresenta grande ênfase em pesquisas dedicadas à tecnologia, a exemplo dos dois com maior fator de impacto, IEEE Communications Magazine e IEEE Transactions on Industrial Electronics, ambos são editados pelo Institute of Electrical and Electronics Engineers (IEEE). O International Journal of Production Research é o único dentre eles dedicado à gestão de produção.

Tabela 4 - Journals com maior número de publicações sobre Manufatura Avançada

\begin{tabular}{l|l|l}
\hline Journal & SJR & Número de Artigos \\
\hline Procedia Manufacturing & 0,105 & 22 \\
IFAC Papersonline & 0,263 & 17 \\
IEEE Access & 0,801 & 8 \\
IEEE Communications Magazine & 2,827 & 8 \\
Elektrotechnik Und Informationstechnik & 0,165 & 7 \\
IEEE Transactions on Industrial Electronics & 2,446 & 6 \\
International Journal of Production Research & 1,463 & 6 \\
Sensors Switzerland & 0,576 & 6 \\
\hline
\end{tabular}

Os países com maiores volumes de publicações podem ser vistos na Tabela 5. O impacto dos movimentos nacionais fica claro ao observar a origem das publicações. A Alemanha com o maior número e os Estados Unidos como terceiro, berços das iniciativas Industrie 4.0 e Industrial Internet. A China, em segundo lugar, tem o maior investimento dentre os países orientais, demonstrando reação às inversões em competitividade no ocidente.

Tabela 5 - Países com maiores quantidades de publicações sobre Manufatura Avançada

\begin{tabular}{ll}
\hline Países e Territórios & Quantidades de Artigos \\
\hline Alemanha & 76 \\
China & 57 \\
Estados Unidos & 39 \\
Espanha & 23 \\
Reino Unido & 21 \\
Itália & 13 \\
Taiwan & 12 \\
Áustria & 11 \\
Coreia do Sul & 11 \\
\hline
\end{tabular}

Os journals (Tabela 6) são, em sua imensa maioria, de pesquisas da área de tecnologia tendo engenharia e ciência da computação como principais temas. Esse resultado demonstra que a Manufatura Avançada ainda é um tema pouco abordado por disciplinas de gestão. 
Tabela 6 - Áreas de interesse dos journals com artigos sobre Manufatura Avançada

\begin{tabular}{ll}
\hline Áreas de Interesse & Número de Journals \\
\hline Engineering & 214 \\
Computer Science & 145 \\
Business, Management and Accounting & 27 \\
Material Science & 21 \\
Decision Sciences & 19 \\
Social Sciences & 19 \\
\hline
\end{tabular}

A predominância de publicações nos campos de engenharia e ciência da computação, sobre Manufatura Avançada, também está presente em trabalho de Liao, Deschamps, Loures, \& Ramos (2017), sobre Industrie 4.0, demonstrando ainda serem escassos estudos que enfoquem impactos econômicos e em processos nas organizações, nessas iniciativas. Kiel, Arnold, Collisi, \& Voigt (2016) afirmam que, apesar da grande expectativa expressada, na literatura existente, quanto ao impacto do tema em modelos de negócios, a pesquisa ainda se concentra em seus aspectos técnicos.

\subsubsection{Análise de Conteúdo}

Estudando as palavras-chave mais frequentes, Liao et al. (2017) encontram como segunda colocada Cyber-Physical System (CPS), só superada por Industry 4.0. CPS é visto como o principal conceito da Manufatura Avançada. O termo CPS foi criado em 2006 por Helen Gill, Diretora do Programa para Sistemas Embarcados e Híbridos da National Science Foundation dos Estados Unidos e se referia à integração da computação com sistemas físicos (E. A. Lee \& Seshia, 2011). No CPS, sistemas embarcados e redes monitoram e controlam processos físicos, normalmente em malha fechada onde esses processos físicos afetam a computação e vice-versa (E. A. Lee \& Seshia, 2011).

Conforme J. Lee et al. (2014), o uso crescente de sensores e equipamentos em rede gera um volume massivo de dados, conhecido por Big Data. Nesse ambiente, o CPS pode ser empregado para gerenciar o Big Data e utilizar a interconectividade dos equipamentos, com vistas a atingir os objetivos de máquinas inteligentes, robustas e auto-adaptáveis. Sistemas industriais que utilizam, dessa forma, o CPS, são chamados de Cyber-Physical Production Systems (CPPS) (Kang et al., 2016).

A arquitetura e tecnologias envolvidas no CPPS ainda são alvos de pesquisas recentes. Genge, Fovino, Siaterlis, \& Masera (2011) e Colombo, Karnouskos, \& Bangemann (2014) propõem a integração de sistemas tradicionais de automação com tecnologias envolvendo 
Supervisory Control and Data Acquisiton (SCADA), Programmable Logic Controller (PLC) e Distributed Control System (DCS). Já J. Lee et al. (2014) e Niggemann et al. (2015) defendem que o CPPS só é possível com o uso de Big Data, Cloud Computing, IoT e tecnologias de Machine Learning.

Os impactos da adoção do CPPS estão intimamente relacionados ao conceito de integração e, portanto, sua atuação não se restringe apenas a sistemas de controle localizados. De acordo com o relatório final do grupo de trabalho do Industrie 4.0 (Henning et al., 2013), para que sejam atingidos os objetivos da Manufatura Avançada devem ser implantados três tipos de integração: uma horizontal, através da cadeia de valor; outra vertical, com sistemas de manufatura e a terceira do ciclo de vida do sistema. Essa proposta de integração guarda semelhanças com a do CIM e dos sistemas integrados envolvendo MES, PLM e ERP.

A integração, de acordo com a teoria de sistemas, tem como objetivo possibilitar a cooperação entre partes de um sistema, ou entre sistemas, com o objetivo de criar emergência. A emergência é a propriedade do sistema de ter capacidades superiores à soma das capacidades de suas partes (Schmidt et al., 2015). Como ilustração, serão apresentados três exemplos simplificados de integração de sistemas industriais: um vertical, um horizontal e um na cadeia de suprimentos.

O primeiro exemplo é de uma integração vertical, tipicamente realizada pelo MES. Em uma indústria que opera por pedidos dos clientes, make to order (MTO), estes são responsáveis pela criação e planejamento das ordens de produção. Dados da ordem, como quantidade a ser produzida e tipo de produto, são comunicados aos equipamentos e operadores das linhas de produção. Ao término da produção, informações como quantidade produzida, consumo de insumos e tempo são reportados ao ERP, que ajusta seus registros de níveis de estoques de produto acabado e de insumos. Esses passos podem ser observados no fluxograma da Figura 5, onde as linhas tracejadas representam os sistemas que desempenham cada uma das funções. 


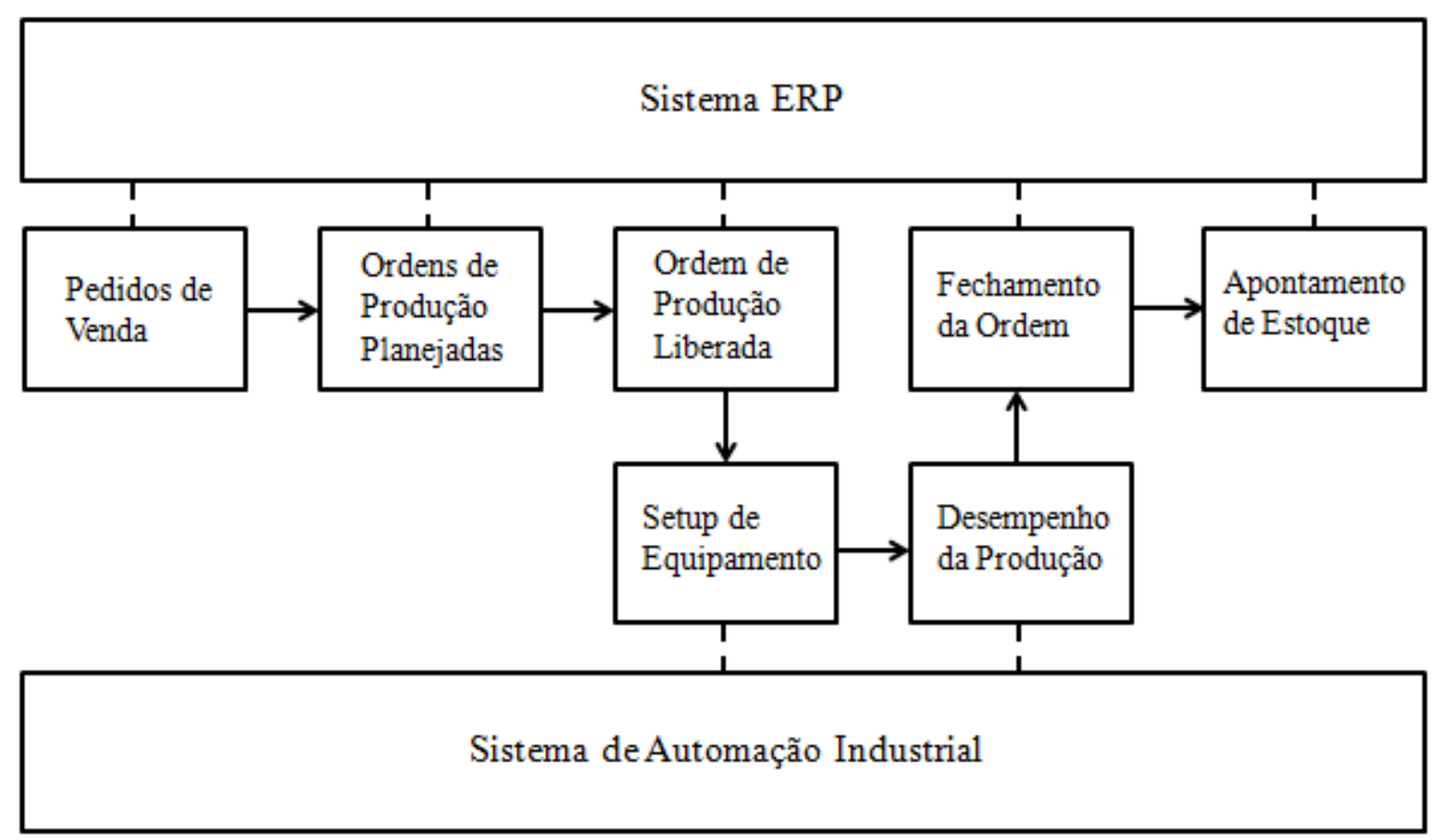

Figura 5 - Exemplo de Integração Vertical

Para a integração horizontal será utilizado um exemplo onde o fornecedor abastece diretamente o estoque do cliente, objetivando manter um nível contratado. Nesse exemplo a integração é realizada por comunicação eletrônica entre os sistemas ERP, em um processo conhecido como Electronic Data Interchange (EDI), conforme Figura 6.

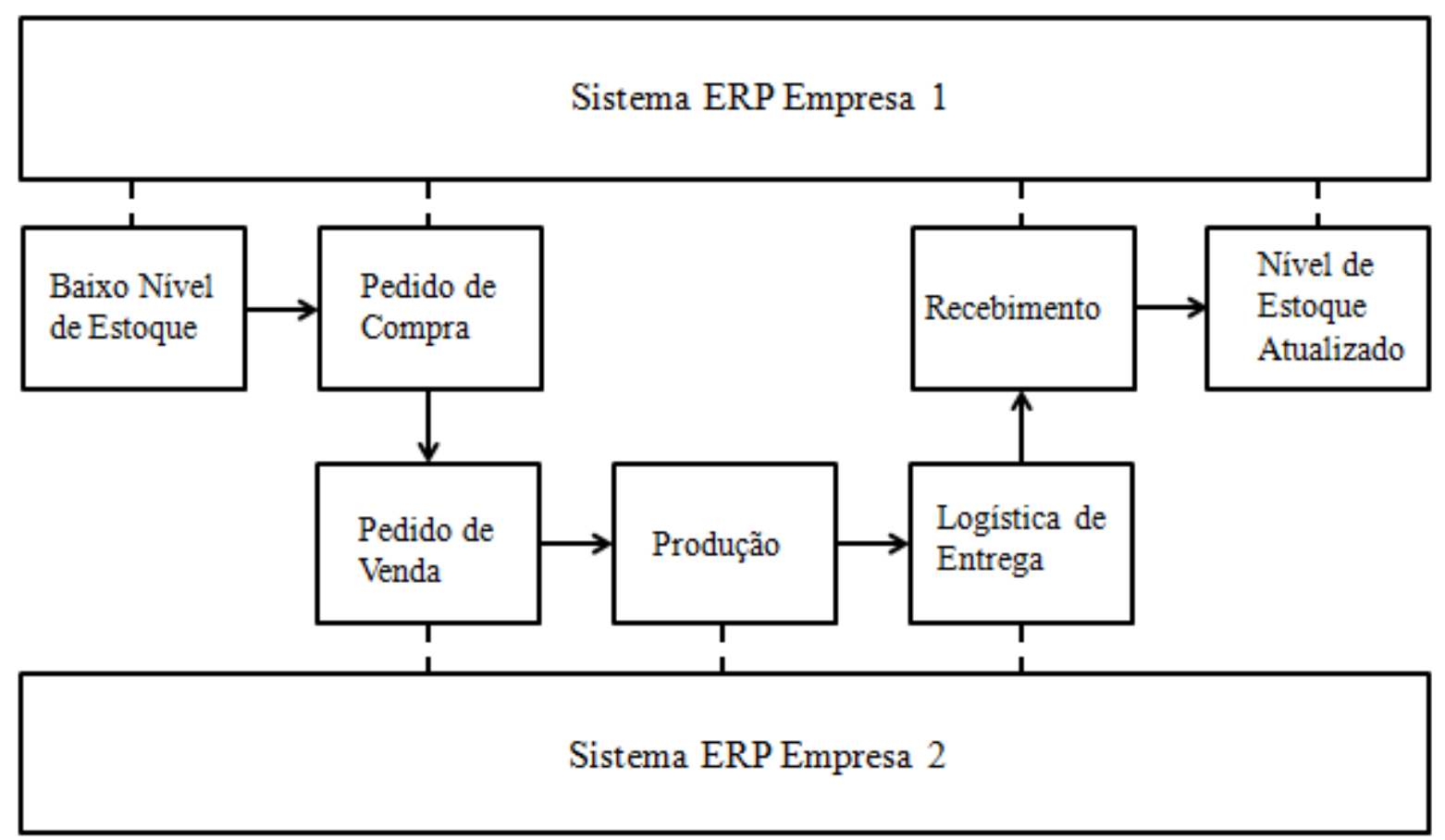

Figura 6 - Exemplo de Integração Horizontal 
Para exemplo de integração no ciclo de vida do produto será apresentado um processo de alteração do projeto de um dos componentes de um produto, tipicamente gerenciado pelo PLM. Ao realizar essa alteração, em seu desenho em CAD, por exemplo, todos os sistemas que acessam a lista de componentes desse produto devem ser notificados. Nesse exemplo o ERP, gerencia estoques e emprego de materiais para produção e o MES é responsável pelo chão de fábrica sendo o sistema de serviços pós-venda, utilizado por equipes de atendimento ao cliente e assistência técnica. Esse fluxo é ilustrado pela Figura 7.

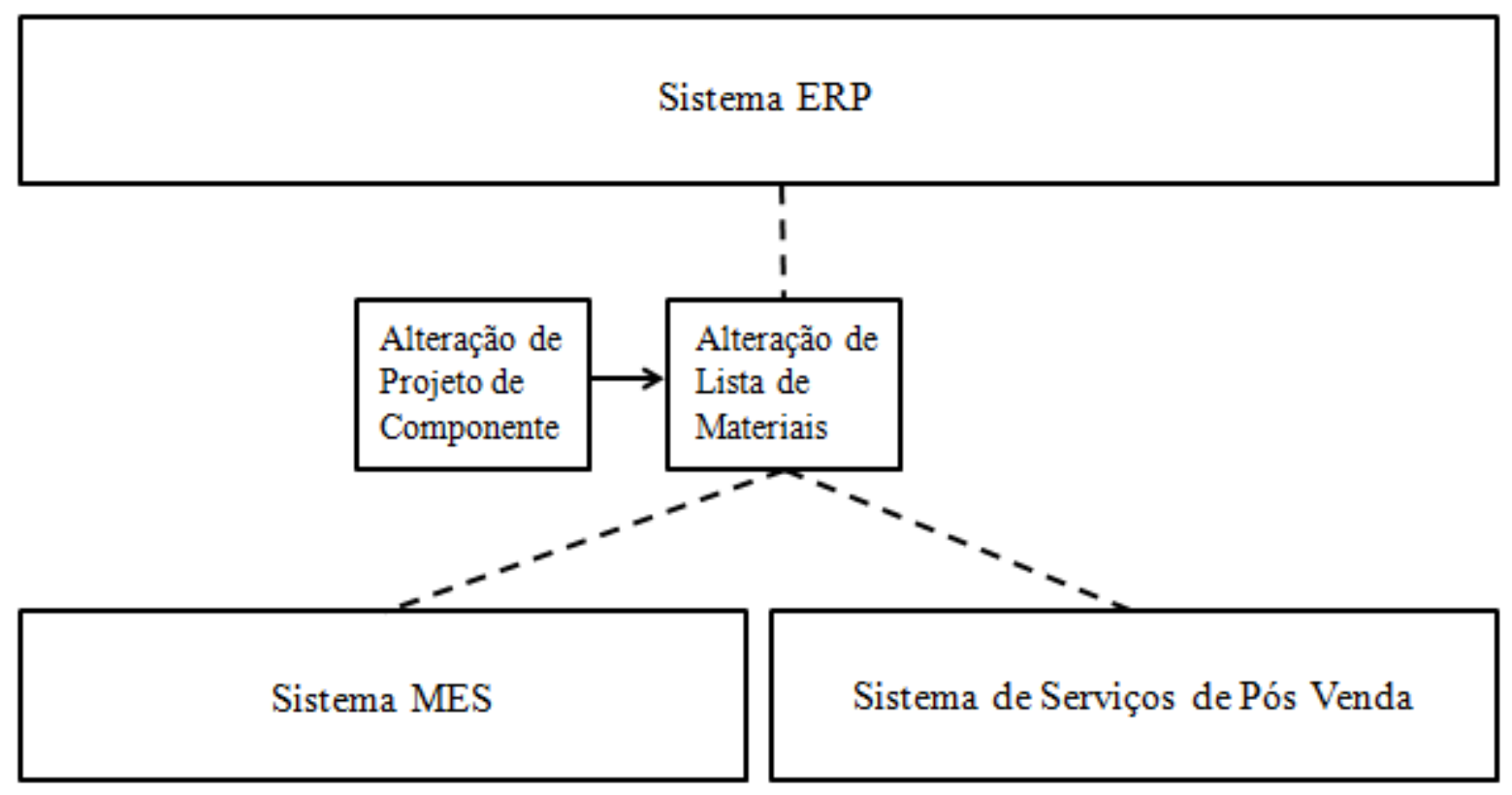

Figura 7 - Exemplo de Integração no Ciclo de Vida do Produto

Apesar de as propostas de integração serem bastante semelhantes às conhecidas em outros modelos, muitos pesquisadores defendem que o uso de novas tecnologias de TIC podem torná-las mais eficientes. Podem, até mesmo, se apresentar viáveis, em situações onde ainda não haviam sido adotadas (Bartodziej, 2017). Essas tecnologias, porém, foram desenvolvidas para aplicações não industriais, exigindo adaptações tecnológicas e familiaridade por parte da mão de obra da manufatura atual.

As principais tecnologias de hardware e software apontadas pela literatura como habilitadoras da Manufatura Avançada são (Buda, Främling, Borgman, Madhikermi, \& Kubler, 2015; Davis et al., 2015; Henning et al., 2013; Kang et al., 2016):

- Internet das Coisas (do inglês, IoT): É a tecnologia que permite a comunicação em rede entre objetos físicos e elementos de software. Trata-se de uma das bases tecnológicas da Manufatura Avançada, responsável pela comunicação com sensores e controladores. 
- Big Data: É um conjunto de dados com ampla variação, estrutura complexa e em grande volume, que não pode ser processado pelos métodos tradicionais. Devido ao volume de dados gerados por sensores e sistemas integrados na Manufatura Avançada, é esperado que ela gere um Big Data.

- Cloud Computing e Cloud Manufacturing: O Cloud Computing é a estrutura para a terceirização de processamento de dados e infraestrutura de TIC. Cloud Manufacturing é a aplicação dessa tecnologia para a comunicação com sensores distribuídos e alocação de recursos de manufatura, sob demanda.

- Manufatura Aditiva: É a tecnologia que converte modelos tridimensionais em objetos físicos. É implementada basicamente por impressoras 3D, que podem fazer parte de plantas de manufatura extremamente flexíveis ou de sistemas de manufatura distribuídos.

- Tecnologia de Sensores: Os sensores são as tecnologias de hardware mais importantes para a Manufatura Avançada, sendo responsáveis pela coleta de dados em tempo real. Para a viabilização da manufatura avançada, sensores devem ter custo adequado, apresentar robustez e oferecer padrões abertos de comunicação.

- Machine Learning e Data Mining: São tecnologias que conseguem extrair conhecimento dos dados e aplicar inteligência para melhorar as decisões. São os elementos inteligentes da Manufatura Avançada, que podem se auto coordenar, criando modelos computacionais que se utilizam de todos os dados capturados pelo sistema.

Davis et al. (2015) propõem que cinco categorias operacionais são impactadas pelas tecnologias da Manufatura Avançada: operação de linhas inteligentes; modelagem em alta fidelidade na produção; decisões dinâmicas; decisões corporativas ou da cadeia de suprimentos; e desenvolvimento de projetos, planejamento e modelos, conforme Tabela 1. 
Tabela 7 - Categorias operacionais das oportunidades da Manufatura Avançada (Davis et al., 2015)

Categoria Aplicações

Operação de linhas inteligentes
- Gestão integrada de equipamentos de processo e produtos

- Comparação de desempenho de interações entre equipamentos e produtos

- Gestão de energia de equipamentos

- Configurações adaptáveis de equipamentos
Modelagem em alta fidelidade na produção
- Gestão avançada de comportamentos complexos

- Qualificação rápida de componentes, produtos e materiais

- Engenharia computacional integrada de materiais

Decisões dinâmicas

- Gestão de performance para decisões globais integradas

- Novos graus de liberdade em eficiência, desempenho e tempo

- Análises corporativas e decisões operacionais de tradeoff

- Dados e análises configuráveis para rápido desenvolvimento de modelos e decisões.

Decisões corporativas ou da cadeia de suprimentos
- Interoperabilidade em Smart Grid

- Medições locais e cadeias de valor integradas

- Rastreabilidade e genealogia

- Integração com parceiros externos e interoperabilidade
Desenvolvimento de projetos, planejamento e modelos
- Construção de modelos em produção

- Qualidade de produtos e materiais em produção

- Inserção de novos produtos, materiais e tecnologia

É importante notar, porém, que o uso das novas tecnologias depende, em muitos casos, da adoção de tecnologias antecedentes. A simples disponibilidade da tecnologia, muitas vezes, não é suficiente para a aplicação, por questões funcionais ou de viabilidade econômica. $\mathrm{Na}$ Tabela 8 foi criada uma cronologia das tecnologias industriais já tratadas neste texto. As datas adotadas foram as do primeiro (ou dos primeiros) artigo que tratam do tema na base Scopus. Pesquisas sobre machine learning, por exemplo, antecedem as pesquisas sobre MES embora sua aplicação ainda seja, em grande parte, uma expectativa futura. 
Tabela 8 - Tecnologias industriais e de TIC

\begin{tabular}{|c|c|c|}
\hline Tecnologia & Ano & Primeiros Artigos \\
\hline Sensores & 1955 & (Papirno \& Gerard, 1955) \\
\hline Machine Learning & 1959 & (Martens, 1959) \\
\hline Simulação Computacional & 1959 & $\begin{array}{l}\text { (Gorton, 1959) } \\
\text { (Leagus, Lee, \& Mealy, 1959) } \\
\text { (McGhee, 1959) } \\
\text { (Clynes, 1959) } \\
\text { (Glaser, 1959) }\end{array}$ \\
\hline CAD / CAM & 1961 & (Ross, 1961) \\
\hline Automação Digital (PLC e DCS) & 1973 & (Coelho, 1973) \\
\hline SCADA & 1973 & (Swarthout \& Fiedler, 1973) \\
\hline Data Mining & 1984 & (Harris Jr., 1984) \\
\hline EDI & 1986 & (Annis, 1986) \\
\hline MES & 1992 & (Gokorsch, 1992) \\
\hline PLM & 1999 & $\begin{array}{l}\text { (Soga, Hiroshige, Dobashi, Okumura, \& } \\
\text { Kusuzaki, 1999) } \\
\text { (Thomas, Neckel, \& Wagner, 1999) }\end{array}$ \\
\hline Big Data & 1999 & (Kenwright, 1999) \\
\hline Internet of Things (Web of Things) & 2003 & $\begin{array}{l}\text { (R.Qiu, 2003) } \\
\text { (Traversat et al., 2003) }\end{array}$ \\
\hline Additive Manufacturing (3D Printer) & 2003 & (Sheng, Xi, Chen, \& Chen, 2003) \\
\hline Cloud Computing & 2007 & $\begin{array}{l}\text { (Yokoyama, Kojima, \& Ishikawa, 2007) } \\
\text { (Biswas \& Akhter, 2014) }\end{array}$ \\
\hline
\end{tabular}

A literatura atual, porém, ainda busca um mapeamento de como aplicar essas tecnologias e qual impacto se deve esperar para a produção. Muito pouco ainda foi investigado sobre como a aplicação pode se adequar a diferentes modelos de manufatura e estratégias de operação. Esse fato, justificado pelos efeitos ainda recentes dos conceitos da Manufatura Avançada, pode ser comparado a outras inovações tecnológicas, como os sistemas ERP, que apenas após suas primeiras implantações se tornou objeto de estudo da administração. 


\subsection{Estratégia de Manufatura}

A necessidade de alinhamento entre as operações da manufatura e a estratégia corporativa, para que a empresa atinja seus objetivos de desempenho, tem sido largamente estudada desde a publicação de Skinner (1969) (Anderson, Cleveland, \& Schroeder, 1989). Em seu artigo, Skinner descreve que o projeto da manufatura e sua posterior operação envolve uma série de escolhas entre alternativas que não podem coexistir, os chamados trade-offs. Como exemplo, pode ser citada a adoção de maiores ou menores níveis de inventário, ou de equipamentos mais genéricos ou mais especializados.

Com isso, surgiu o conceito de estratégia de manufatura, responsável por contextualizar a manufatura dentro da estratégia corporativa e tratar da coordenação das áreas de decisão, conforme as prioridades competitivas (Figura 8).

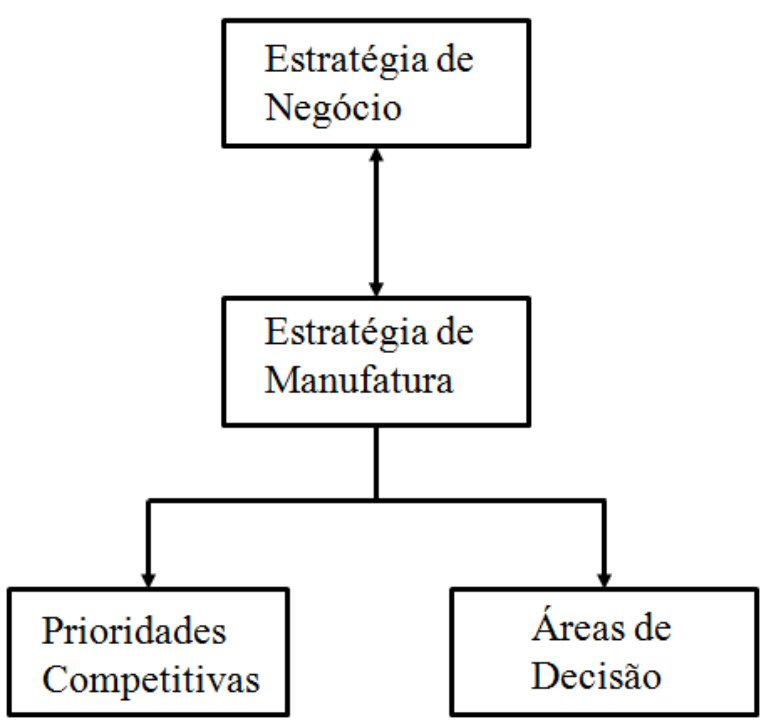

Figura 8 - Modelo de Estratégia de Manufatura (Leong et al., 1990)

O primeiro passo para a tomada de decisões que afetem a manufatura, portanto, é a ponderação sobre as prioridades competitivas, definidas como uma série consistente de objetivos para a unidade de negócio (Leong et al., 1990). Uma tipologia para prioridades largamente adotada pela literatura (Kotha \& Orne, 1989; Leong et al., 1990; Miltenburg, 2005; Skinner, 1969) é:

- Qualidade: produtos de alta qualidade e desempenho

- Desempenho de entrega: maior velocidade de entrega ou entrega dentro do tempo planejado 
- Custo: produção no menor custo

- Flexibilidade: reagir rapidamente a mudanças de tipos de produtos ou de volumes a serem produzidos

O conceito de flexibilidade, porém, foi posteriormente ampliado por Gerwin (1987) e Schmenner \& Tatikonda (2005) para que abrangesse um número maior de processos e tivesse maior rigor, acrescentando as reações a variações do mix, a modificações de produtos, a mudanças de rotas e variações de insumos.

Pesquisas mais recentes, apontam, ainda, como prioridades competitivas, a inovação (Choudhari et al., 2010), descrita como a capacidade de criar novos produtos e implantar novos processos, além de garantir a sustentabilidade (Longoni \& Cagliano, 2015), como, por exemplo, conseguir provocar menores impactos ambientais e sociais.

Subordinadas às prioridades competitivas, estão as áreas de decisão da manufatura. Elas recebem diversas propostas de classificações, como as apontadas por Skinner (1969) e Hayes, Wheelwright, \& Clark (1988), entre outros, mas que apresentam a mesma essência (Leong et al., 1990). Miltenburg (2005) organiza as áreas de decisão da manufatura em seis subsistemas:

- Planejamento e controle de produção

- Estrutura e controle da organização

- Recursos humanos

- Instalações

- Fornecimento

- Tecnologia de processo

As áreas de decisão, porém, não são independentes. Decisões em uma área podem afetar outras, sendo necessária uma coerência entre elas para que o sistema de produção tenha desempenho adequado (Choudhari et al., 2010; Olhager \& Rudberg, 2002).

Uma decisão também impactada por esse conjunto se refere à escolha do sistema de produção, que recebeu especial atenção da literatura. Conforme proposto por Kim \& Lee (1993), esse sistema deve ser selecionado de acordo com duas dimensões: a complexidade técnica do produto e a flexibilidade técnica exigida do processo. Dessa forma, são propostas quatro categorias de sistemas de produção, de acordo com a Figura 9. 


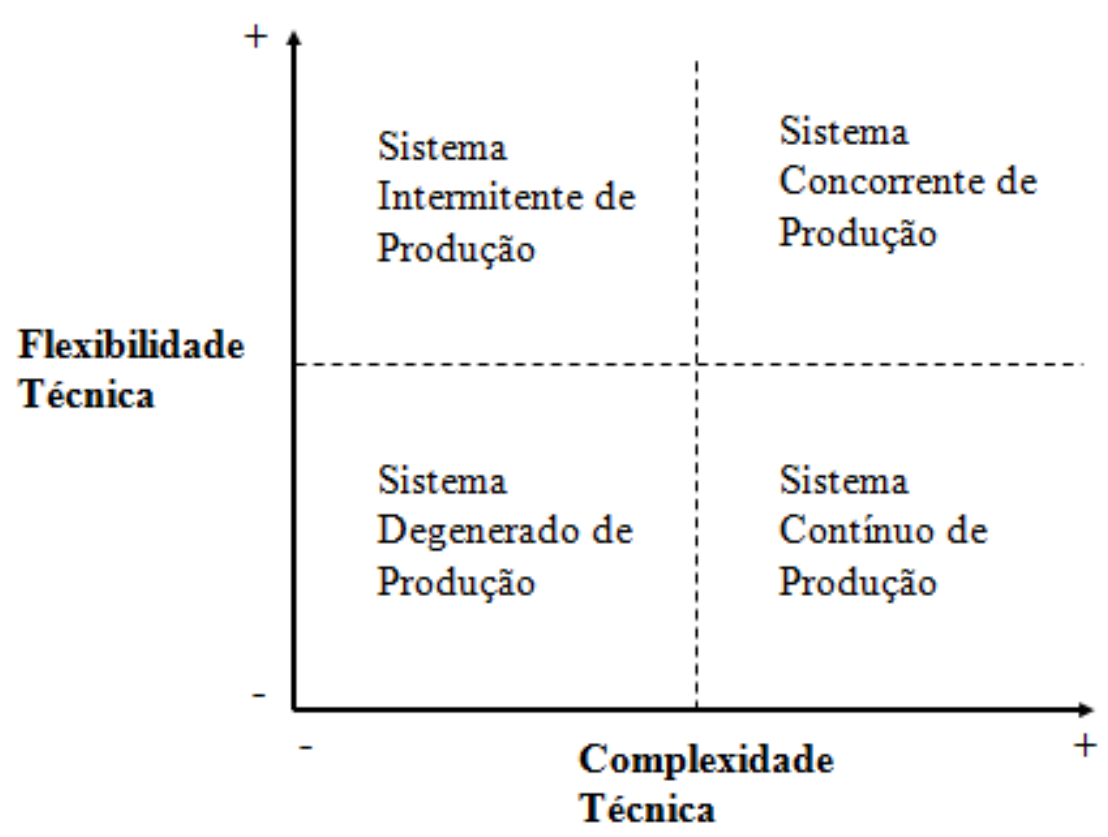

Figura 9 - Tipologia de sistemas de produção (Kim \& Lee, 1993)

Segue o detalhamento dos quatro tipos de sistemas de produção (Kim \& Lee, 1993):

- Sistema de produção intermitente: Produz de acordo com especificações do cliente. Possui equipamentos flexíveis em rotas, volume e produto, e uma equipe capaz de atender os parâmtros solicitados pelo cliente. Não tem a capacidade de uso contínuo dos recursos.

- Sistema de produção contínuo: Gera um grande volume de produtos padronizados, com uso contínuo dos recursos produtivos. Os produtos são complexos em termos de conhecimento, automação e integracão.

- Sistema de produção concorrente: Envolve tecnologias complexas em termos de conhecimento, automação e integracão, mas também tem a capacidade de produzir pequenos volumes de diferentes produtos. Sistemas desse tipo se utilizam de várias tecnologias de automação que buscam reduzir o compromisso entre flexibilidade e eficiência em custos, como sistemas flexíveis de manufatura, computer aided manufacturing (CAM) e engenharia concorrente.

- Sistema de produção degenerado: Representa a manufatura pouco competitiva, que não adota tecnologia de processo, investimentos, gestão do trabalho ou processos de monitoramento de custos.

Essa classificação considera que diferentes prioridades competitivas levam à seleção de diferentes sistemas de produção. Kim \& Lee (1993) entendem que sistemas contínuos são 
adequados para estratégias voltadas a custo e produção intermitente a estratégias que competem por diferenciação.

A indústria de processo é a responsável por grande parte das exportações do Brasil (Simoes Gaspar, 2012). Ela tem como insumos e produtos finais materiais ou ingredientes, ao invés de componentes ou produtos montados (Frishammar, Lichtenthaler, \& Kurkkio, 2012). Embora represente uma parte considerável do setor industrial mundial, há um volume pequeno de publicações da área de estratégia de operações dedicado a suas características particulares (Lager, Samuelsson, \& Storm, 2017). Estão nessa categoria os segmentos da agroindústria, química e petroquímica, além de alimentos, bebidas, mineração e metais.

Compartilham algumas características com a indústria de manufatura discreta, como modelos de processo contínuos para produtos mais padronizados ou em lotes, normalmente chamados de bateladas. Contudo, para produtos mais variados, muitas vezes apresentam grande variabilidade de qualidade de insumos, cadeias de suprimentos rígidas, uso intensivo de ativos e grande integração (Lager et al., 2017). Todas essas características trazem impacto direto nas prioridades competitivas e áreas de decisão.

\subsection{TIC e Estratégia de Manufatura}

Os sistemas de TIC podem ser vistos como de apoio às áreas de decisão e, como elas, devem estar alinhados à estratégia. Kathuria \& Igbaria (1997) apontam que, apesar da grande ênfase que pesquisadores de TIC e operações deram ao estudo desse alinhamento, os resultados da implantação de sistemas de TIC ainda são um problema frequente na prática. Por isso os autores propõem um modelo onde o resultado do desempenho acontece na congruência entre as tarefas-chave de gestão, decorrentes das prioridades competitivas e da estrutura de processos, e as aplicações de TIC. Esse modelo pode ser visto na Figura 10. 


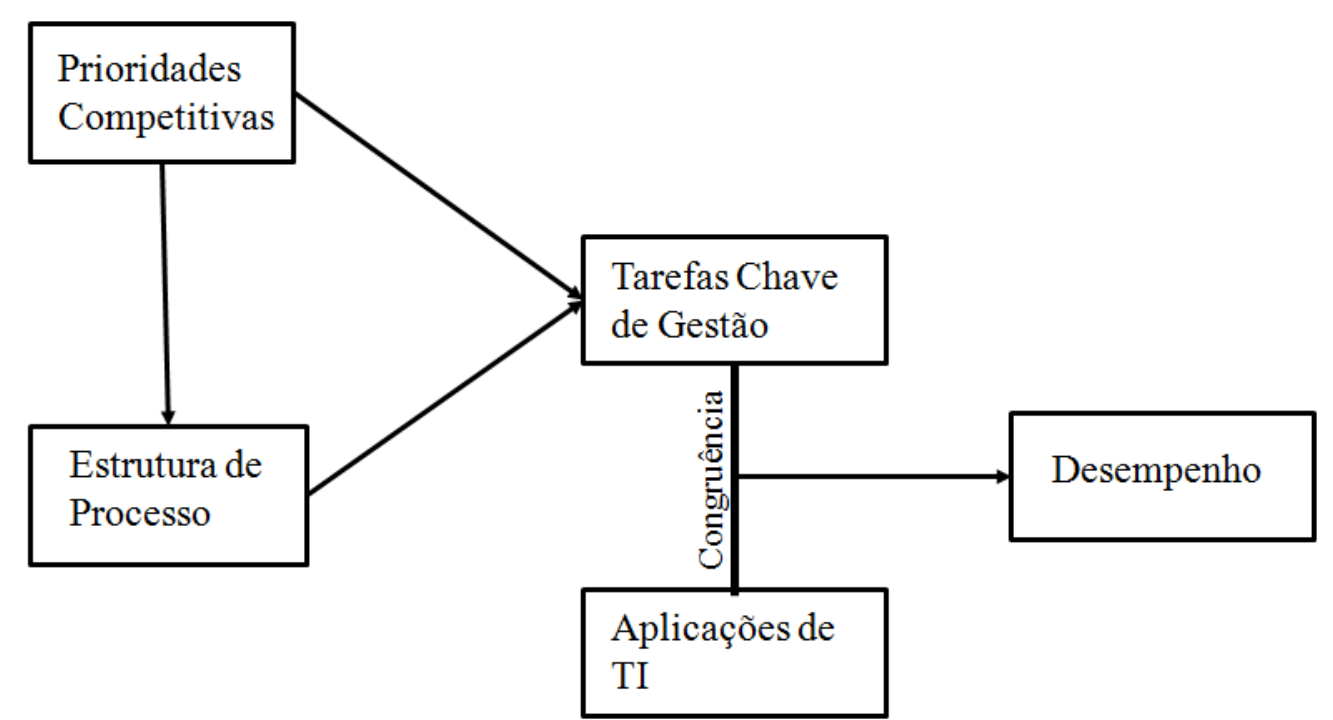

Figura 10 - Framework relacionando prioridades competitivas, estrutura de processo e aplicação de TIC em empresas de manufatura (Kathuria \& Igbaria, 1997)

Estudos empíricos mostram que o esforço da alta gestão em manter o alinhamento estratégico muitas vezes não é suficiente para impactar o desempenho quando o consenso estratégico não é alcançado (Kathuria, Joshi, \& Porth, 2007). Diferentemente do alinhamento estratégico, que procura garantir que as prioridades estratégicas da empresa estejam adequadas a seu ambiente, o consenso estratégico é o entendimento das prioridades estratégicas pelos diferentes grupos de decisão da organização, desde seus níveis de gestão até os operacionais (Walter, Kellermanns, Floyd, Veiga, \& Matherne, 2013). Decisões operacionais que impactam o desempenho são tomadas em todos os níveis da empresa, incluindo adoção, configuração e operação de sistemas TIC, e deve-se garantir a consistência da estratégia não só entre os grupos, mas também entre os indivíduos (Edh Mirzaei, Fredriksson, \& Winroth, 2016).

A interação entre diferentes níveis de consenso estratégico e alinhamento estratégico é organizada por Walter et al. (2013) na Tabela 9: 
Tabela 9- Interação entre consenso estratégico e alinhamento estratégico (Walter et al., 2013)

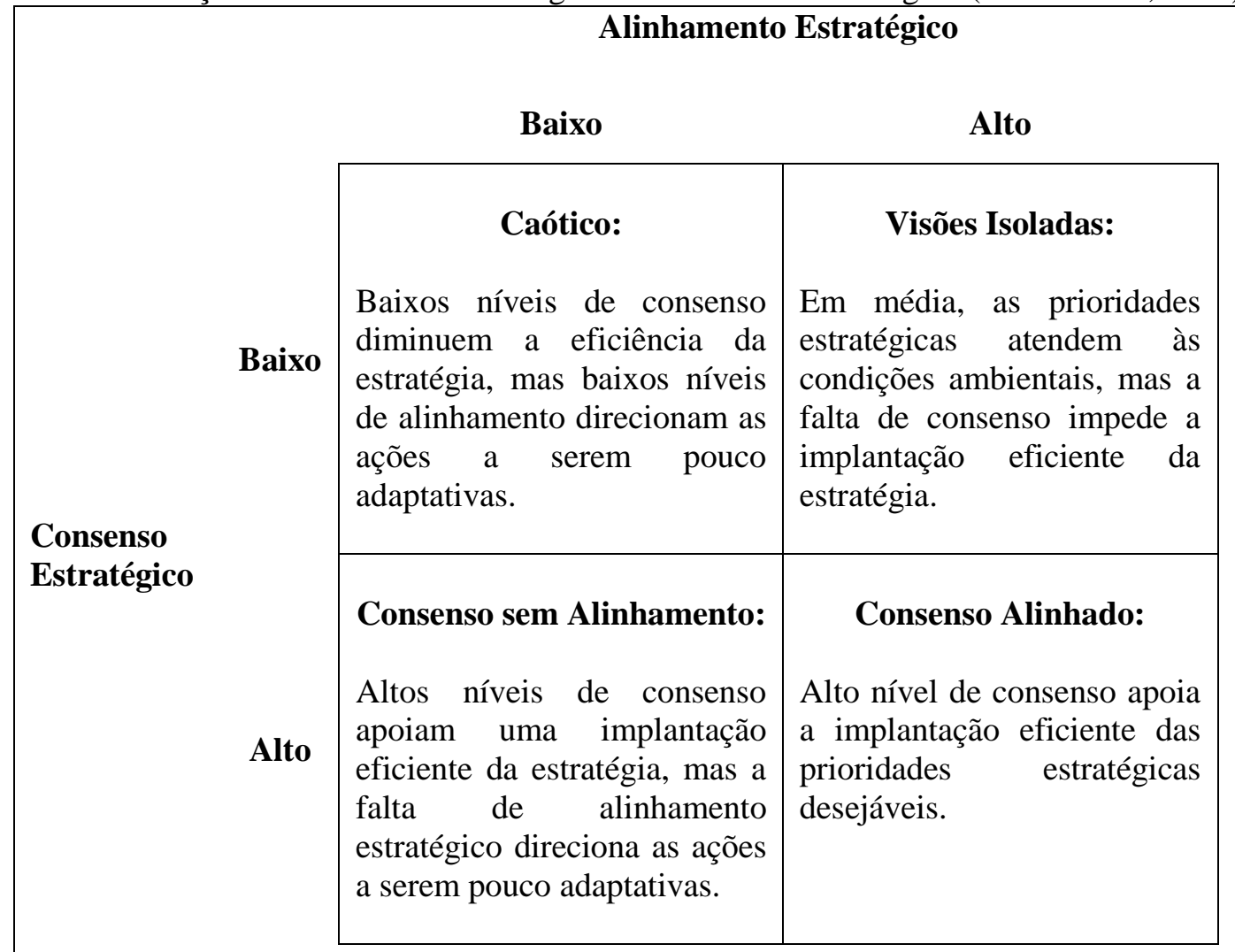

\subsection{Affordances}

As mudanças sociais promovidas pela tecnologia são objetos de estudo da sociologia há várias décadas. Nos moldes do modelo proposto para as revoluções industriais, Toffler (1981) considera que a invenção do computador iniciou a "Terceira Onda", que se seguiu à "Primeira Onda", da agricultura e à "Segunda Onda", da industrialização, cada uma delas responsável por profundos impactos sociais e culturais.

A discussão sobre os impactos da tecnologia, na década de 90, levou ao debate quanto aos efeitos do realismo e do construtivismo sobre a interação entre usuários ou grupos sociais e artefatos tecnológicos. O realismo considera que objetos físicos possuem propriedades que conduzem e restringem o uso, induzindo sua utilização. O construtivismo vê o uso do objeto como uma construção puramente social, com maior dependência do contexto do que do artefato em si. A pergunta central desse debate é se a tecnologia determina ou é determinada por sua aplicação social.

Nesse contexto, Hutchby (2001) propõe que a tecnologia não seja abordada, nem por sua "essência tecnológica", como propõe o realismo, nem por sua "interpretação textual", 
conforme o construtivismo, mas, em termos de seus affordances, que são, de acordo com conceito proposto por Gibson (1979), especificamente para a área da ecologia:

[...] aspectos funcionais e relacionais que restringem, quando não determinam, as possibilidades de ação de um agente em relação a um objeto. Dessa forma, tecnologias podem ser entendidas como artefatos que podem ao mesmo tempo moldar e ser moldados pelas práticas humanas de uso ou interação com elas. (tradução livre de Gibson, 1979, p.3)

Gibson argumenta que tanto animais quanto pessoas não percebem, no primeiro contato, as propriedades físicas de um objeto, mas o que o objeto pode lhes oferecer (do inglês, afford), ou seja, os indivíduos veem inicialmente somente os affordances (Gibson, 1979). Dessa forma, os affordances não são definidos unicamente pelo artefato tecnológico em si, mas por sua interação com um determinado agente.

Como exemplo do domínio que deu origem à palavra, uma planta que boia em um lago não permite a ação de se apoiar sobre sua superfície a um elefante, que não a percebe, portanto, oferecendo essa possibilidade, mas tem esse potencial para uma borboleta. Apesar dessa avaliação poder ser realizada por ambos os animais, ao primeiro contato, características como sua geometria, textura e densidade não são avaliadas a priori. Affordances, portanto, devem ser antes percebidos para depois serem utilizados. Sua percepção, no entanto, não significa que o animal ou pessoa irá realizar a ação, embora visualizada como possível (Seidel, Recker, \& Vom Brocke, 2013).

Nos últimos dez anos, pesquisadores da área de sistemas de informação passaram a utilizar o conceito de affordance para investigar as relações entre tecnologias de informação e comunicação (TIC), usuários e organizações. Como exemplo, Leonardi (2008) pesquisou, dentro de vários ciclos de melhorias em um sistema, como os affordances, em cada versão, conduziram os requisitos dos usuários. Seidel, Recker, \& Vom Brocke (2013) estudaram as principais affordances que, percebidas no projeto de um sistema de informação, foram necessárias para a transformação de um negócio em ambientalmente sustentável. Sebastian \& Bui (2014) tratam das relações entre características da equipe e dos sistemas com os impactos desejados, no setor da saúde.

Conforme argumentam Volkoff \& Strong (2013), o uso do termo affordance na literatura de TIC, principalmente nos artigos iniciais, estava restrito a aspectos específicos como a percepção, pelo usuário, de estímulos visuais de sistemas referentes pesquisas sobre interfaces 
gráficas. Os affordances propõem a utilização de sistemas de forma mais abrangente, considerando todos os comportamentos potenciais resultantes da relação entre o artefato tecnológico e atores orientados por determinado objetivo.

Seidel, Recker, \& Vom Brocke (2013) apontam as quatro principais propriedades dos affordances quando aplicados a sistemas de informação:

- Affordances dependem das propriedades materiais dos sistemas de informação;

- Affordances emergem quando as propriedades materiais dos sistemas de informação são interpretadas como viabilizando possibilidades de ação em seu contexto de uso;

- Affordances aparecem quando indivíduos interpretam sistemas de informação através de seus objetivos;

- Affordances criam potencial, mas não são condições necessárias nem suficientes para ações orientadas por objetivos.

Pozzi et al. (2014) propõem, com base na literatura, uma classificação dos affordances em quatro diferentes fases: existência (ou potencial), percepção, realização e efeito.

A existência de affordances é o assunto mais estudado pela literatura. São os potenciais de ação, ou de restrições a elas, oferecidas ao ator pelo objeto. Elas existem mesmo que o ator não interaja ou, mesmo, não as perceba. No contexto de sistemas de informação são potenciais oferecidos pela tecnologia, tanto para o indivíduo quanto para a organização.

A percepção do affordance é a primeira fase que exige uma ação do observador: a de compreender seu potencial. É um ato de reconhecimento, não só influenciado pela existência dos affordances, mas, também, pelos objetivos do ator, recursos do objeto, competências do ator e informações externas.

Realização e efeito dos affordances são, respectivamente, a ação realizada pelo ator, aproveitando-se da percepção de um ou mais affordances e a sua posterior consequência. São duas fases de grande interesse de pesquisadores de sistemas de informação, pois abordam a jornada individual ou organizacional na utilização de uma determinada tecnologia e na previsão de seus impactos. 


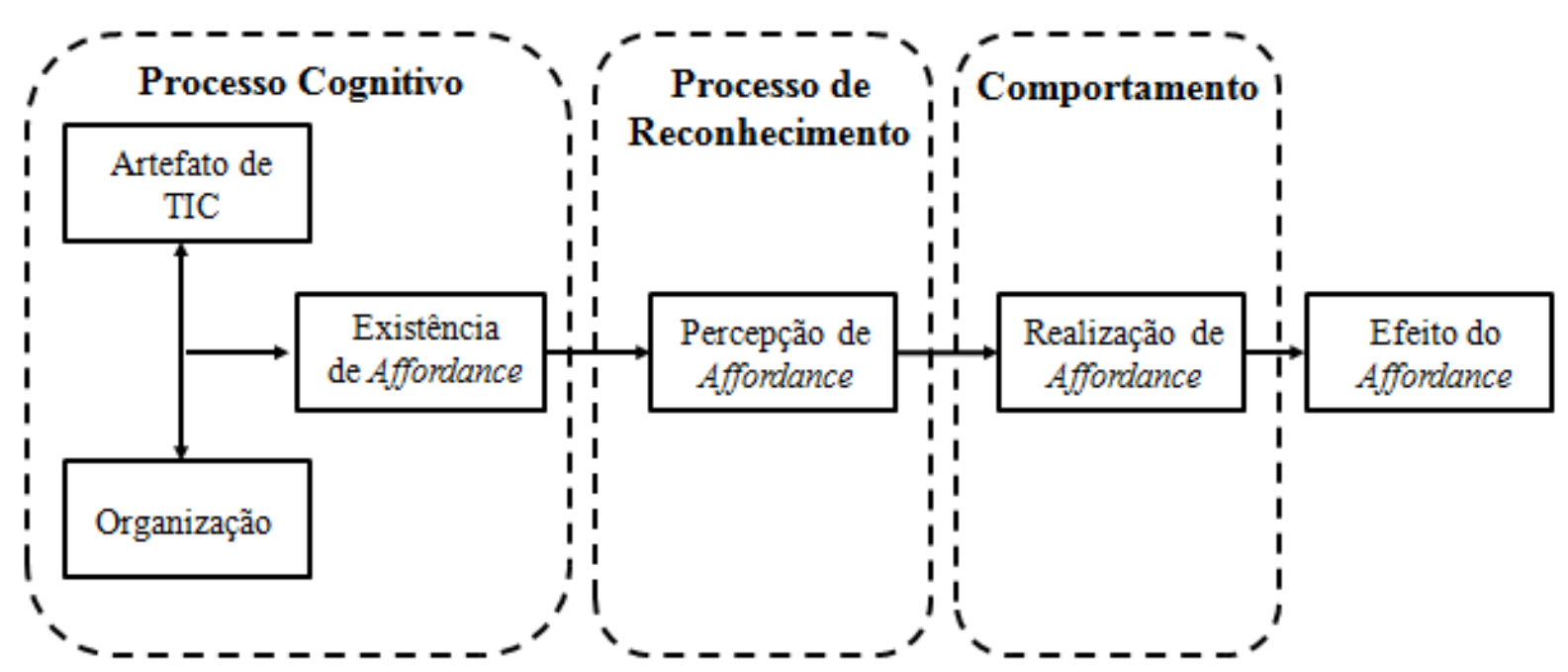

Figura 11- Estrutura dos Tipos de Affordance (Pozzi et al., 2014)

\subsection{Framework de Pesquisa Proposto}

A adoção de sistemas de Manufatura Avançada representa, em sua essência, um problema de escolha de tecnologias a ela incorporadas. Desta forma deve ser vista sob a ótica da estratégia da manufatura e das áreas de decisão. Isto apresenta, porém, um elemento particular que é a presença de tecnologias que, em sua maioria, nasceram fora do domínio industrial e são de conhecimento de profissionais ou de empresas de outros segmentos.

Essas tecnologias, de acordo com a proposta central da Manufatura Avançada, possuem affordances que impactariam as funções da manufatura, trazendo vantagens competitivas. Para que isso aconteça, esses potenciais devem ser identificados e utilizados pelas indústrias.

A proposta deste trabalho é estudar a Manufatura Avançada por meio de um framework que integre construtos da estratégia da manufatura e affordances, a fim de analisar como a percepção dos potenciais tecnológicos está relacionada à estratégia de manufatura, para a adoção de tecnologias de Manufatura Avançada.

Os constructos utilizados foram: 
- Affordances Existentes: São potenciais de ação ou de restrição a eles oferecidos por uma determinada tecnologia. (Pozzi et al., 2014)

- Affordances Percebidos: São potenciais de ações ou restrições a eles oferecidos por uma determinada tecnologia e percebidos pelo usuário ou organização. (Pozzi et al., 2014)

- Competências Tecnológicas: Conhecimento sobre tecnologias das organizações, que permite a percepção de potenciais passíveis de ser aplicados a necessidades internas. (Pozzi et al., 2014)

- Sistema de Produção: Sistema adotado para a manufatura, como produção contínua ou discreta. (Kim \& Lee, 1993)

- Áreas de Decisão: Configuração de recursos da manufatura, como pessoal e nível de automação. (Miltenburg, 2005)

- Consenso Estratégico: Consenso da visão da estratégia da empresa entre as diversas áreas, com ênfase em manufatura e tecnologia. (Edh Mirzaei et al., 2016)

- Adoção de Tecnologias de Manufatura Avançada: Execução de projetos de integração horizontal, vertical ou no ciclo de vida do produto, utilizando um conjunto de tecnologias de TIC habilitadoras.

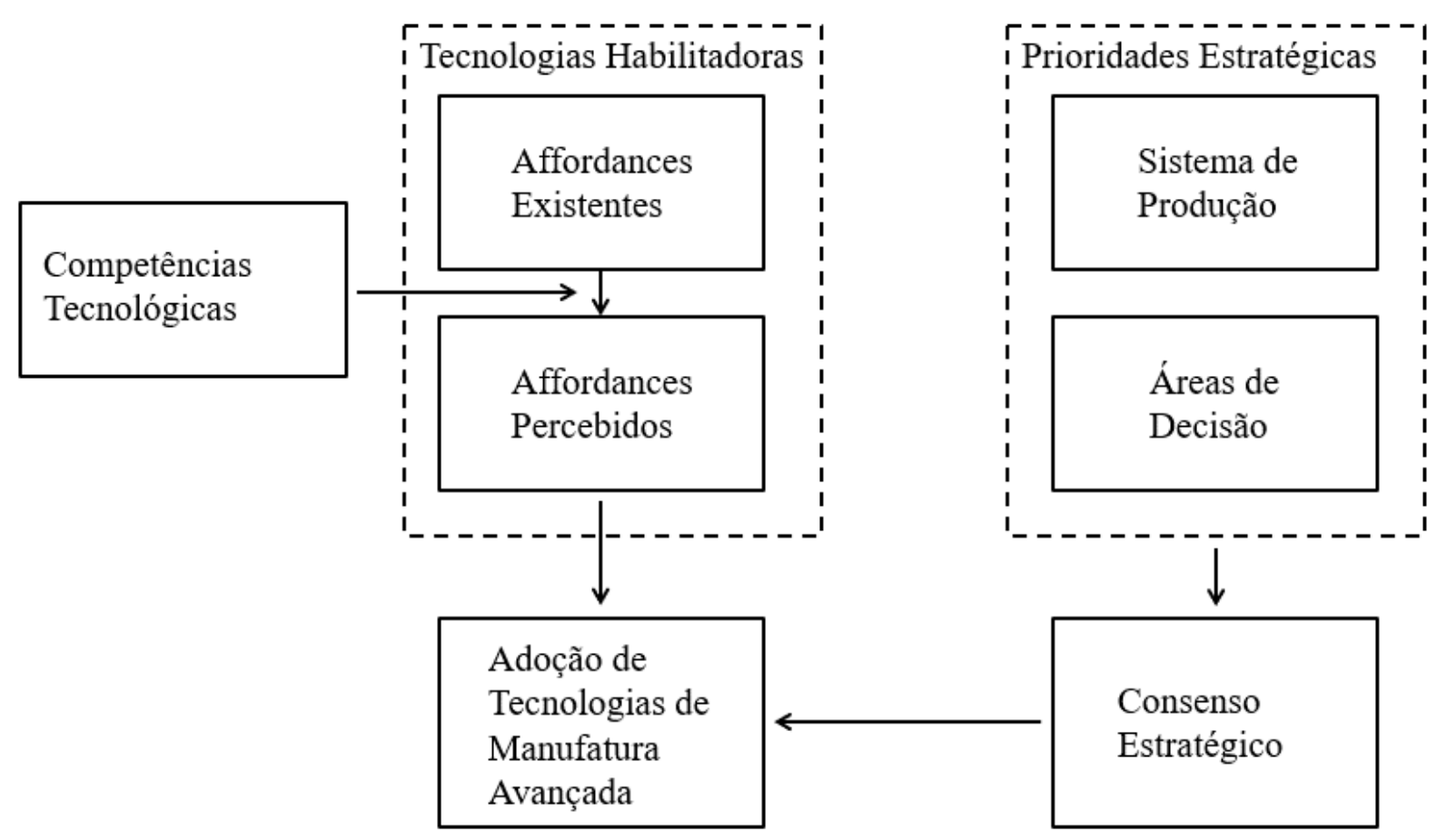

Figura 12- Framework de Pesquisa

Tendo o framework como base, podem-se derivar as seguintes proposições: 
- Proposição 1: Equipes com maior conhecimento em tecnologia apresentam maior capacidade de perceber affordances de tecnologias habilitadoras.

- Proposição 2: Empresas com diferentes prioridades estratégicas adotam diferentes tecnologias de manufatura avançada.

- Proposição 3: Empresas que atingem um maior consenso estratégico entre suas equipes de tecnologia e a alta gestão, adotam tecnologias mais alinhadas a suas prioridades estratégicas.

- Proposição 4: A adoção de tecnologias específicas de manufatura avançada depende da estratégia de manufatura e da percepção de seus affordances nos processos de manufatura da empresa. 


\section{Metodologia}

A fase empírica desta pesquisa foi formatada com base no framework apresentado na Figura 12, extraído da literatura. Seus elementos serão estudados em empresas brasileiras de grande porte, de diferentes segmentos, buscando uma diversidade de cenários tecnológicos e estratégicos que permitam a compreensão, a mais ampla possível, das relações propostas.

Devido à natureza exploratória da pesquisa, assim como a escassez de casos de adoção das tecnologias analisadas, no Brasil, o estudo de casos múltiplo foi adotado como método de exploração, porque permite a visualização detalhada do fenômeno e de suas implicações, dentro do contexto das empresas (Voss, Tsikriktsis, \& Frohlich, 2002).

Embora este trabalho não se proponha à construção de uma nova teoria científica, sua contribuição pode se situar no confronto das evidências empíricas com a literatura considerada, podendo validar ou desafiar alguns de seus resultados (Eisenhardt, 1989). Dessa forma, usando a classificação proposta por Ketokivi \& Choi (2014) foi adotado, neste trabalho, o modelo de estudo de caso classificado como elaboração da teoria. Serão, portanto, levadas a campo questões extraídas da teoria, mas sem limitação a ela, permitindo que novos elementos sejam adicionados ao modelo final.

Como referência de estrutura, foi utilizado o protocolo proposto por Eisenhardt (1989) para estudos de caso, que compreende os passos:

- Início: definição das questões de pesquisa e construtos que possam ser definidos $a$ priori;

- Seleção de casos: especificação da abrangência da pesquisa e seleção de casos baseada em adequação, e não aleatória;

- Desenvolvimento de instrumentos e protocolo: criação de instrumento de pesquisa para orientar o trabalho de campo;

- Trabalho de campo: trabalho simultâneo de coleta de dados e análise, busca por mecanismos de coleta de dados flexível e que aproveite as oportunidades encontradas;

- Análise de dados: análises dos dados dentro de cada caso e busca de padrões entre casos;

- Desenvolvimento de hipóteses: organização das evidências de cada construto, replicação da lógica entre casos e busca por evidências do por quê de cada relação;

- Comparação com a literatura: cruzamento de dados com literaturas que conflitem ou confirmem os resultados observados; 
- Fechamento: atingir a saturação teórica, sempre que possível.

Como instrumento de pesquisa foi elaborado um questionário com perguntas abertas para conduzir as entrevistas presenciais e garantir que os conceitos extraídos da literatura fossem abordados de forma padronizada, permitindo que os múltiplos casos contribuíssem para a mesma estrutura teórica (Anexo A) (Eisenhardt, 1989). No decorrer das pesquisas o questionário sofreu revisões a fim de englobar novos conceitos extraídos em campo. Nesses casos, quando necessários, novos questionamentos foram realizados por e-mail ou telefone, aos anteriormente entrevistados.

Os textos das entrevistas foram transcritos, codificados e analisados usando o software ATLAS.ti versão 7.5.4, da empresa ATLAS.ti GmbH (Anexo II).

As entrevistas presenciais foram complementadas com observação, em campo, do uso das tecnologias, informações de documentação dos fornecedores das tecnologias adotadas, informações tornadas públicas em relatórios e disponíveis em websites das companhias e participações em reuniões referentes a projetos em andamento, além de conversas informais com integrantes de equipes de projetos e com usuários dos sistemas.

Como o objeto da pesquisa são os projetos de Manufatura Avançada, foram escolhidas empresas que já realizaram ou estão realizando projetos de integração vertical, horizontal ou no ciclo de vida do produto, e estejam adotando tecnologias recentes de TIC para a manufatura. As empresas estudadas estão entre as líderes de seus segmentos e representam processos com grandes diferenças técnicas entre si, garantindo maior diversidade de características de operações. Seus segmentos são açúcar e álcool, produtos de grande importância para a balança comercial do país; bebidas, em especial cerveja, um dos maiores segmentos industriais do Brasil; montagem de eletrônicos, indústria com grande relevância para o mercado interno e com maior ênfase em desenvolvimento de produtos entre as três.

Os nomes das empresas e dos entrevistados não serão citados no trabalho, para garantia da confidencialidade. Os dados coletados e projetos considerados estão na tabela 10. 
Tabela 10 - Coleta de Dados
Empresa
Dados
Projetos

Açúcar, Álcool e

Energia
- Entrevista presencial com Gestor de TI e Projeto 1 - Sistema Gestor de Tecnologia Industrial (1:30h) Integrado para Usinas

- Entrevista presencial com Gestor de TI e Gestor de Inovação (1:30h)

- Visita a duas usinas (Projeto 1)

- Reunião com equipe de projeto do instituto de pesquisa (Projeto 2)

- Relatórios públicos e website da companhia
Projeto 2 - Sistema Integrado para Área Agrícola
Bebidas

Montagem de

Eletrônicos
- Entrevista com Gerente de Engenharia $(1: 30 \mathrm{~h})$

- Participação em três reuniões de projeto

- Reunião com fornecedor de tecnologia

- Relatórios públicos e website da companhia
Projeto - Projeto Coleta de Dados
- Entrevista presencial com Gerente de Inovação da planta de Reciclagem (2h)

- Entrevista presencial com Gerente de Engenharia (2h)

- Visita à planta de reciclagem (Projeto 1)

- Relatórios públicos e website da companhia
Projeto 1 - Sistema para

Coleta de Material para

Reciclagem

Projeto 2 - Sistema de Rastreabilidade 


\section{Estudos de Caso}

A apresentação dos casos será realizada sem a exposição dos nomes das empresas e entrevistados, visando manter a confidencialidade. Como se trata de empresas de grande porte, que se posicionam entre as líderes de seus segmentos, alguns dados como quantidade total de plantas disponíveis e detalhes sobre itens produzidos são suficientes para identificá-las. Portanto, essas informações serão omitidas até porque não têm relevância para a análise. Todas as entrevistas e coletas de dados foram realizadas mediante aceite dos envolvidos e seus superiores, com informações claras sobre sua utilização.

Para que a omissão dos nomes das empresas não dificulte a compreensão do texto, serão usados nomes fictícios derivados de seus segmentos: A. Álcool para o grupo do segmento de Açúcar e Álcool, M. Eletrônica para a empresa de montagem de eletrônicos e R. Cervejas para a empresa de bebidas, com refrigerantes e cervejas como principais produtos.

\subsection{Grupo de Açúcar e Álcool}

O Brasil é o maior produtor mundial de açúcar e um dos maiores produtores e exportadores de etanol, álcool utilizado principalmente como biocombustível. Muitas das plantas brasileiras são flexíveis entre etanol e açúcar, usando uma tecnologia nacional que permite a produção de ambos os produtos da cana-de-açúcar em um mesmo sistema fabril. Em plantas modernas, a parcela de produção de cada produto pode variar de $65 \%$ a $35 \%$ da produção total (Drabik, De Gorter, Just, \& Timilsina, 2014). Na última década, eletricidade se tornou também um produto importante. Muitas das indústrias do segmento são autossuficientes em energias térmica, mecânica e elétrica, produzidas pelo bagaço da cana, um subproduto do processo de moagem, utilizado como combustível para sistemas de cogeração. Em sistemas de geração mais modernos, a eletricidade produzida é suficiente para uso interno e para comercialização (Ensinas, Nebra, Lozano, \& Serra, 2006).

O período entre 2010 e 2015 foi de grande volatilidade de preços para esse mercado. Políticas públicas, mudanças climáticas e novos concorrentes no mercado internacional levaram à falência oitenta entre as quase quinhentas plantas do país (Frias, 2015). O grupo estudado é um dos maiores produtores de açúcar e etanol do Brasil e conseguiu manter um desempenho financeiro crescente nesse período. Ele é reconhecido pela UNICA (União Nacional de 
Indústrias de Cana-de-Açúcar) como referência em aplicações inovadoras de tecnologia, tanto na área fabril quanto na agrícola (“UNICA - União da Indústria de Cana-de-Açúcar,” 2016).

Os dados empíricos foram coletados em duas entrevistas, em profundidade, de uma hora e meia cada uma, com o Gerente Corporativo de TI e com o Coordenador de TI para Produção; em uma reunião com o grupo de desenvolvimento de tecnologia para o projeto agrícola; em observações e entrevistas informais com os usuários dos sistemas e, também, em análise dos relatórios de produção de chão de fábrica, automáticos e manuais.

\subsubsection{Projeto de Sistema Integrado para Usinas}

O suporte da alta gestão a projetos inovadores e a reputação de referência tecnológica no setor são bastante reconhecidos em todos os níveis da companhia. O primeiro projeto de sistema de informação inovador mencionado foi a implantação do ERP, em 1998. Esse foi o primeiro projeto do desenvolvedor do ERP em uma planta de cana-de-açúcar no Brasil, o que exigiu que a empresa preparasse uma equipe interna, para configurar o módulo de gestão de produção. A companhia tinha apenas uma planta produtiva nessa época (Planta A).

A configuração padrão do ERP não era adequada ao processo de produção de Açúcar e Etanol. Ao contrário de muitos dos processos de manufatura, manter estável a qualidade do produto, na área de manufatura agrícola, pode requerer variações dos insumos utilizados. Canas-de-açúcar com diferentes níveis de sacarose ou de impurezas, por exemplo, exigem diferentes aditivos químicos, quando processadas. Essas características da produção foram operacionalizadas no ERP. Com essa implantação a equipe de TI ganhou importante experiência nessa implantação, passando a formar parceria com o fornecedor do ERP nos projetos, do mesmo segmento, que se sucederam.

Outra etapa que exigiu grande esforço de adaptação ocorreu na substituição de um sistema legado de gestão de produção, desenvolvido especialmente para o processo de açúcar e etanol e que fornecia os principais indicadores utilizados para a gestão da planta, como perdas e taxas de recuperação. Os dados para esses cálculos e as informações reais da produção passaram a ser obtidos de leituras do sistema de automação, consolidados por operadores e supervisores e, depois, digitados no ERP, uma vez ao dia.

Em 2002 foi adquirida uma nova planta (Planta B) e o projeto do ERP necessitou ser expandido. Essa planta, de capacidade produtiva bastante inferior à da Planta A, já possuía equipamentos e mão de- bra especializados na produção de açúcar e etanol para aplicações 
particulares, como indústrias químicas, que exigem controle de qualidade mais rígido e possuem valor de mercado superior.

Um pouco depois, em 2005, o grupo decidiu construir mais uma planta produtiva (Planta C), em uma nova região geográfica sem tradição no negócio de cana-de-açúcar. A área de TI foi, então, desafiada a apoiar uma produção que, embora operada por mão de obra inexperiente, atingisse os padrões de desempenho do grupo.

A Planta $\mathrm{C}$ foi projetada para operar sistemas de automação e redes de sensores modernos e utilizar o sistema ERP corporativo, seguindo o mesmo modelo produtivo das outras usinas. Mas, apesar de todo o investimento em tecnologia, existiam lacunas entre os sistemas de automação e o ERP que demandavam grande volume de coleta manual de dados e a realização de cálculos, para apoiar decisões operacionais críticas e a alimentação do ERP. Os dados coletados constituíam fonte para contabilização da produção e para cálculo dos indicadores de desempenho, utilizados para avaliação de investimentos e outras decisões da alta gestão. As dificuldades se refletem nas palavras do Coordenador de TI para Produção:

Nós tivemos vários problemas com as entradas manuais na época. Entradas incorretas ou incompletas causaram várias consequências sérias para o processo. (...) quando um diretor percebe que a recuperação não é consistente com os investimentos, logo questiona as entradas automatizadas e as manuais, as medições e os sistemas.

Em uma planta nova, com altos investimentos e mão de obra inexperiente, esses problemas podem ser muito críticos. O fornecedor do ERP e a equipe de automação, consultados, decidiram adotar um middleware de integração desenvolvido pelo próprio fornecedor do ERP e o historiador de processo líder de mercado. Historiadores de processo, ou historiadores industriais, são bancos de dados dedicados, que coletam e armazenam dados de sensores industriais, em alta velocidade, normalmente implantados para a detecção e identificação de condições anormais de processamento, elaboração de relatórios de processos e integração de dados (Yu \& Qin, 2008).

O software de middleware foi implantado em 2007. Foi configurado para ser a principal interface com os usuários finais, repassando, para os operadores de processos, informações dos sistemas de automação referentes ao planejamento da produção e às combinações de produtos, além de coletar dados da produção, de insumos consumidos e de atividades de chão de fábrica. Os dados de qualidade, inseridos manualmente no sistema ERP pela equipe de laboratório, podiam se integrar a dados coletados no chão de fábrica, gerando relatórios mais abrangentes e 
permitindo reações mais ágeis às informações relativas a processos e a variações de parâmetros. Depois do início da operação da Planta C com o middleware, os padrões de desempenho atingiram os valores requeridos.

O historiador de processo, por si só, se mostrou uma ferramenta útil para ajudar os usuários de produção a terem uma visão mais ampla do processo, ampliando a segurança nas decisões operacionais. Um usuário treinado agora podia utilizar essa base de dados na avaliação das condições de equipamentos, de processos, de qualidade e de eventos anormais, o que passou a viabilizar decisões mais rápidas e melhores quanto a intervenções nas linhas de produção.

Tais resultados justificaram a implantação de um historiador de processo, também na Planta A, em 2012. Nesse projeto não houve implantação de middleware de integração, mas foi desenvolvida interface exclusivamente para registrar os dados de laboratório na base do historiador, possibilitando que os usuários consultassem dados de processos e de qualidade utilizando as mesmas ferramentas.

A quarta planta (Planta D) foi adquirida em 2014. Uma usina de açúcar e etanol com um historiador de processo já implantado (de um fornecedor diferente) e o mesmo ERP das demais plantas. Por questões financeiras, decidiu-se pela fusão deste ERP com os existentes nas demais plantas, no menor prazo possível. A área de TI, liderando uma equipe de consultores externos, finalizou essa tarefa em sessenta dias. Esse projeto é citado, pelos entrevistados, como exemplo de alinhamento entre TI e estratégia corporativa.

A quatro plantas possuem importantes diferenças. A Planta A é a maior, com produção de açúcar e etanol. A Planta B é a menor, produzindo açúcar e etanol para um mercado premium, com especificações de qualidade customizadas. A planta $\mathrm{C}$ é uma usina de alta eficiência que produz apenas etanol. A Planta D é a segunda maior do grupo e produz açúcar e etanol. Essas características estão resumidas na Tabela 10. 
Tabela 11 - Resumo das plantas produtivas

\begin{tabular}{lllll} 
& Planta A & Planta B & Planta C & Planta D \\
\hline Volume de Produção & Alto & Baixo & Alto & Alto \\
\hline Produtos & Etanol e & Etanol e & Etanol & Etanol e \\
& Açúcar & Açúcar & & Açúcar \\
\hline Tipo de Produto & Padrão & Premium & Padrão & Padrão \\
\hline ERP & Sim & Sim & Sim & Sim \\
\hline Historiador de Processo & Sim & Não & Sim & Sim \\
\hline Integração Automação - ERP & Limitada & Não & Sim & Não \\
\hline
\end{tabular}

Quando questionados sobre os objetivos dos projetos para a manufatura, ambos os entrevistados responderam serem redução de custos e produtividade. $\mathrm{O}$ gerente corporativo de TI atribui a obtenção de ótimo desempenho financeiro à alta produtividade das usinas. Um dos fatores é a revisão mensal do mix de produção, desde 2008, planejado uma vez ao ano, no decorrer da safra anterior. A implantação da revisão mensal, porém, não se deveu aos sistemas integrados, mas à comercialização independente dos produtos finais que passou a ocorrer após a saída da cooperativa Copersucar do mercado. De acordo com o gestor, o planejamento do mix é feito com a mesma frequência nas quatro plantas, mas, devido ao valor baixo dos produtos, um acréscimo na flexibilidade operacional não aparenta ter impactos nos resultados financeiros. "No nosso caso, a planta totalmente integrada (Planta C) só produz etanol e, então, não é um bom exemplo", completa o gestor.

A companhia tem a intenção de adotar um modelo integrado para as quatro plantas, no futuro, mas esse projeto ainda não é uma prioridade. Os gestores estão implantando um historiador de processo de pequena abrangência na Planta B, aproveitando uma grande atualização, em andamento, em um sistema de automação.

\subsubsection{Projeto de Sistema Integrado para Área Agrícola}

A adoção de equipamentos agrícolas automatizados, pelo grupo empresarial sob estudo, iniciou-se na década de 1970, em conjunto com a automação industrial de suas usinas de 
processamento de cana-de-açúcar. Máquinas agrícolas automatizadas são fundamentais para a produtividade no campo, principalmente no que se refere à redução de perdas. A produtividade no campo sempre mereceu foco importante dos gestores, já que de $60 \%$ a $70 \%$ dos custos totais de produção se concentram nessa fase das operações.

O grupo mantém estrutura permanente dedicada a tecnologias, com um gestor corporativo especificamente voltado a projetos de inovação. Este gestor é responsável por encontrar oportunidades no mercado e, conhecendo os desafios internos, recrutar os profissionais necessários à avaliação de novas propostas e, ainda, viabilizar o desenvolvimento de projetos-pilotos e planos de implantação. De acordo com os entrevistados, o grupo mantém uma cultura de colaboração entre áreas, que facilita esse recrutamento, além de incentivar estas áreas a perseguirem o sucesso, com projetos inovadores.

Devido à importância da produção no campo, a empresa mantém, há décadas, um programa chamado Automação Agrícola. Formado pelos pilares planejamento, gestão de ativos, logística e agricultura de precisão, esse programa deu origem a uma série de projetos de equipamentos e de processos, que culminaram no desenvolvimento de novos veículos, adaptação de tecnologias de outras áreas e até criação de produtos comercializados por multinacionais parceiras. Embora essas inovações não apresentem objetivos especificamente comerciais mas, sim de melhoria no processo, o grupo de inovação já acumula várias patentes.

Com quase $100 \%$ da frota agrícola automatizada, incluindo equipamentos responsáveis pela adubação, plantio e colheita da cana, cada veículo dispõe de computador de bordo e piloto automático, concentrando uma série de informações provenientes de sensores existentes nos equipamentos ou geradas pelos próprios operadores. O piloto de bordo registra e compartilha mapas de rotas, a ser seguido por quaisquer veículos que cruzem a lavoura. A cana-de-açúcar pertence à família das gramíneas, onde uma mesma planta pode produzir por várias safras. Um mapa de rotas precisamente compartilhado pelos veículos minimiza o esmagamento de plantas, aumentando a produtividade no decorrer dos anos.

Esses equipamentos armazenam dados ricos para análise da estratégia de plantio, utilização de implementos agrícolas, desgaste e condição de operação dos equipamentos e eficiência dos operadores, entre outras informações.

O Centro de Operações Agrícolas (COA) existente utiliza os dados coletados dos equipamentos, para análises, mas precisa lidar com a diversidade de tecnologias de transmissão de dados disponibilizadas pelos fabricantes, entre elas pen drives, módulos de memória e rádios de curto alcance. Essa limitação tecnológica faz com que os dados somente estejam disponíveis de um a três dias após a coleta. 
A transmissão dos dados em tempo real sempre foi almejada pelo grupo, já que permitiria a reação a falhas ou desvios de planejamento, de forma imediata, com a consequente redução do correspondente impacto no desempenho. Mas, embora os fornecedores dos equipamentos disponibilizem tecnologias de telemetria, todas elas dependem de estruturas de telecomunicações e de telefonia com cobertura em toda a área de plantio, comuns em várias partes do mundo, mas insuficientes no Brasil.

Devido a programas, do BNDES, de incentivo à adoção de tecnologias de TIC na manufatura e na agricultura, o gestor de inovação teve contato com um grupo de estudos especializado em telecomunicações, que desenvolve pesquisas para empresas de telefonia. Com tecnologias de IoT, o grupo desenvolveu um projeto de equipamentos para operação em frequência privada, aproveitando-se da tecnologia desenvolvida para a telefonia móvel, de forma a garantir comunicação bidirecional, grande raio de alcance e alta capacidade de tráfego de dados.

Foi realizado um projeto-piloto com a adoção de softwares analíticos oferecidos pelos fornecedores dos equipamentos utilizados. Segundo os entrevistados a avaliação do impacto do projeto ainda não pode ser totalmente realizada, porque as possibilidades de usos desses dados são muitas. Visto como um dos cinco maiores projetos atuais de inovação na atividade, esperase a diminuição do consumo de diesel, que representa o maior custo de insumos na área agrícola, a redução da quantidade de máquinas e consequentes economias nos custos com manutenção e mão de obra e o aumento da disponibilidade das usinas de processamento. Tratando-se de fábricas com grande poder de processamento, para que trabalhem em sua máxima capacidade, cargas vindas da colheita devem entregar cana com frequência menor que a de um caminhão a cada cinco minutos. Pequenos atrasos podem causar ineficiências ou até paralisações na produção, com altos custos de consumo de energia e de outros decorrentes da indisponibilidade.

A utilização de análises de big data e machine learning é vista como os próximos passos para a melhor exploração dos novos dados disponíveis. A capacidade de predição de falhas é a principal meta, mas ainda não foi atingida por não existir tecnologia disponível e recursos humanos capazes de lidar com esses novos conceitos.

\subsection{Indústria de Bebidas}

O mercado de bebidas no Brasil tem como principais produtos a cerveja e o refrigerante, representando aproximadamente $82 \%$ do volume de produção total e $76 \%$ do valor de vendas (Cervieri Júnior, Teixeira Junior, Galinari, Rawet, \& Silveira, 2014). A empresa estudada tem 
como principal produto a cerveja, embora também produza, em menor volume, bebidas não alcoólicas como sucos, refrigerantes e isotônicos. Ela está entre as quatro maiores cervejarias do país, que atingem, juntas, 98,4\% do mercado nacional (Cervieri Júnior et al., 2014). A produção de cerveja no Brasil, em 2015, foi de quase 14 bilhões de litros, o que o torna o terceiro maior produtor do mundo, depois dos Estados Unidos e da China (Junior \& Alves, 2016).

A R. Cerveja tem várias plantas produtivas em diferentes regiões do país. Suas linhas de produção foram construídas com a utilização de diferentes tecnologias, tendo, algumas, poucos anos de operação e, outras, mais de vinte anos. Esse nível de tecnologia, heterogêneo entre as plantas, é relatado como uma das principais complexidades para a gestão da automação industrial, presente em todas as plantas, mas com sistemas de disponibilizam recursos bastante diversificados, dependendo do ano de implantação.

Possui sistemas ERP e MES consolidados e geridos pela equipe de TI. O ERP é um produto comercial com grande disponibilidade de mão de obra treinada no mercado brasileiro, com manutenção prestada por equipes internas e consultores terceirizados. O MES é um sistema desenvolvido para a companhia há mais de 15 anos, sendo que, o contrato de manutenção vigente, foi celebrado com a própria empresa que o desenvolveu.

Nas fábricas mais recentes, os dados de chão de fábrica, como produção e disponibilidade de equipamentos, são coletados por meio de historiadores industriais e registrados, automaticamente, no MES. Para plantas mais antigas, onde os sistemas de automação não disponibilizam recursos de integração em rede, as informações são apontadas manualmente pelas equipes de operação. Os sistemas de automação e historiadores são geridos pela equipe de Tecnologia da Automação (TA).

Embora o MES apresente integração com o ERP para apontamentos de produção e estoques, as ordens de produção são gerenciadas e reportadas à operação de forma manual. Os gestores da companhia entendem que esse processo poderia ser realizado de forma mais confiável e com o uso menor de mão de obra, se fosse automatizado. Mas sua complexidade, por envolver diversos produtos, múltiplas plantas e centros de distribuição e seu dinamismo, com muitos casos de mudanças no planejamento de produção, tornam a modelagem desse sistema muito complexa e, até hoje, não foram apresentadas opções viáveis para essa automação.

Com as constantes pressões da diretoria por iniciativas tecnológicas que melhorassem a produtividade, as equipes de TI e de TA apresentaram, isoladamente, iniciativas que frequentemente se sobrepunham. Muitas vezes uma equipe chegava à fase de implantação de um projeto, sem que a outra tivesse sido consultada. Depois, ao aumentar o interesse 
corporativo por tecnologias de Manufatura Avançada, foram criadas equipes multidisciplinares responsáveis pela proposição de novas tecnologias, combinando conhecimentos do negócio, automação industrial e TIC.

De acordo com os entrevistados, foram necessários alguns anos para que as equipes passassem a trabalhar juntas de fato, pois precisaram uniformizar conceitos e entender as terminologias específicas de cada uma das disciplinas. Um exemplo citado foram os projetos propostos pela TI, de equipamentos de coletas de dados dos sensores do chão de fábrica, que muitas vezes não apresentavam a robustez necessária para o ambiente ou traziam funcionalidades já disponíveis nos controladores existentes.

Embora essas equipes ainda sejam novas, já foram implantados alguns projetos bem sucedidos, como o Projeto Coleta de Dados. Por se tratarem de equipes menores, com foco em inovação, mostram-se mais ágeis e permitem uma supervisão mais próxima pela alta gestão, garantindo o alinhamento estratégico entre os projetos aprovados para execução e as políticas corporativas.

A principal expectativa apresentada pelos entrevistados se refere à possibilidade de processamento dos dados de produção e de logística, por algoritmos de inteligência artificial. Os resultados seriam utilizados para a geração de insights e busca de oportunidades de otimização ainda não disponíveis. Apesar desse grande interesse, ainda não foram implantadas tecnologias de data mining e machine learning. Segundo os entrevistados, as oportunidades de aplicação ainda não estão claras e eles estão avaliando propostas de grandes fornecedores e de startups, para essas aplicações.

Dados empíricos foram coletados em entrevista de uma hora e meia de duração, com o Gerente de Engenharia: em visita a fornecedor da tecnologia de hardware adotada no Projeto Coleta de Dados e, também, participação em três reuniões de acompanhamento desse projeto. Esses dados empíricos são apresentados a seguir.

\subsubsection{Projeto Coleta de Dados}

Com o crescente interesse na análise de dados que possam impactar na produtividade, a confiabilidade dos dados presentes no MES passou a ser prioritária para várias frentes da companhia. Surgiram, porém, duas barreiras importantes: a inserção manual de dados de produção nas plantas mais antigas e os altos custos de implantação de alterações, por tratar-se de sistema de tecnologia antiga e desenvolvido exclusivamente para a empresa. 
Sem a utilização de tecnologias de IoT, a alternativa para a coleta de dados, nas linhas de produção antigas, seria a substituição dos sistemas de automação. Para isso, além da aquisição de novos PLCs, seria necessário que todas as lógicas de controle fossem implantadas novamente e validadas em produção. Além disso, precisariam ser criadas estruturas de redes de comunicação, com a passagem de fibras ópticas pela área de produção, o que demandaria longos períodos de paralisação das atividades.

Buscando eliminar essas limitações, foi constituída equipe com profissionais de TA e TI, que selecionou duas tecnologias para um projeto-piloto. Uma, utilizando hardware, com dispositivos industriais que utilizam tecnologias de IoT, para a coleta de dados sem a necessidade de substituição dos controladores existentes e, outra, de software que, utilizando Service Oriented Architecture (SOA), substitui parte do sistema MES, tornando-o mais flexível e permitindo manutenções mais ágeis e com menores custos.

Os novos hardwares apresentam custos na ordem de vinte vezes menores que os de um PLC, pois apresentam apenas as funcionalidades de coleta de dados e comunicação em rede sem fio, o que viabiliza a implantação sem a passagem de novos cabos. Como os controladores não estão sendo substituídos, não são necessárias paradas de produção.

O sistema de integração selecionado é o de um grande fornecedor de tecnologia da companhia, que já disponibiliza interface com os sistemas MES, com os softwares de automação e com o ERP adotados e não exige novos desenvolvimentos para esse projeto. Dessa forma, a adição de novas linhas de produção ao MES, que exigiria projetos a implantar em algumas semanas, passaram a ser realizadas em poucos dias.

O projeto-piloto foi realizado em uma das plantas mais antigas da companhia e se mostrou viável. O planejamento é de que, dentro de dois anos, todas as plantas estejam com os dados sendo coletados automaticamente para o MES.

\subsection{Indústria de Montagem de Eletrônicos}

A indústria de eletrônicos, em sua origem, projetava, manufaturava, testava e distribuía os seus próprios produtos. Devido a flutuações no mercado consumidor, aos preços limitadores do consumo, à rápida obsolescência dos produtos e à grande variação da demanda, que levava a contratações e demissões cíclicas da mão de obra, surgiu o mercado de empresas especializadas em atuar na manufatura dos produtos desse segmento, de forma terceirizada (Mason, Cole, Ulrey, \& Yan, 2002). Elas se especializaram em trabalhar com um mix de 
clientes, de desenvolvedores de produtos eletrônicos e de tipos de produtos que permitem a utilização estável, tanto da mão de obra, como dos equipamentos de produção.

A empresa estudada está entre as três líderes mundiais do ramo de montagem de eletrônicos, atuando principalmente nas áreas de informática e telecomunicações. Esses dois segmentos representam quase $40 \%$ do faturamento do mercado de eletroeletrônicos do Brasil, que atingiu R \$129 bilhões em 2016 (Rochel \& Martins, 2016).

A companhia adota sistemas padronizados mundialmente e geridos pela equipe de TI corporativa. Entre eles o ERP, sistema comercial com adaptações regionais, um sistema de gestão de chão de fábrica, desenvolvido internamente, um sistema de gestão de documentação e, também, um sistema comercial, onde todas as informações de produtos e processos são compartilhadas com as áreas envolvidas na produção.

O ERP utilizado no Brasil é mantido em uma versão antiga, devido a adaptações regionais realizadas para o atendimento das obrigações fiscais do país, o que dificulta a atualização. A produção é tratada de forma bastante consolidada pelo sistema, para que os diferentes processos de manufatura, ao redor do mundo, possam ser gerenciados dentro da mesma estrutura. Particularidades produtivas são tratadas pelo sistema de gestão do chão de fábrica, que é adaptado por equipes locais, sempre que necessário.

A M. Eletrônico possui uma divisão de projetos de inovação de TIC, que desenvolve projetos para seus clientes e para outras divisões do grupo.

A divisão analisada tem equipes especializadas em IoT envolvidas, no Brasil, em pesquisas de sistemas para rastreabilidade de produtos em todo o ciclo de vida, algumas delas financiadas por programas do BNDES. Implantou no país a primeira planta do grupo dedicada à logística reversa e reciclagem de eletrônicos. Oferece, a seus clientes, um serviço completo de logística, desde o recebimento do produto em seus centros de distribuição até a coleta e o descarte.

Dados empíricos foram coletados em uma entrevista, de duas horas, com o Gerente de Inovação da planta de reciclagem, seguida por uma visita ao chão de fábrica e por outra entrevista, também de duas horas, com o Gerente de Engenharia da planta de montagem de eletrônicos.

\subsubsection{Projeto de Reciclagem}

A unidade de reciclagem e logística reversa foi implantada, no Brasil, com o objetivo de desenvolver modelo de negócio, processos de manufatura e processos logísticos que 
pudessem ser utilizados em outras unidades onde fosse oferecido o serviço. Essa atividade, porém, apresenta uma série de características que diferem da logística e manufatura tradicionais.

Ao contrário da logística convencional, onde os produtos são transportados de plantas de manufatura a centros de distribuição de clientes, os produtos recicláveis são coletados diretamente nos clientes finais, bastante pulverizados e com pequena previsibilidade de volumes e composição da carga. As plantas de reciclagem recebem uma diversidade de mais de mil itens, que devem ser desmontados e processados, gerando não mais que 50 diferentes produtos finais. Devido à exigência de grande flexibilidade a diferentes materiais de entrada, a triagem e desmontagem são manuais, com a utilização de algumas linhas automatizadas para processos específicos, como o equipamento de trituração (Shredder).

O ERP corporativo é utilizado para o controle financeiro e fiscal, mas não apresenta qualquer funcionalidade para a gestão da logística ou produção, dadas as características específicas das operações. O sistema de gestão de chão de fábrica não foi adotado por, também, não apresentar funcionalidades adequadas ao processo: adaptações nesses sistemas não foram consideradas viáveis pela companhia, por ainda não apresentar processos bem definidos. Mesmo fornecedores de sistemas comerciais, quando consultados pela equipe interna, não apresentaram sistemas que atendessem às necessidades.

Todo controle de produção, portanto, passou a ser realizado por planilhas eletrônicas. A principal informação dos produtos processados, a lista de materiais reversa (do inglês, RBOM), é armazenada em planilhas que são atualizadas sempre que um novo produto é identificado pela triagem. O RBOM é o mapeamento dos materiais resultantes do processamento de um determinado produto: a partir dele, são calculadas a produção prevista e o desempenho esperado para cada um dos itens.

Com a ausência de sistemas comerciais ou corporativos específicos, a equipe de processos decidiu pela adoção de um sistema em cloud destinado à gestão de chamadas para o gerenciamento dos pedidos de retirada de material, buscando, com base nas informações correspondentes, melhorar a previsão do esforço de processamento de fábrica. Como esse sistema é baseado em Software as a Service (SaaS), seu modelo comercial prevê pagamentos mensais, proporcionais às funcionalidades utilizadas. Com custo baixo e utilização apenas quando necessária, o aplicativo pôde ser implantado com mão de obra interna, sendo compatível com o orçamento de manutenção do processo. A solicitação de reciclagem foi modelada no sistema como uma abertura de chamada sendo, seu fluxo, adaptado ao processo de coleta e processamento de materiais. Utilizando recursos nativos do sistema, são gerenciados 
calendários de coleta de materiais, chegadas de cargas na planta de manufatura e tipos de produtos a serem transportados e processados. Apesar de as especificações de cada carga ser informadas pelo cliente, frequentemente com imprecisões e erros, o sistema permitiu um melhor controle do fluxo da manufatura. A manutenção e alterações do sistema, quando necessárias, são realizadas pela própria equipe usuária.

\subsubsection{Projeto Aplicativos}

Ao contrário da planta de reciclagem, a de manufatura de eletrônicos tem à disposição tecnologias adotadas por plantas similares ao redor do mundo. O sistema de gestão de chão de fábrica, com funcionalidades de MES, se integra com os equipamentos, permitindo o acompanhamento das ordens de produção e desempenho das máquinas. Todos os documentos de produtos e processos são gerenciados e disponibilizados por meio de um sistema de gestão de documentação, funcionalidade característica do PLM.

Esses sistemas, porém, são geridos por equipes globais de TI. A equipe de automação, constantemente cobrada por desempenho e redução de tempos de setup e de perdas de qualidade, tem pouco acesso para a realização de manutenção ou alterações. Além disso, os próprios sistemas, de acordo com os entrevistados, não apresentam interfaces adequadas a análises flexíveis dos usuários, necessárias na ocorrência de falhas ou em projetos de melhorias.

Com apoio do gerente da planta, egresso de uma empresa de tecnologia web, foi criada uma equipe de desenvolvimento de softwares, dentro da área de automação, conhecida internamente como startup. Utilizando modelos ágeis de desenvolvimento de softwares, essa equipe já desenvolveu uma plataforma de aplicativos para atender a necessidades pontuais dos usuários de manufatura, oferecendo ferramentas de consulta e análise de dados disponíveis nos demais sistemas da empresa.

Com características como agilidade na entrega de sistemas e proximidade com os usuários, segundo os entrevistados qualidades que a diferenciam da TI corporativa, passou a se envolver em diversos projetos internos de tecnologia, sendo responsável pela adoção de hardwares de IoT para o monitoramento de temperatura em pontos críticos da planta e em veículos autônomos (AVT) que operam no interior das plantas para a reposição de peças em postos de trabalho. Este último projeto foi desenvolvido em unidade do exterior, mas implantado, pela primeira vez, aqui. 


\section{Discussão dos Casos Analisados}

Neste capítulo serão discutidos os casos empiricamente estudados, cujas descrições constam do capítulo anterior. As apresentações serão realizadas individualmente e em conjunto, destacando-se as principais contribuições identificadas para o tema da Manufatura Avançada.

Às empresas analisadas, conforme dito anteriormente, foram atribuídos os nomes fictícios de A. Álcool para o grupo do segmento de Açúcar e Álcool, M. Eletrônica para a empresa de montagem de eletrônicos e R. Cervejas para a empresa de bebidas, com refrigerantes e cervejas como principais produtos.

\subsection{Grupo de Açúcar e Álcool}

O grupo dispõe de quatro plantas industriais, com as seguintes características principais, conforme melhor detalhado no capítulo anterior:

- Planta A - a primeira e maior planta da empresa é produtora de açúcar e etanol e apresenta alto volume de produção; nela foi instalado projeto de ERP que, por ser pioneiro, exigiu importantes adaptações por parte do desenvolvedor e da equipe da empresa; após as adaptações, dados e informações reais de produção passaram a ser obtidos de leituras do sistema de automação, sendo consolidados e, depois, digitados no ERP, uma vez ao dia, resultando em integração automação - ERP funcional, mas limitada; mais tarde foi implantado um historiador de processo, que se destina à captação de dados de processamento, elaboração de relatórios de processos e integração de dados;

- Planta B - adquirida posteriormente é a menor planta da empresa e produz açúcar e etanol para um mercado premium, com especificações de qualidade customizadas; utiliza o mesmo ERP acima, devidamente expandido e não dispõe de historiador de processo;

- Planta C - construída pela empresa, em região geográfica sem tradição no negócio de canade-açúcar, é uma usina de alta eficiência que produz apenas etanol; a operação dos sistemas de automação, da moderna rede de sensores e do sistema ERP corporativo, pela inexperiente mão de obra disponível na região, levou à implantação de um historiador de processo, interligado ao ERP por um middleware de integração, fazendo desta a planta com a mais completa integração entre automação e ERP do grupo; 
- Planta D - adquirida por último, é a segunda maior do grupo e produz açúcar e etanol; dispõe de um historiador de processo já implantado (de um fornecedor diferente) e o mesmo ERP das demais plantas, que foi interligado ao restante do grupo.

O processo de produção de açúcar e álcool adota um modelo de produção contínua, tendo como prioridade competitiva, de acordo com todos os entrevistados, o custo. Esse resultado é consistente com a matriz produto processo (Kim \& Lee, 1993), onde o processo, por ser contínuo, apresenta baixa flexibilidade e, o produto, alta complexidade. Apesar disso a alta variabilidade das características dos insumos, por sua origem agrícola, é um grande desafio para a indústria da cana-de-açúcar, exigindo flexibilidade de processo para manter estável a qualidade do produto.

O sistema integrado das usinas foi implantado, como visto, com diferenças de funcionalidades entre as plantas, uma vez que estas apresentam variações nos mercados atendidos por seus produtos, além de diferentes configurações de suas áreas de decisão, em especial na qualificação da mão de obra.

Na Planta A, de maior volume de produção e onde está alocada a equipe de gestão da tecnologia, é utilizado o ERP apenas no processo de garantia de qualidade integrada, ao passo que os relatórios de controle de produção e materiais são gerados no domínio do historiador industrial. Na Planta D, com características operacionais semelhantes às da Planta A e onde são produzidos idênticos relatórios de chão de fábrica, ainda não foi implantada a integração.

Na planta $\mathrm{C}$ há maior aplicação de tecnologia em decorrência do desafio de atingir os padrões corporativos de extração com uma equipe menos experiente; a integração foi vista como uma compensação para a menor capacitação dos recursos humanos disponíveis na região. Contrariamente, na planta $\mathrm{B}$, onde são gerados menores volumes e processados produtos de maior valor agregado, é onde existe o menor nível de tecnologia de TIC.

Foram estudados dois projetos de integração vertical, entre equipamentos de processo e sistemas corporativos, um para as usinas e outro para a área agrícola. Apesar de os ganhos potenciais dos dois projetos serem conhecidos pelos gestores, apenas o primeiro foi considerado economicamente viável e realizado em um primeiro momento. Somente após 15 anos, com a disponibilidade das tecnologias de IoT, o segundo foi realizado.

Verifica-se, desta forma, que pequenas variações na estratégia de produtos e de configuração das áreas de decisão, levaram os gestores a tomar decisões de investimentos diferentes, na adoção da tecnologia de integração vertical. 


\subsection{Indústria de Bebidas}

A R. Cerveja, fabricante de grandes volumes de cervejas e refrigerantes tem, também, como principal prioridade estratégica, o custo. Devido ao tipo de produto, porém, o modelo de processo é o de produção em lotes, com duas fases diferentes e bastante definidas: a fabricação e o envase.

A fase de fabricação se assemelha à de uma planta de processo, trabalhando com múltiplos lotes das receitas das diferentes bebidas produzidas em cada planta. A fabricação de cerveja tem uma diferença fundamental da produção de bebidas não alcoólicas: devido ao processo de fermentação, seu tempo de processamento leva entre cinco e sete dias, ao contrário das poucas horas dedicadas aos demais produtos.

O envase combina os múltiplos produtos da fase de fabricação com suas diferentes embalagens e rótulos. São linhas de produção discretas, de alta velocidade, que ditam o ritmo da planta, sendo consideradas, portanto, seu gargalo. Ganhos de eficácia nessa fase impactam diretamente na produtividade global da planta.

O sistema de coleta de dados, viabilizado por tecnologias de IoT, permitiu a expansão do sistema MES corporativo, com identificação precisa de ineficiências e falhas de manutenção nas linhas de envase, permitindo que as ações de melhoria de desempenho sejam melhor orientadas.

\subsection{Indústria de Montagem de Eletrônicos}

A M. Eletrônico, manufatura discreta com modelo de produção em lotes tem, como principal negócio, a montagem de equipamentos eletrônicos. Trabalha com uma grande diversidade de produtos e de tecnologias, o que leva à existência de algumas linhas de produção altamente automatizadas e, de outras, com maior necessidade de intervenções manuais dos operadores. O custo é uma prioridade estratégica importante, pois é o principal valor entregue a seus clientes, mas a flexibilidade para a diversificação de produtos tem bastante relevância, por fatores externos e internos. A capacidade de reprogramar rapidamente pedidos é valorizada pelos clientes, o que motivou a adoção do EDI. A flexibilidade de utilização de linhas e de operadores, porém, garante o uso eficiente dos recursos de produção, por permitir o compartilhamento entre diversificadas linhas de produto e, quando possível, entre diferentes 
clientes. A possibilidade de intensa utilização dos recursos é uma das principais vantagens que tornam viável o negócio desse segmento.

A equipe de TI, centralizada na matriz e com pouca integração com as equipes de engenharia locais, realiza a implantação de sistemas padronizados como o de gestão de chão de fábrica, o que uniformiza boas práticas produtivas entre as diferentes plantas do mundo. Por outro lado, não atende diretamente às necessidades locais de plantas que apresentem diferentes modelos produtivos, como a de reciclagem, distanciamento que levou à adoção de tecnologias locais não alinhadas aos padrões corporativos.

\section{$5.4 O$ impacto da estratégia}

De acordo com a literatura, o principal objetivo da adoção de sistemas integrados é a flexibilidade para diversificação de produtos (Cagliano \& Spina, 2000; S. M. Lee et al., 2012; Saenz de Ugarte et al., 2009). Nos casos estudados, porém, verificou-se que sistemas integrados foram adotados buscando outros impactos que não essa flexibilidade e que suas características foram influenciadas por contextos específicos da manufatura.

Empresas que têm o custo como prioridade estratégica, como foi apontado por todos os casos estudados, com exceção da planta de reciclagem da M. Eletrônico, enxergam a integração vertical como um aliado para o aumento da produtividade, em especial quando há fluxo de dados dos equipamentos para os sistemas analíticos. Nas três empresas, sistemas desse tipo já haviam sido adotados há mais de uma década e trouxeram ganhos de abrangência e funcionalidade.

A principal utilização desses dados, nas plantas industriais, se refere ao cálculo do Overall Equipment Effectiveness (OEE) e seus indicadores derivados, da forma mais precisa e mais próxima do tempo real possível. O OEE é uma medição de desempenho, que busca identificar os desperdícios de tempo de produção em um determinado posto de trabalho, equipamento ou linha de produção e é alinhado ao conceito do Total Productive Maintenance (TPM), proveniente das práticas de manufatura japonesas (Ljungberg, 1998).

Por meio da decomposição dos indicadores do OEE é possível identificar a taxa de perdas decorrentes da baixa de qualidade, de reduções no ritmo de produção e de quebras de equipamento, permitindo ações corretivas mais eficazes em casos de redução do desempenho produtivo (Ramlan, Ngadiman, Omar, \& Yassin, 2015). A R. Cerveja apontou como ganho obtido com o cálculo automático a distinção precisa entre perdas por falhas de equipamento e as devidas à queda de ritmo de produção. 
Antes da automação que gerou esses resultados, o primeiro indicador era calculado pela equipe de manutenção e, o segundo, pela equipe de operação, sendo utilizados para a avaliação dos desempenhos. Isso gerava grandes disparidades entre os relatórios das duas equipes, que tinham à disposição apenas informações parciais sobre o desempenho, sendo, consequentemente, motivo de constantes conflitos entre os gestores.

A busca pela flexibilidade, apresentada como essencial para a planta de montagem da M. Eletrônico, leva à priorização em adotar integrações na cadeia de suprimentos, como mostra o uso já maduro de sistemas EDI. A flexibilidade para reação a alterações nas características dos insumos da A. Álcool, normalmente encontrada em indústrias agrícolas, motivou a comunicação automatizada de dados de qualidade da cana-de-açúcar à operação, em duas de suas plantas. A planta de reciclagem da M. Eletrônico apresenta característica semelhante, tendo seu produto final altamente dependente dos insumos recebidos. Nos três casos, o impacto esperado é a possibilidade de rápida reação da manufatura na tomada de decisões de produção, sempre que ocorrerem alterações em outras etapas da cadeia.

A planta de montagem da M. Eletrônico é a que apresenta produtos de maior complexidade, além de uma grande diversidade de especificações de qualidade fornecidas por seus clientes. Dessa forma, é a única entre as entrevistadas que mantém um sistema de integração atingindo todo o ciclo de vida do produto, da criação à manufatura, chegando, em alguns casos, à reciclagem.

Tabela 12 - Modelos de produção e tecnologias adotadas nos casos estudados

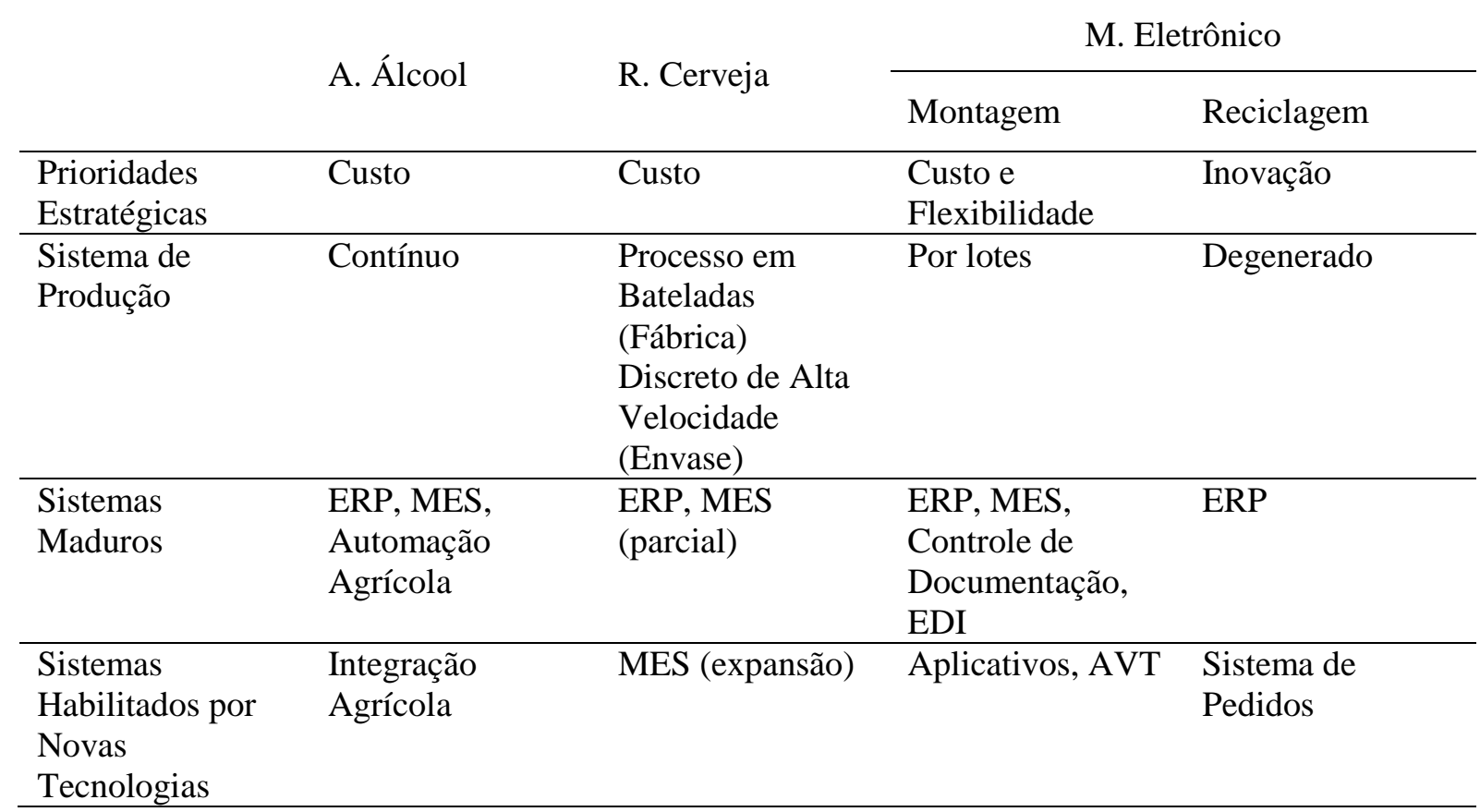




\subsection{Tecnologias com affordances de novas funcionalidades ou por novos padrões de custo}

A expectativa da utilização de novas tecnologias, na literatura de Manufatura Avançada, é bastante centrada na habilitação de novas funcionalidades. Trabalhos científicos (Bartodziej, 2017) e relatórios técnicos (Henning et al., 2013) apresentam modelos de negócio, graus de colaboração e aplicações inteligentes que só são possíveis com tecnologias de desenvolvimento recente.

Entre os casos estudados, o AVT, utilizado pela M. Eletrônico para o transporte de peças no chão de fábrica, é um exemplo. Sem a combinação entre sensores, tecnologias de comunicação, algoritmos de controle e softwares não seria possível a adoção de um veículo autônomo que convivesse com operadores de forma eficiente e segura.

Considerando o projeto Coleta de Dados da R. Cerveja, porém, a tecnologia não apresenta uma nova possibilidade funcional, mas a viabilidade econômica de uma funcionalidade que já era possível e adotada em outros cenários. Os dispositivos de IoT adotados para coleta de dados apresentam algumas funcionalidades, ou affordances, que os PLCs adotados em outras plantas, mas a um custo que viabiliza a adoção em novos casos. O IoT, nesse caso, pode também ser considerado uma tecnologia habilitadora, já que antes dela não seria viável a coleta dos dados das linhas de envase, mas por questão de custo e, não, de funcionalidade.

O sistema de pedidos da área de reciclagem da M. Eletrônica pode ser visto da mesma forma. Embora o grupo já possuísse um sistema de EDI bastante maduro para sua manufatura, a implantação de um sistema de pedidos no ERP envolveria custos de softwares e mão de obra que inviabilizariam a implantação em um processo ainda em formação e com necessidades básicas de integração com seus clientes. A tecnologia de cloud e o modelo de negócio de SaaS viabilizaram economicamente a informatização desse processo.

A identificação, a partir de affordances, de tecnologias que permitam a utilização de funcionalidades já conhecidas, a custos expressivamente mais baixos, pode trazer grande impacto para alguns cenários industriais. Apesar de terem sido observados casos de implantação de tecnologias como estas dentre os projetos estudados, esse potencial ainda não pareceu claro para os gestores entrevistados, representando muitas vezes uma barreira à percepção e realização desses affordances. Foram citados exemplos onde novas tecnologias não foram ao menos avaliadas simplesmente por suas funcionalidades serem semelhantes a de outros 
sistemas já utilizados pelos entrevistados. A justificativa para isso foi, normalmente, "já temos isso aqui" sem nenhuma avaliação sobre custo.

Todos os projetos avaliados envolvem uma ou mais das seguintes funcionalidades, na manipulação de dados: coleta, transmissão, armazenamento e visualização. Nenhum deles, porém, utiliza tecnologias de data mining ou machine learning. Apesar disso, essas tecnologias foram citadas em todas as entrevistas como uma das mais promissoras sendo, nos casos da R. Cerveja e A. Álcool, citadas como os próximos recursos a serem incorporados aos sistemas em fase de implantação.

Quando questionado sobre a futura utilização prevista, de inteligência de dados, o gestor de inovação da A. Álcool afirmou que são muitas as oportunidades, mas ainda não é possível enxergar claramente as primeiras aplicações. Os maiores projetos do grupo, envolvendo fornecedores e startups, correspondem à busca por algoritmos que permitam a previsão de falhas e de produtividade, com grande precisão.

À mesma pergunta o gestor da R. Cerveja, respondeu:

A gente ainda não implantou nada nesse sentido. Cloud sim, já é comum na TI, mas soluções de inteligência em cloud ainda não. Mas não somos só nós: isso acontece também nas outras companhias. Ainda existe uma dúvida quanto ao que fazer e se alguém já fez. Todos sabem que essa é a estrada, mas ainda falta uma luz.

O conhecimento de inteligência artificial para as equipes industriais ainda é bastante novo, o que se torna uma barreira para a aplicação, tanto na execução técnica quanto na percepção de seu potencial (affordance percebida). As tecnologias de Big Data e Data Mining, hoje aplicadas com sucesso em ramos como comércio eletrônico e redes sociais, ainda não se provaram diretamente compatíveis ao contexto industrial.

Dayal, Gupta, Vennelakanti, Vieira, \& Wang (2015) sugerem a existência de um Big Data industrial, com características particulares que exigem tratamento específico. Dessa forma, a solução de problemas por meio da análise inteligente de dados pode exigir adaptações nas tecnologias existentes ou, ainda, o desenvolvimento de novos algoritmos, adequados não só a essas novas características de dados, mas também aos diferentes tipos de análise requeridos por esse setor.

Embora os gestores admitam que suas equipes precisarão desenvolver conhecimentos de análises de dados e de inteligência artificial, afirmam que a contratação de profissionais com 
esse perfil ou capacitações nessas disciplinas ainda não foram iniciadas. Ao ser questionado sobre qual o perfil ideal para esse profissional, o gestor de inovação da A. Álcool respondeu:

A gente brinca que tem de ter garapa na veia. O "cara" precisa entender um pouco de agricultura, talvez de cana. É um perfil muito difícil. Eu particularmente acho mais fácil transformar um engenheiro de processo, que conheça o negócio, em um analista desses, do que pegar um estatístico e fazer acontecer.

\subsection{O papel das áreas de gestão de tecnologia e das equipes multidisciplinares, na percepção e realização de affordances}

Projetos de Manufatura Avançada exigem combinações de conhecimentos fundamentais para percepção e realização de affordances das novas tecnologias, mas que, anteriormente, não estavam disponíveis em profissionais das áreas operacionais e de TI da empresa.. Essa necessidade levou a soluções diversificadas nos casos estudados, como a criação de uma área de TI dentro da engenharia na M. Eletrônico, a formação de equipes multidisciplinares na R. Cerveja ou, em outros casos, a movimentação de um profissional experiente da área de automação industrial para a de TI.

Conflitos e dificuldades de comunicação, porém, foram reportados nos dois exemplos acima. Por motivos históricos, as companhias criaram equipes de tecnologia, separadas da área geralmente conhecida como TI, para tecnologias de produção, muitas vezes chamadas de Tecnologia da Automação (TA) ou, mais recentemente, Tecnologia da Operação (TO). A necessidade de integração entre sistemas das duas naturezas e a convergência das tecnologias de computação adotadas para os dois tipos de aplicação levaram a interações pouco comuns no passado (Dayal et al., 2015). Qian \& Hou (2015) propõem que diferenças entre o perfil dos profissionais, além da existência de demandas distintas e características específicas dos sistemas, gerenciados separadamente pelas equipes de TI e TO, são as principais barreiras para a colaboração entre elas. A Tabela 13 enumera algumas dessas barreiras: 
Tabela 13 - Diferenças entre TI e TO (Qian \& Hou, 2015)

\begin{tabular}{|c|c|c|}
\hline Categoria & TI & TO \\
\hline Profissionais & $\begin{array}{l}\text { Graduados em computação } \\
\text { Engenheiros de geração mais } \\
\text { jovem }\end{array}$ & $\begin{array}{l}\text { Engenheiros } \\
\text { Técnicos } \\
\text { O gerente de produção }\end{array}$ \\
\hline Foco & $\begin{array}{l}\text { Confidencialidade e integridade } \\
\text { dos dados } \\
\text { Automação do processo de } \\
\text { negócio } \\
\text { Gestão e controle da informação }\end{array}$ & $\begin{array}{l}\text { A segurança e proteção do } \\
\text { processo } \\
\text { Resposta a situações de } \\
\text { emergência } \\
\text { O controle do processo }\end{array}$ \\
\hline Ciclo de vida dos equipamentos & 3 a 5 anos & 15 a 20 anos \\
\hline Prioridades de segurança & $\begin{array}{l}1 \text { - Confidencialidade } \\
2 \text { - Integridade } \\
3 \text { - Disponibilidade }\end{array}$ & $\begin{array}{l}1 \text { - Disponibilidade } \\
2 \text { - Integridade } \\
3 \text { - Confidencialidade }\end{array}$ \\
\hline Requisitos de desempenho & $\begin{array}{l}\text { Não tempo-real } \\
\text { Grandes volumes } \\
\text { Tolerância com atrasos }\end{array}$ & $\begin{array}{l}\text { Tempo-real } \\
\text { Tempo de resposta limitado } \\
\text { Atrasos são inaceitáveis }\end{array}$ \\
\hline Dados & $\begin{array}{l}\text { Tipos de dados complexos } \\
\text { Análises multinível } \\
\text { Baixa taxa de dados }\end{array}$ & $\begin{array}{l}\text { Único tipo de dado } \\
\text { Análises temporais } \\
\text { Alta taxa de dados }\end{array}$ \\
\hline Interface e rede & $\begin{array}{l}\text { Interfaces Web } \\
\text { Teclados } \\
\text { Protocolos baseados em TCP/IP }\end{array}$ & $\begin{array}{l}\text { Interfaces homem-máquina } \\
\text { Sensores } \\
\text { Display touch screen }\end{array}$ \\
\hline
\end{tabular}

Os entrevistados concordam em que as estruturas organizacionais devem se adaptar a novos desafios tecnológicos, mas apresentam opiniões diferentes sobre qual será o cenário daqui a alguns anos, entre elas a fusão das áreas ou a assimilação de uma pela outra.

$\mathrm{O}$ gerente de engenharia da área de manufatura da M. Eletrônico, ao ser questionado sobre como as equipes de tecnologia da informação e de automação deveriam se organizar para enfrentar os projetos de manufatura avançada, respondeu: "Eu acredito que o ideal seria criar uma equipe única de tecnologia, mas ainda estamos muito distantes de conseguir isso. Precisamos, portanto, viabilizar o desenvolvimento desse tipo de projeto dentro da nossa própria estrutura". 


\subsection{O ERP como principal sistema corporativo}

O ERP, em todos os casos estudados, se mostrou o principal sistema TIC da companhia, agregando, além de todos os dados financeiros, informações sobre produtos, logística e sobre a própria manufatura. Muitos dos sistemas de integração envolvem diretamente o ERP, como o MES da R. Cerveja, o sistema de integração das usinas da A. Álcool e os sistemas EDI e de gestão de chão de fábrica da M. Eletrônico. Mesmo onde não existem integrações, dados do processo são apontados manualmente no ERP, como os pedidos e produção da planta de reciclagem da M. Eletrônico.

É consenso, portanto, que o ERP tem um papel importante para a Manufatura avançada. Largamente adotado entre companhias de médio e grande porte, ele já apresenta, estruturalmente, um ambiente integrado entre várias funções, antes desempenhadas por sistemas especializados como softwares contábeis e de gestão de materiais (Haddara \& Elragal, 2015).

De acordo com Haddara \& Elragal (2015) o ERP é considerado a espinha dorsal da Manufatura Avançada. Apesar disso, ainda não está claro se os produtos disponíveis no mercado estão prontos para desempenhar essa função.

Sendler (2013), sobre a Industrie 4.0, aponta que profissionais da indústria alemã de software têm debatido sobre qual será a plataforma definitiva para a gestão da manufatura: o MES ou o ERP. Defendem que o cenário mais provável é de que as funcionalidades de ambos continuem existindo, porém com maior convergência de tecnologias entre eles.

\subsection{As barreiras para a adoção de sistemas de integração}

A planta de montagem da M. Eletrônico e a planta da R. Cerveja trabalham com uma grande quantidade de produtos distintos e apontam o planejamento de produção como um grande desafio. Devido à grande complexidade do processo, não foram encontrados sistemas que conseguissem lidar com a quantidade de restrições existente, observando a agilidade necessária.

A planta de reciclagem da M. Eletrônico também encontra outras barreiras para a adoção de sistemas integrados. Esse fato é atribuído ao caráter inovador da operação, com processos ainda instáveis no chão de fábrica, poucos exemplos semelhantes que poderiam servir como 
base e um modelo de negócio em processo de desenvolvimento, levando à identificação ainda imprecisa das prioridades competitivas.

O custo foi apontado como uma grande barreira para as linhas de produção antigas da R. Cerveja e para a área agrícola da A. Álcool, principal motivação para a adoção de tecnologias de IoT. Essa barreira está diretamente relacionada às funcionalidades das tecnologias de TO, com altos custos de atualização. Essa combinação de tecnologias da Manufatura Avançada com tecnologias antigas, expandindo funcionalidades, é vista por alguns como o primeiro passo para a adoção em grandes parques industriais já consolidados.

Nelson (2017) afirma que a viabilidade econômica de projetos de Manufatura Avançada depende do aproveitamento de equipamentos e tecnologias já presentes nas linhas de produção. Segundo ele, hoje, $85 \%$ dos equipamentos da manufatura não estão conectados, e sua vida útil varia entre quinze e vinte e cinco anos. Ainda, entende que a instalação de equipamentos de comunicação e de sensores de baixo custo são a melhor alternativa para o aproveitamento dos investimentos já realizados na produção.

\subsection{O impacto da mudança de perfil do consumidor}

Um elemento importante dos movimentos de manufatura avançada, de acordo com a literatura, é a mudança de perfil do consumidor, com a exigência de atendimentos mais rápidos e oferta de produtos mais personalizados (Bartodziej, 2017; Reinhard Geissbauer et al., 2016). Essa pressão não foi percebida por nenhum dos entrevistados, não sendo apontada nenhuma ação de adoção tecnológica para esse fim.

Isso provavelmente acontece devido ao perfil de negócio das empresas estudadas. Como trabalham principalmente com clientes corporativos (B2B), como a M. Eletrônico e a A. Álcool, ou possuem um modelo de produção para estoque (MTS), como a R. Cerveja, a manufatura tem menor vínculo direto com o consumidor final. Segundo o gerente de engenharia da R. Cerveja "Não vejo como um consumidor final poderia influenciar diretamente em uma decisão de produção em tempo real. Nossa área de marketing, sim, tem trabalhado com ferramentas que se comunicam mais diretamente com o público." 


\section{Conclusões}

Como última análise dos resultados deste trabalho serão discutidas proposições, com base nos casos estudados, permitindo uma avaliação do framework proposto.

\section{Proposição 1: Equipes com maior conhecimento em tecnologia apresentam maior capacidade de perceber affordances de tecnologias habilitadoras}

O conhecimento tecnológico foi mencionado como uma preocupação central, em alguns dos cases estudados, não só para a identificação das potenciais aplicações das tecnologias habilitadoras, mas também para a implantação. $\mathrm{O}$ uso de especialistas externos à companhia como no projeto agrícola da A. Álcool, a criação de equipes com conhecimentos específicos como na M. Eletrônico e a criação de equipes mistas com conhecimentos de TI e automação industrial, na R. Cerveja, foram fundamentais, tanto para a viabilização desses projetos de Manufatura Avançada, como para a seleção, com base em seus affordances, das tecnologias a serem aplicadas.

Mais do que equipes com profundos conhecimentos tecnológicos, essas iniciativas criaram equipes multidisciplinares que eram capazes de lidar com conceitos e tecnologias de diferentes domínios. Essa característica se mostrou essencial no caso da formação da equipe da R. Cerveja: como as áreas de tecnologia eram separadas no período inicial, em que ainda não colaboravam de forma efetiva, não foram elaborados projetos de Manufatura Avançada bemsucedidos, pois o conhecimento parcial do assunto apresentado por uma e por outra equipe não era suficiente para que barreiras práticas, como ausência de robustez de equipamentos ou de capacidade de lidar com grandes volumes de dados, fossem transpostas.

Esse resultado é condizente com a teoria de affordances. Os affordances não são propriedades unicamente do objeto, ou do artefato tecnológico, mas da sua interação com o usuário ou área de aplicação. Ao ser deslocada do ambiente corporativo para o de manufatura, uma tecnologia deve ser reavaliada e ter suas capacidades reinterpretadas, o que exige conhecimentos específicos.

\section{Proposição 2: Empresas com diferentes prioridades estratégicas adotam diferentes tecnologias de manufatura avançada}


Os casos estudados mostraram uma grande diversidade de abordagens tecnológicas entre os diferentes processos. A adoção da integração vertical, com ênfase na coleta de dados dos equipamentos de operação, se mostrou bastante relacionada à prioridade em custos com a busca de aumento de produtividade, como observado nos projetos da R. Cerveja e A. Álcool. A produção em menor volume de produtos premium em uma das plantas da A. Álcool e, portanto, uma pressão competitiva por custos baixos, levou à redução da prioridade de implantação do projeto de integração nessa planta.

Quando a flexibilidade esteve entre as prioridades, outras abordagens de integração foram adotadas. Com a demanda de flexibilidade de produto, as plantas de montagem da M. Eletrônico utilizam sistemas EDI para receber pedidos dos clientes. Por necessitar reações rápidas a diferentes insumos, ou flexibilidade a materiais, a linha de reciclagem da $\mathrm{M}$. Eletrônico e as plantas da A. Álcool utilizam sistemas que trazem para a linha de produção informações da cadeia de suprimentos a jusante, como produtos enviados para reciclagem à planta e características de qualidade da cana, respectivamente.

Outros fatores subordinados às prioridades estratégicas, como sistemas de produção e áreas de decisão, também são importantes para a decisão de tecnologias habilitadoras. Diferentes sistemas de produção, presentes nas diversas fases de fabricação da cerveja, levaram à adoção de diferentes graus de tecnologia para as plantas da R. Cerveja. Os motivos reportados foram o maior impacto das otimizações, com maior tecnologia, na produtividade da área de envase e, também, a complexidade maior dos processos na área de fabricação, que aumentariam os custos da adoção da tecnologia.

A menor qualificação da mão de obra disponível levou a planta $\mathrm{C}$ da A. Álcool a ser o primeiro caso de integração vertical do grupo. O uso intensivo de mão de obra nas plantas da M. Eletrônico justificou a adoção de AVT para reposição de peças, sendo que, a complexidade e variedade de seus produtos, fez com que os projetos necessitassem ser gerenciados e compartilhados por sistemas de gestão de documentação.

Argumentos genéricos sobre a aplicabilidade das tecnologias de Manufatura Avançada para todos os tipos de indústria, de forma homogênea, comumente encontrados nos textos de negócios (Alter et al., 2014; Wee et al., 2015), não encontram comprovação quando se observam aplicações práticas. Diferenças de estratégias e de modelos de processo exigem diferentes tecnologias, sejam recentes ou consolidadas, para que os objetivos sejam atingidos. 
Proposição 3: Empresas que atingem um maior consenso estratégico entre suas equipes de tecnologia e a alta gestão, adotam tecnologias mais alinhadas às prioridades estratégicas

Todas as empresas estudadas apresentaram mecanismos para que as diversas áreas estivessem alinhadas com os objetivos estratégicos. As três empresas apresentam programas de gestão de metas, por equipe e por processos de aprovação de projetos, com o envolvimento da alta gerência, que procura incentivar ações compatíveis com as prioridades estratégicas.

Mecanismos de comunicação, como o envolvimento direto de gestores estratégicos na equipe de inovação da R. Cerveja ou, ainda, a gestão de equipes compostas por técnicos das áreas operacionais, pelo gestor de inovação da A. Álcool, propagam a divulgação de diretrizes corporativas para todas as camadas da organização.

\section{Proposição 4: A adoção de tecnologias específicas de manufatura avançada depende da estratégia de manufatura e da percepção da aplicabilidade de seus affordances aos processos de manufatura da empresa}

Como discutido anteriormente, as diferentes estratégias de operações e diferentes características das equipes de tecnologia apresenta grande influência sobre o tipo e o grau de adoção da tecnologia aplicada na Manufatura Avançada.

Porém, a simples existência de equipes capazes de entender tecnologias e implantar projetos, ainda que aliada ao atendimento a impactos de prioridades estratégicas, não se mostrou suficiente para a adoção de tecnologias habilitadoras. O custo foi um fator central para o projeto de automação agrícola da A. Álcool e para as plantas mais antigas da R. Cerveja. Em ambos os casos, a aplicação da integração vertical era considerada desejável e as equipes conheciam tecnologias que poderiam implementá-la, mas a um custo inviável.

Isso demonstra a necessidade de atenção a um tipo específico de affordance de tecnologias de Manufatura Avançada: o que apresenta potencial de viabilizar a adoção de projetos com funcionalidades já conhecidas. Conceitos como CIM, conforme afirma (Bartodziej, 2017), ou, outros posteriores, como MES, PLM ou mesmo ERP, não serão necessariamente substituídos por novas arquiteturas com a Manufatura Avançada, mas expandidos para outras aplicações, para empresas de diferentes portes ou para segmentos industriais que antes não os adotavam por questões econômicas. 
O projeto de automação agrícola da A. Álcool, especificamente, demonstra que o campo oferece possibilidades ainda maiores para aplicação das tecnologias de Manufatura Avançada, abrindo amplos espaços, ainda pouco explorados, para pesquisas, tanto na área de tecnologia como na de recursos humanos.

Com essas considerações, é possível ampliar o framework proposto na figura 13, de acordo com a seguinte.

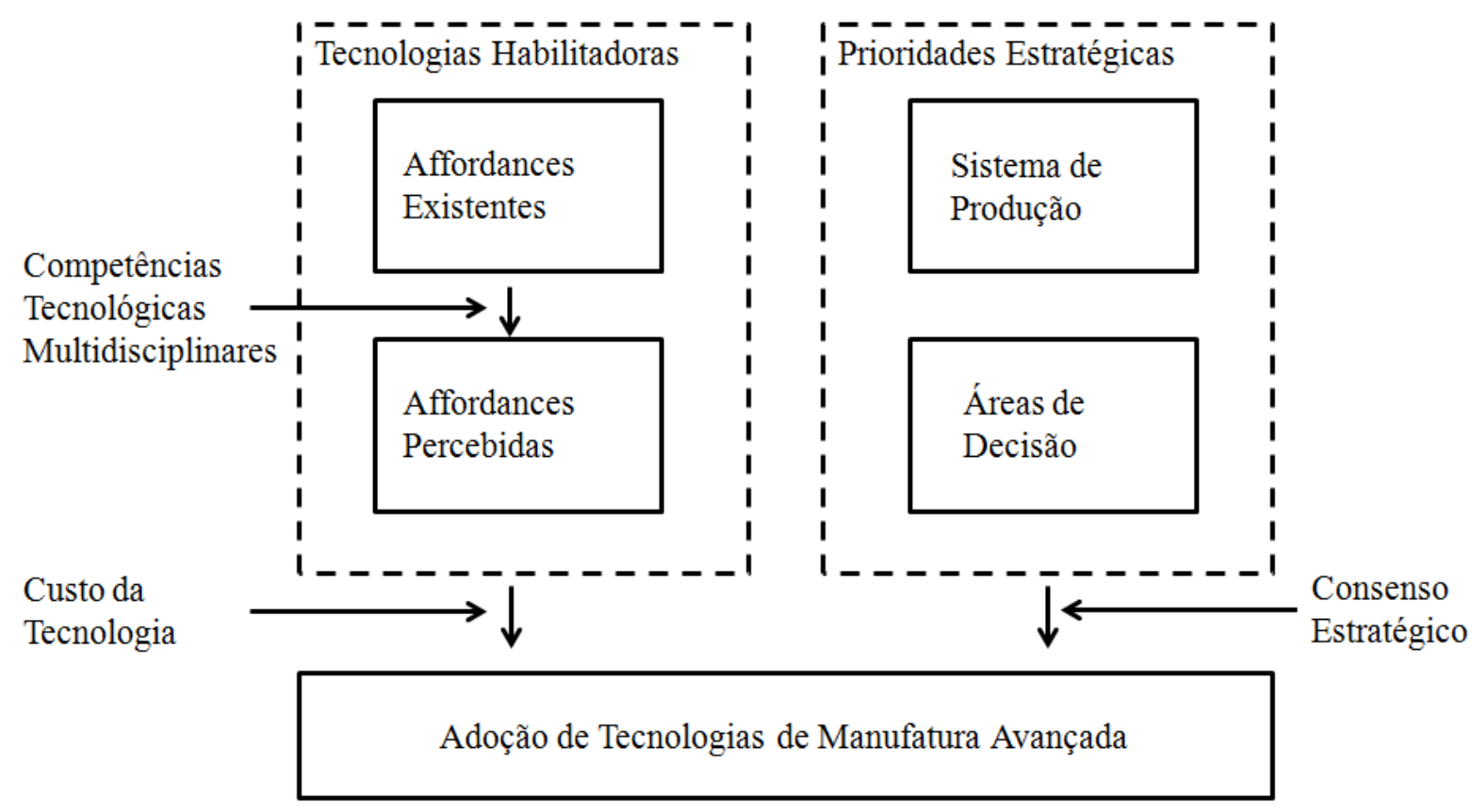

Figura 13- Framework Revisado

Dentre os cases estudados, apenas o projeto agrícola da A. Álcool apontou para iniciativas governamentais, pelo uso de financiamento do BNDES. Essas iniciativas apresentam papel fundamental para os movimentos dos EUA e Alemanha. A Manufatura Avançada, como afirmam Daudt \& Willcox (2016), não é um movimento global empreendida de forma coordenada, mas políticas particulares que enfocam características e desafios regionais. Esse fato apresenta uma oportunidade para o desenvolvimento de iniciativas mais adequadas ao contexto brasileiro e maior engajamento das indústrias que atuam no país.

Este trabalho objetiva apresentar contribuição às áreas de gestão de operações e de TI, trazendo o tema de Manufatura Avançada para seu contexto e expondo casos que reforçam alguns dos conceitos aplicáveis ao tema, além de apresentarem características particulares que podem melhor ilustrar sua complexidade. A expectativa é de que gestores industriais e públicos possam se beneficiar do framework da figura 13 como uma proposta de abordagem de desafios tanto para a adoção e avaliação de propostas de projetos, como para o desenvolvimento de políticas públicas. 
Por tratar-se de área de pesquisa ainda em fase embrionária, este trabalho pode suscitar oportunidades de investigações futuras com diversas lentes teóricas e diferentes objetivos. $\mathrm{O}$ framework proposto pode ser adotado como base para pesquisas em territórios e segmentos industriais aqui não abordados, assim como para a aplicação de diferentes métodos, como pesquisa quantitativa ou pesquisa-ação. Podem ainda serem enfocados aspectos da Manufatura Avançada não abordados, como desenvolvimento de produtos e a aplicação de IoT nos produtos finais.

A ainda recente literatura sobre affordances pode ser aplicada em novas pesquisas sobre a utilização de tecnologias de Manufatura Avançada. A combinação de recentes tecnologias com novos perfis de usuários e de organizações apresenta terreno fértil para a avaliação de como as tecnologias são percebidas e aplicadas, quando deslocadas para novos contextos.

Pesquisas das áreas de tecnologia e engenharia também são bastante promissoras. As entrevistas mostraram que a aplicação de IoT para a viabilização financeira de projetos de coleta de dados é campo que tem apontado para uma série de aplicações práticas. O interesse e as altas expectativas despertados pelas tecnologias de Data Mining e inteligência artificial, aliados às barreiras para sua adoção, apontam para um campo ainda pouco explorado por especialistas em produção industrial e cientistas da computação.

A necessidade de interação entre áreas de tecnologia que ainda não apresentam convergências operacionais, de realização de novas capacitações, bem como, em alguns casos, o surgimento de novos departamentos na indústria, representam oportunidades para pesquisadores de organizações e de recursos humanos. 


\section{Bibliografia}

Alter, A., Banerjee, P., E.Daugherty, P., \& Negm, W. (2014). Driving Unconventional Growth through the Industrial Internet of Things. Retrieved from https://www.accenture.com/mz-en/_acnmedia/Accenture/next-gen/reassemblingindustry/pdf/Accenture-Driving-Unconventional-Growth-through-IIoT.pdf

Anderson, J. C., Cleveland, G., \& Schroeder, R. G. (1989). Operations strategy: A literature review. Journal of Operations Management, 8(2), 133-158. https://doi.org/10.1016/0272-6963(89)90016-8

Annis, T. (1986). JIT via EDI. Manufacturing Systems, 4(11), 62-63.

ANSI/ISA-95.00.03-2013 Enterprise-Control System Integration - Part 3: Activity Models of Manufacturing Operations Management. (2005). Instrumentation, Systems and Automation Society. Retrieved from https://www.isa.org/store/products/productdetail/?productId $=116782$

Archambault, É., Campbell, D., Gingras, Y., \& Larivière, V. (2009). Comparing bibliometric statistics obtained from the web of science and Scopus. Journal of the American Society for Information Science and Technology, 60(7), 1320-1326. https://doi.org/10.1002/asi.21062

Bartodziej, C. J. (2017). The Concept Industry 4.0. Berlin, Germany: Springer. https://doi.org/10.1007/978-3-658-16502-4

Ben Khedher, A., Henry, S., \& Bouras, A. (2011). Integration between MES and product lifecycle management. IEEE International Conference on Emerging Technologies and Factory Automation, ETFA. https://doi.org/10.1109/ETFA.2011.6058993

Biswas, S., \& Akhter, T. (2014). Cloud Based Healthcare Application Architecture and Electronic Medical Record Mining: An Integrated Approach to Improve Healthcare System.

Brown, J., \& Houlihan, D. (2008). Integrating the PLM Ecosystem. Aberdeen Group.

Buchholz, S. (2011). Factories of the future. Manufacturing Chemist (Vol. 82). https://doi.org/10.2777/29815

Buda, A., Främling, K., Borgman, J., Madhikermi, M., \& Kubler, S. (2015). Data supply chain in Industrial Internet. 11th IEEE World Conference on Factory Communication Systems (WFCS 2015), (May).

Cagliano, R., \& Spina, G. (2000). Advanced manufacturing technologies and strategically flexible production. Journal of Operations Management, 18(2), 169-190. https://doi.org/10.1016/S0272-6963(99)00022-4

Cervieri Júnior, O., Teixeira Junior, J. R., Galinari, R., Rawet, E. L., \& Silveira, C. T. J. (2014). O Setor de Bebidas no Brasil. Banco Nacional de Desenvolvimento Econômico E Social, 40, 93-129. https://doi.org/ISSN 1414-9230

Choudhari, S. C., Adil, G. K., \& Ananthakumar, U. (2010). Congruence of manufacturing decision areas in a production systema: a research framework. International Journal of Production Research, 48(20). https://doi.org/10.1080/00207540903164644

Clynes, M. (1959). Some nonlinear control techniques novel to control engineers employed by a biological control system. IRE Transactions on Automatic Control, 4(3), 45.

Coelho, W. A. (1973). APPLICATION OF A PROGRAMMABLE LOGIC CONTROLLER TO A DRY MATERIAL HANDLING SYSTEM. In Adv in Instrum (p. Volume 28, 6p).

Collaboration for Interoperability. (2016). Retrieved from http://www.iiconsortium.org/iicand-i40.htm

Colombo, A. W., Karnouskos, S., \& Bangemann, T. (2014). Towards the next generation of 
industrial Cyber-Physical Systems. Industrial Cloud-Based Cyber-Physical Systems: The IMC-AESOP Approach, 1-22. https://doi.org/10.1007/978-3-319-05624-1_1

Daudt, G. M., \& Willcox, L. D. (2016). Reflexões críticas a partir das experiências dos Estados Unidos e da Alemanha em manufatura avançada. BNDES Setorial, (44), 5-45. Retrieved from https://web.bndes.gov.br/bib/jspui/handle/1408/9936

David, M., \& Rowe, F. (2016). What does PLMS (product lifecycle management systems) manage: Data or documents? Complementarity and contingency for SMEs. Computers in Industry, 75, 140-150. https://doi.org/10.1016/j.compind.2015.05.005

Davis, J., Edgar, T., Graybill, R., Korambath, P., Schott, B., Swink, D., ... Wetzel, J. (2015). Smart Manufacturing. Annual Review of Chemical and Biomolecular Engineering, 6, 141-60. https://doi.org/10.1146/annurev-chembioeng-061114-123255

Dayal, U., Gupta, C., Vennelakanti, R., Vieira, M. R., \& Wang, S. (2015). An approach to benchmarking industrial big data applications. Lecture Notes in Computer Science (Including Subseries Lecture Notes in Artificial Intelligence and Lecture Notes in Bioinformatics), 8991, 45-60. https://doi.org/10.1007/978-3-319-20233-4_6

Deuel, A. C. (1994). The benefits of a manufacturing execution system for plantwide automation. ISA Transactions, 33(2), 113-124. https://doi.org/10.1016/00190578(94)90042-6

Dhinesh Kumar, K., Karunamoorthy, L., Roth, H., \& Mirnalinee, T. T. (2005). Computers in manufacturing: towards successful implementation of integrated automation system. Technovation, 25(5), 477-488. https://doi.org/10.1016/j.technovation.2003.09.004

Drabik, D., De Gorter, H., Just, D. R., \& Timilsina, G. R. (2014). The Economics of Brazil's Ethanol-Sugar Markets, Mandates, and Tax Exemptions. American Journal of Agricultural Economics, 1-18. https://doi.org/10.1093/ajae/aau109

Drath R., \& Horch A. (2014). Industrie 4.0 - hit or hype? IEEE Industrial Electronics Magazine , (June), 56-58. Retrieved from https://www.researchgate.net/profile/Rainer_Drath/publication/263285662_Industrie_40 _Hit_or_Hype_Industry_Forum/links/5909965e458515ebb495dde7/Industrie-40-Hit-orHype-Industry-Forum.pdf

Edh Mirzaei, N., Fredriksson, A., \& Winroth, M. (2016). Strategic consensus on manufacturing strategy content. International Journal of Operations \& Production Management, 36(4), 429-466. https://doi.org/10.1108/IJOPM-07-2014-0309

Eisenhardt, K. M. (1989). Building Theories from Case Study Research. Academy of Management Review, 14(4), 532-550. https://doi.org/10.5465/AMR.1989.4308385

Electric, S. (2015). IoT - How Connectivity Drives Operational Intelligence.

EMBRAPII - Quem Somos. (n.d.). Retrieved June 16, 2017, from http://embrapii.org.br/categoria/institucional/quem-somos/

Ensinas, A. V, Nebra, S. A., Lozano, M. A., \& Serra, L. (2006). Analysis of cogeneration systems in sugar cane factories - alternative of steam and combined cycle power plants. Ecos 2006, 1177-1184.

Evans, P. C., \& Annunziata, M. (2012). Industrial Internet: Pushing the Boundaries of Minds and Machines. General Electric, 37.

Ferrazzi, A. (2013). Manufacturing execution systems : a case study in the aerospace industry. University of Padua.

Frishammar, J., Lichtenthaler, U., \& Kurkkio, M. (2012). The front end in non-assembled product development: A multiple case study of mineral- and metal firms. Journal of Engineering and Technology Management - JET-M, 29(4), 468-488. https://doi.org/10.1016/j.jengtecman.2012.07.001

Genge, B., Fovino, I. N., Siaterlis, C., \& Masera, M. (2011). Analyzing Cyber-Physical Attacks on Networked Industrial Control Systems. Critical Infrastructure Protection V, 
367, 167-183. https://doi.org/10.1007/978-3-642-24864-1_12

Gerwin, D. (1987). An Agenda For Research on the Flexibility of Manufacturing Processes. International Journal of Operations \& Production Management, 7(1), 38-49. https://doi.org/10.1108/eb054784

Gibson, J. J. (1979). The Ecological Approach to Visual Perception. of Experimental Psychology Human Perception and (Vol. 39). https://doi.org/10.2307/989638

Glaser, W. A. (1959). Job Mobility between Government and other Social Structures. American Behavioral Scientist, 3(3), 20-23.

Gokorsch, S. E. (1992). Manufacturing data-the search for the integrated enterprise. In AUTOFACT (pp. 18-11).

Gorbach, G., Polsonetti, C., \& Chatha, a. (2014). Planning for the Industrial Internet of Things Industrial Internet of Things ( IoT ) Enables New Business Models. ARC Advisory Group. Retrieved from http://www.arcweb.com/brochures/planning-for-theindustrial-internet-of-things.pdf

Gorton, J. V. (1959). The chrysler aerial jeep project. SAE Technical Papers. https://doi.org/10.4271/590192

Guerra-Zubiaga, D., Donato, L., Ramirez, R., \& Contero, M. (2006). Knowledge sharing to support collaborative engineering at PLM environment. Practical Aspects of Knowledge Management, Proceedings, 4333, 86-96.

Gunendran, A. G., \& Young, R. I. M. (2010). Methods for the capture of manufacture best practice in product lifecycle management. International Journal of Production Research, 48(20), 5885-5904. https://doi.org/10.1080/00207540903104210

Haddara, M., \& Elragal, A. (2015). The Readiness of ERP Systems for the Factory of the Future. Procedia Computer Science, 64, 721-728. https://doi.org/10.1016/j.procs.2015.08.598

Harris Jr., J. M. (1984). Coronary angiography and its complications. The search for risk factors. Archives of Internal Medicine, 144(2), 337-341.

Hatakeyama, K., \& Machado, M. (2016). Integrated approach bridging PLM, ERP, SCM in automobile industry. Advances in Transdisciplinary Engineering, 4, 739-748. https://doi.org/10.3233/978-1-61499-703-0-739

Hayes, R., Wheelwright, S., \& Clark, K. (1988). Dynamic Manufacturing. The Free Press.

Henning, K., Wolfgang, W., \& Johannes, H. (2013). Recommendations for implementing the strategic initiative INDUSTRIE 4.0. Final report of the Industrie 4.0 WG.

Hutchby, I. (2001). Technologies, texts and affordances. Sociology, 35(2), 441-456. https://doi.org/10.1177/S0038038501000219

Junior, A. S. V., \& Alves, F. C. D. (2016). Bebidas alcoólicas: Cerveja.

Kang, H. S., Lee, J. Y., Choi, S., Kim, H., Park, J. H., Son, J. Y., ... Noh, S. Do. (2016). Smart manufacturing: Past research, present findings, and future directions. International Journal of Precision Engineering and Manufacturing-Green Technology, 3(1), 111-128. https://doi.org/10.1007/s40684-016-0015-5

Kathuria, R., \& Igbaria, M. (1997). Aligning IT applications with manufacturing strategy: an integrated framework. International Journal of Operations \& Production Management, 17(6), 611-629. https://doi.org/10.1108/01443579710167285

Kathuria, R., Joshi, M. P., \& Porth, S. J. (2007). Organizational alignment and performance: past, present and future. Management Decision, 45(3), 503-517. https://doi.org/10.1108/00251740710745106

Kenwright, D. (1999). Automation or interaction: what's best for big data? In Proceedings Visualization '99 (pp. 491-495). https://doi.org/10.1109/VISUAL.1999.809940

Ketokivi, M., \& Choi, T. (2014). Renaissance of case research as a scientific method. Journal of Operations Management, 32(5), 232-240. https://doi.org/10.1016/j.jom.2014.03.004 
Kiel, D., Arnold, C., Collisi, M., \& Voigt, K.-I. (2016). The Impact of the Industrial Internet of Things on Established Business Models. In International Association for Management of Technology IAMOT 2016 Proceedings (Vol. 240, pp. 673-695). https://doi.org/10.1007/978-3-319-40515-5_7

Kim, Y., \& Lee, J. (1993). Manufacturing strategy and production systems: an integrated framework. Journal of Operations Management, 11, 3-15. https://doi.org/10.1016/02726963(93)90029-O

Kotha, S., \& Orne, D. (1989). Generic manufacturing strategies: A conceptual synthesis. Strategic Management Journal, 10(3), 211-231. https://doi.org/10.1002/smj.4250100303

Lager, T., Samuelsson, P., \& Storm, P. (2017). Modelling company generic production capabilities in process industries. International Journal of Operations \& Production Management (Vol. 37). https://doi.org/10.1108/IJOPM-11-2014-0544

Leagus, D. C., Lee, C. Y., \& Mealy, G. H. (1959). Verification of the Logic Structure of an Experimental Switching System on a Digital Computer. Bell System Technical Journal, $38(2), 467-476$.

Lee, E. A., \& Seshia, S. A. (2011). Introduction to Embedded Systems A Cyber-Physical Systems Approach (1st ed.). LeeSeshia.org.

Lee, J., Bagheri, B., \& Kao, H.-A. (2014). A Cyber-Physical Systems architecture for Industry 4.0-based manufcturing systems. Science Direst, Manufactur, 18-23.

Lee, S. M., Hong, S. G., Katerattanakul, P., \& Kim, N. R. (2012). Successful implementations of MES in Korean manufacturing SMEs: an empirical study. International Journal of Production Research, 50(7), 1942-1954. https://doi.org/10.1080/00207543.2011.561374

Leonardi, P. M. (2008). 2010.04.22.When Flexible Routines Meet Flexible Technologies. MIS Quarterly, (Itr 0427173).

Leong, G. K., Snyder, D. L., \& Ward, P. T. (1990). Research in the process and content of manufacturing strategy. Omega, 18(2), 109-122. https://doi.org/10.1016/03050483(90)90058-H

Liao, Y., Deschamps, F., Loures, E. de F. R., \& Ramos, L. F. P. (2017). Past, present and future of Industry 4.0 - a systematic literature review and research agenda proposal. International Journal of Production Research, 55(12), 3609-3629. https://doi.org/10.1080/00207543.2017.1308576

Lin, S.-W. (2015). Three Main Themes in the Industrial Internet of Things. Journal of Innovation, (December), 4-15.

Liu, H., Ke, W., Wei, K. K., \& Hua, Z. (2013). The impact of IT capabilities on firm performance: The mediating roles of absorptive capacity and supply chain agility. Decision Support Systems, 54(3), 1452-1462. https://doi.org/10.1016/j.dss.2012.12.016

Ljungberg, Õ. (1998). Measurement of overall equipment effectiveness as a basis for TPM activities. International Journal of Operations \& Production Management, 18(5), 495507. https://doi.org/10.1108/01443579810206334

Longoni, A., \& Cagliano, R. (2015). Environmental and social sustainability priorities: their integration in operations strategies. International Journal of Operations \& Production Management, 35(2), 216-245. https://doi.org/10.1108/IJOPM-04-2013-0182

Martens, H. H. (1959). Two notes on machine "Learning." In Information and Control (Vol. 2, pp. 364-379). https://doi.org/10.1016/S0019-9958(59)80014-0

Mason, S. J., Cole, M. H., Ulrey, B. T., \& Yan, L. (2002). Improving electronics manufacturing supply chain agility through outsourcing. International Journal of Physical Distribution \& Logistics Management, 32(7), 610-620. https://doi.org/10.1108/09600030210442612

McGhee, R. (1959). Spectral characterization of control system nonlinearities. IRE Transactions on Automatic Control, 4(3), 199-211. 
MESA, I. (1997). MES Functionalities \& MRP to MES Data Flow Possibilities. MESA International, (2), 1-8. Retrieved from http://scholar.google.com/scholar?hl=en\&btnG=Search\&q=intitle:MES+Functionalities+ $\&+$ MRP+to+MES+Data+Flow+Possibilities\#1

MESA Model. (2011). Retrieved June 28, 2017, from http://www.mesa.org/en/modelstrategicinitiatives/mesamodel.asp

Miltenburg, J. (2005). Manufacturing strategy: how to formulate and implement a winning plan. Professional Manager (Vol. Vol. 2). https://doi.org/10.1016/S07376782(96)90159-9

Moones, E., Vosgien, T., Kermad, L., Dafaoui, E. M., Mhamedi, A. El, \& Figay, N. (2015). PLM standards modelling for enterprise interoperability: A manufacturing case study for ERP and MES systems integration based on ISA-95. In Enterprise Interoperability 6th International IFIP Working Conference. https://doi.org/10.1007/978-3-662-47157-9

Morgan, J., \& O'Donnell, G. E. (2015). The cyber physical implementation of cloud manufactuirng monitoring systems. Procedia CIRP, 33, 29-34. https://doi.org/10.1016/j.procir.2015.06.007

Muhr, T. (1991). ATLAS/ti - A prototype for the support of text interpretation. Qualitative Sociology, 14(4), 349-371. https://doi.org/10.1007/BF00989645

Nelson, S. (2017). 3 keys to financial success in the Industrial Internet of Things. Retrieved from http://www.cio.com/article/3176948/internet-of-things/3-keys-to-financial-successin-the-industrial-internet-of-things.html

Niggemann, O., Biswas, G., Kinnebrew, J. S., Khorasgani, H., Volgmann, S., \& Bunte, A. (2015). Data-driven monitoring of cyber-physical systems leveraging on big data and the internet-of-things for diagnosis and contro. CEUR Workshop Proceedings, 1507, 185192.

Olhager, J., \& Rudberg, M. (2002). Linking manufacturing strategy decisions on process choice with manufacturing planning and control systems. International Journal of Production Research, 40(10), 2335-2351. https://doi.org/10.1080/00207540210131842

Papirno, R., \& Gerard, G. (1955). Dynamic deflection transducer utilizing photoconductive sensors. In Review of Scientific Instruments (Vol. 26, pp. 968-969). https://doi.org/10.1063/1.1715167

Pozzi, G., Pigni, F., \& Vitari, C. (2014). Affordance Theory in the IS Discipline: a Review and Synthesis of the Literature. Twentieth Americas Conference on Information Systems, Savannah, 2014, 13, 1-12. https://doi.org/10.1007/978-3-319-22921-8_10

Prause, G. (2015). Sustainable Business Models and Structures for Industry 4.0. Journal of Security and Sustainability Issues, 5(2). https://doi.org/http://dx.doi.org/10.9770/jssi.2015.5.2(3)

Qian, X., \& Hou, Y. (2015). The application of virtualization technology in fusing operation technology and information technology. Proceedings of the 2015 27th Chinese Control and Decision Conference, CCDC 2015, 4300-4304. https://doi.org/10.1109/CCDC.2015.7162685

R.Qiu. (2003). Design of Enterprise Web Servers in Support of Instant Information Retrievals. In Proceedings of the IEEE International Conference on Systems, Man and Cybernetics (pp. 2661-2666).

Ramlan, R., Ngadiman, Y., Omar, S. S., \& Yassin, A. M. (2015). Quantification of machine performance through Overall Equipment Effectiveness. 2nd International Symposium on Technology Management and Emerging Technologies, ISTMET 2015 - Proceeding, 407411. https://doi.org/10.1109/ISTMET.2015.7359068

Reinhard Geissbauer, Vedso, J., \& Schrauf, S. (2016). Indústria 4.0: Digitização como vantagem competitiva no Brasil, 33 . Retrieved from 
www.pwc.com/industry4.0\%0Ahttps://www.pwc.com.br/pt/publicacoes/servicos/assets/c onsultoria-negocios/2016/pwc-industry-4-survey-16.pdf

Rochel, L. C. E., \& Martins, J. C. (2016). Desempenho Setorial. Retrieved from http://www.abinee.org.br/abinee/decon/decon15.htm

Rosenthal, S. R. (1984). Progress Toward the "Factory of the Future." Journal of Operations Management, 4(3), 203-229. https://doi.org/10.1016/0272-6963(84)90012-3

Ross, D. T. (1961). Computer-Aided Design. Communications of the ACM, 4(5), 235.

Saaksvuori, A., \& Immonen, A. (2002). Product Lifecycle Management.

Saenz de Ugarte, B., Artiba, a., \& Pellerin, R. (2009). Manufacturing execution system - a literature review. Production Planning \& Control, 20(6), 525-539. https://doi.org/10.1080/09537280902938613

Saldanha, T. J. V, Melville, N. P., Ramirez, R., \& Richardson, V. J. (2013). Information systems for collaborating versus transacting: Impact on manufacturing plant performance in the presence of demand volatility. Journal of Operations Management, 31(6), 313329. https://doi.org/10.1016/j.jom.2013.07.007

Schmenner, R. W., \& Tatikonda, M. V. (2005). Manufacturing process flexibility revisited. International Journal of Operations \& Production Management, 25(12), 1183-1189. https://doi.org/10.1108/01443570510633585

Schmidt, N., Lüder, A., Rosendahl, R., Foehr, M., \& Vollmar, J. (2015). Characterizing Integration Approaches: Identifying integration approach candidates for use in industrie 4.0. In IEEE International Conference on Industrial Informatics (pp. 527-532).

Scholten, B. (2007). The Road to Integration: a guide to applying the ISA-95 standard in manufacturing. International Society of Automation.

Sebastian, I. M., \& Bui, T. (2014). The influence of information systems affordances on work practices in high velocity, high reliability organizations: A relational coordination approach, 3648592, 187. Retrieved from http://proxy2.hec.ca/login?url=http://search.proquest.com/docview/1651936731?account id=11357\%5Cnhttp://gutenberg.hec.ca:3210/sfxlcl3?url_ver=Z39.88-

2004\&rft_val_fmt=info:ofi/fmt:kev:mtx:dissertation\&genre=dissertations+\&+theses\&si $\mathrm{d}=$ ProQ:ProQuest+Dissertati

Seidel, S., Recker, J., \& Vom Brocke, J. (2013). Sensemaking and Sustainable Practicing: Functional Affordances of Information Systems in Green Transformations . MIS Quarterly, 37(4), 1275-1299. Retrieved from http://search.ebscohost.com/login.aspx?direct=true\&profile=ehost\&scope=site\&authtype $=$ crawler \&jrnl $=02767783 \& A N=91906282 \& \mathrm{~h}=\mathrm{GW} 61 \mathrm{ld} 3375 \mathrm{Nm}+\mathrm{zEo} / 13 \mathrm{AlmW} 6 \mathrm{xH} 64 \mathrm{xtj} 9$ AgmgCQppkRGLnur6IfyesrxGZ9sZnvqPi0Jx1v1QMP+hNUWgkT/HBnw==\&crl=c\%5 Cnpapers3://publication/uuid/9A8B343E-

Sendler, U. (2013). Industrie 4.0. Beherrschung Der Industriellen Komplexität Mit SysLM, Online-Ressource (XII, 144 S. 71 Abb, online resou. https://doi.org/10.1007/978-3-64236917-9

Sergi, B. S. (2015). Strategic Factor Analysis for Industry 4.0. Journal of Security and Susteinability Issues, 8(2), 159-169.

Sheng, W., Xi, N., Chen, H., \& Chen, Y. (2003). Part Geometric Understanding for Tool Path Planning in Additive Manu fact ur ing Part Geometry Preprocessing (pp. 1-6).

Simoes Gaspar, A. J. (2012). The Observatory : Designing Data-Driven Decision making tools. MIT Media Lab, 1-59. Retrieved from

http://macroconnections.media.mit.edu/papers/SimoesMasterThesis.pdf

Skinner, W. (1969). Manufacturing--missing link in corporate strategy. Harvard Business Review. https://doi.org/10.1016/S0267-3649(00)88914-1

Smart Manufacturing Leadership Coalition. (2012). SMLC Forum: Priorities, Infrastructure, 
and Collaboration for Implementation of Smart Manufacturing, (October), 1-27.

Soga, S., Hiroshige, Y., Dobashi, A., Okumura, M., \& Kusuzaki, T. (1999). Products lifecycle management system using radio frequency identification technology. In Ieee.

Sommer, L. (2015). Industrial Revolution - Industry 4.0: Are German Manufacturing SMEs the First Victims of this Revolution? Journal of Inustrial Engineering and Management, 8(5), 1512-1532. https://doi.org/10.3926/jiem.1470

SONDAGEM-Indústria 4.0: novo desafio para a indústria brasileira. (2016). Confederação Nacional da Indústria. Retrieved from http://www.portaldaindustria.com.br/estatisticas/sondesp-66-industria-4-0/

Sprakel, E. B., \& Severiano Filho, C. (1999). A Evolução dos Sistemas de PCP sob a Ótica da Engenharia de Produção. 1999, 16. Retrieved from http://www.abepro.org.br/biblioteca/ENEGEP1999_A0654.PDF

Swarthout, R. W., \& Fiedler, H. J. (1973). Exploration of Utility Automation Applications Trough Supervisory Control, I(1), 12-20.

Swink, M., \& Nair, A. (2007). Capturing the competitive advantages of AMT: Designmanufacturing integration as a complementary asset. Journal of Operations Management, 25(3), 736-754. https://doi.org/10.1016/j.jom.2006.07.001

Thomas, V., Neckel, W., \& Wagner, S. (1999). Information technology and product lifecycle management. In Electronics and the Environment, 1999. ISEE -1999. Proceedings of the 1999 IEEE International Symposium on (pp. 54-57).

Toffler, A. (1981). The Thrird Wave. London: Collins.

Toro, C., Barandiaran, I., \& Posada, J. (2015). A Perspective on Knowledge Based and Intelligent Systems Implementation in Industrie 4.0. Procedia Computer Science, 60, 362-370. https://doi.org/10.1016/j.procs.2015.08.143

Traversat, B., Abdelaziz, M., Doolin, D., Duigou, M., Hugly, J. C., \& Pouyoul, E. (2003). Project JXTA-C: Enabling a Web of things. Proceedings of the 36th Annual Hawaii International Conference on System Sciences, HICSS 2003. https://doi.org/10.1109/HICSS.2003.1174816

UNICA - União da Indústria de Cana de Açúcar. (2016). Retrieved from http://www.unica.com.br

Vogel-Heuser, B., \& Hess, D. (2016). Guest Editorial Industry 4.0-Prerequisites and Visions. IEEE Transactions on Automation Science and Engineering, 13(2), 411-413. https://doi.org/10.1109/TASE.2016.2523639

Volkoff, O., \& Strong, D. (2013). Critical Realism and Affordances: Theorizing IT-associated Organizational Change Processes. MIS Quarterly, 37(3), 819-834. https://doi.org/10.1080/1354570032000057071

Voss, C. A., Tsikriktsis, N., \& Frohlich, M. (2002). Case research in operations management. International Journal of Operations \& Production Management (Vol. 22). https://doi.org/10.1108/01443570210414329

Walter, J., Kellermanns, F. W., Floyd, S. W., Veiga, J. F., \& Matherne, C. (2013). Strategic alignment: A missing link in the relationship between strategic consensus and organizational performance. Strategic Organization, 11(3), 304-328. https://doi.org/10.1177/1476127013481155

Wee, D., Kelly, R., Cattel, J., \& Breunig, M. (2015). Industry 4.0 - how to navigate digitization of the manufacturing sector. McKinsey \& Company, 1-62. https://doi.org/10.1007/s13398-014-0173-7.2

Williams, T. J. (1994). The Purdue enterprise reference architecture. Computers in Industry, 24(2-3), 141-158. https://doi.org/10.1016/0166-3615(94)90017-5

Yokoyama, S., Kojima, I., \& Ishikawa, H. (2007). FREDDY: A web browser-friendly lightweight data-interchange method suitable for composing continuous data streams. In 
CEUR Workshop Proceedings (Vol. 470, pp. 39-50).

Yu, J., \& Qin, S. J. (2008). Multimode process monitoring with bayesian inference-based finite Gaussian mixture models. AIChE Journal, 54(7), 1811-1829.

https://doi.org/10.1002/aic.11515 


\section{Anexo A - Questionário utilizado para as estrevistas}

\section{Sobre a empresa}

1. Número de funcionários.

2. Produtos fabricados.

3. Quantas plantas existem no grupo e como elas se diferenciam.

4. Quais os mercados atendidos (B2B, consumidor, ...)

5. Qual o modelo de produção?

\section{Sobre o entrevistado}

1. Área dentro da empresa.

2. Atribuições da área.

3. Posição do entrevistado.

\section{Estratégia}

1. Como a empresa compete? Por que os clientes compram seus produtos ao invés dos produtos dos concorrentes?

2. Quem são seus concorrentes?

3. Velocidade de mudança tecnológica.

4. Facilidade de predição de demanda.

5. Qual a ordem de prioridade entre qualidade, entrega, custo, flexibilidade, inovação ou sustentabilidade?

6. Como os gestores de outras áreas priorizariam essas vantagens? Se for de forma diferente, por quê?

\section{Comunicação}

1. Como acontece o fluxo de informações entre as áreas de vendas e manufatura?

2. Como acontece o fluxo de informações entre compras, manufatura e logística? 
3. Como acontece o fluxo de informações entre o mercado, desenvolvimento de produtos e manufatura?

\section{Tecnologia}

1. Quais os principais sistemas da empresa nas áreas de logística, manufatura e desenvolvimento de produtos?

2. São usados sistemas entre empresas da cadeia de suprimentos?

3. A empresa adota soluções de TI que a diferenciam dos seus concorrentes?

4. Existem programas de inovação em tecnologias para manufatura (Manufatura Avançada ou Indústria 4.0)

5. Foram ou estão sendo realizados projetos de inovação em tecnologias para manufatura?

6. Quais as tecnologias de TIC que têm potencial de impacto na logística, manufatura ou desenvolvimento de produto?

7. Como o conhecimento para identificação, implantação e operação dessas novas tecnologias é gerenciado internamente? 


\section{Anexo B - ATLAS.ti}

O ATLAS.ti é um software para suporte à interpretação de textos e outros registros para pesquisa qualitativa, desenvolvido pelo projeto ATLAS (Archive for Technology, the Lifeworld, and Everyday Language) da Technical University of Berlin, da Alemanha (Muhr, 1991).

Sua estrutura, responsável pela organização dos dados de pesquisa, é formada por projetos de pesquisa, denominados unidades hermenêuticas. Dentro de cada unidade, são criados os documentos primários (P-Docs), com os textos a serem analisados, as citações (Quotes), que armazena partes dos P-Docs que serão utilizados como citações, códigos (Codes), que relacionam trechos dos textos com conceitos específicos, e notas (Memos).

Para este projeto de pesquisa, foi criada uma unidade hermenêutica com cinco documentos primários, um para cada entrevista em profundidade transcrita. As notas foram utilizadas para relacionar elementos externos às entrevistas, como observações e informações retiradas de documentos das companhias, a partes específicas do texto. Os códigos foram criados com base nos conceitos do framework proposto, e usados para identificá-los no texto, de acordo com a Figura 14.

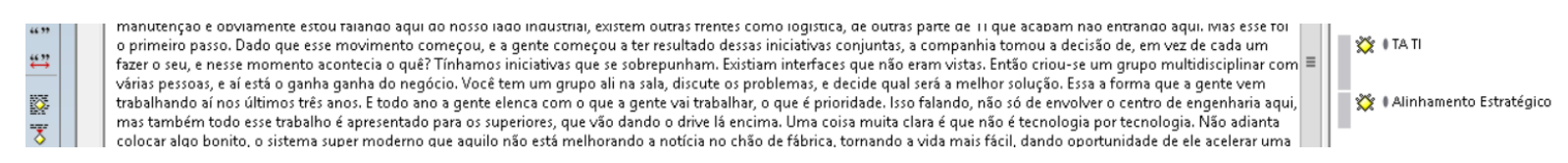

Figura 14 - Exemplo de Texto Codificado

Além dos códigos diretamente extraídos da revisão da literatura, conceitos considerados relevantes durante as análises do texto também foram codificados. Alguns deles, quando se repetiram em diferentes projetos, foram utilizados na análise e integrados ao framework, como competências tecnológicas multidisciplinares, codificada como TA TI.

O objetivo da adoção do ATLAS.ti para este trabalho foi a organização dos textos das entrevistas em códigos e citações. Desta forma, os códigos funcionam como um sumário, permitindo acesso imediato a todos os trechos das entrevistas que se relacionam com ele. 